\title{
WWW and its enduring effects on export marketing : do web capabilities matter?
}

Citation for published version (APA):

Beckers, I. (2009). WWW and its enduring effects on export marketing : do web capabilities matter?

[Doctoral Thesis, Maastricht University]. Universiteit Maastricht. https://doi.org/10.26481/dis.20091105ib

Document status and date:

Published: 01/01/2009

DOI:

10.26481/dis.20091105ib

Document Version:

Publisher's PDF, also known as Version of record

\section{Please check the document version of this publication:}

- A submitted manuscript is the version of the article upon submission and before peer-review. There can be important differences between the submitted version and the official published version of record.

People interested in the research are advised to contact the author for the final version of the publication, or visit the DOI to the publisher's website.

- The final author version and the galley proof are versions of the publication after peer review.

- The final published version features the final layout of the paper including the volume, issue and page numbers.

Link to publication

\footnotetext{
General rights rights.

- You may freely distribute the URL identifying the publication in the public portal. please follow below link for the End User Agreement:

www.umlib.nl/taverne-license

Take down policy

If you believe that this document breaches copyright please contact us at:

repository@maastrichtuniversity.nl

providing details and we will investigate your claim.
}

Copyright and moral rights for the publications made accessible in the public portal are retained by the authors and/or other copyright owners and it is a condition of accessing publications that users recognise and abide by the legal requirements associated with these

- Users may download and print one copy of any publication from the public portal for the purpose of private study or research.

- You may not further distribute the material or use it for any profit-making activity or commercial gain

If the publication is distributed under the terms of Article $25 \mathrm{fa}$ of the Dutch Copyright Act, indicated by the "Taverne" license above, 


\section{$W W W$}

and its $\boldsymbol{E}$ nduring $\boldsymbol{E f f e c t s}$ on $\boldsymbol{E x p o r t}$ Marketing:

Do Web Capabilities Matter?

Ingrid Beckers 
$\boldsymbol{W} \boldsymbol{W} \boldsymbol{W}$ and its $\boldsymbol{E}$ nduring $\boldsymbol{E f f e c t s ~ o n ~} \boldsymbol{E x p o r t ~ M a r k e t i n g : ~}$ Do Web Capabilities Matter?

(C) I. Beckers, Maastricht, 2009

All rights reserved. No part of this publication may be reprinted or utilized in any form or by any electronic, mechanical or other means, now known, or hereafter invented, including photocopying and recording, or in any information storage or retrieval systems, without written permission from the copyright owner.

ISBN: 978-90-9024531-7

Cover design: Anke Berresheim

Printed by: Medienteam 


\title{
$W W W$ \\ and its $\boldsymbol{E}$ nduring $\boldsymbol{E f f e c t s}$ on $\boldsymbol{E x p o r t}$ Marketing: \\ Do Web Capabilities Matter?
}

\author{
PROEFSCHRIFT
}

Ter verkrijging van de graad van doctor aan de Universiteit Maastricht, op gezag van de Rector Magnificus, Prof. mr. G.P.M.F. Mols volgens het besluit van het College van Decanen, in het openbaar te verdedigen

op donderdag 5 november 2009 om 14.00 uur

door

Ingrid Beckers 


\section{Promotoren:}

Prof. dr. J.C. de Ruyter

Prof. dr. M.G.M. Wetzels

\section{Copromotor:}

Dr. P. Pauwels

\section{Beoordelingscommissie:}

Prof. dr. J.G.A.M. Lemmink (Voorzitter)

Dr. W. Letterie

Prof. dr. P. Matthyssens (Universiteit Antwerpen, Belgium) 
For my parents 



\section{Acknowledgements}

In this dissertation, we unfold the complex relationship between Web capabilities and export marketing performance. Each of the three projects in this $\mathrm{PhD}$ uniquely contributes to understanding the Web-performance link. I am proud of the result and I would like to thank the people who made this achievement possible.

First and foremost, I would like to thank my supervisor Piet Pauwels. Without Piet's enormous expertise, experience, and enthusiasm, this $\mathrm{PhD}$ could have never reached such a high quality. After a meeting with Piet, I always felt motivated, because his feedback has always been both constructive and challenging. From Piet I also learnt to be less worried, to be less Catholican than the Pope, and to put things in perspective. Everyone knows that Piet's jokes are hilarious. If Piet had not shared his smart ideas and good sense of humor with me, I would now be stuck somewhere in the Brazilian jungle and my story would be very similar to that of Tom Hanks in 'Cast Away'.

I would also like to thank my promoter, Ko de Ruyter, for his endless support and faith. I think as a consequence of my meetings with Ko, my self-efficacy and efficiency at work have increased by $10^{100}$. Moreover, I did not only learn from Ko how to produce high quality work, but also how to clearly communicate it. Entering Ko's office has always been an adventure to me. On our journey to the top of icebergs, we developed clear conceptualizations instead of panaceas for both real and virtual worlds. Ko, working with you was inspiring and exciting!

Furthermore, I would like to thank my supervisor Martin Wetzels. Martin's expertise on market research methods and statistical concepts is amazing. Whenever I had a statistical question, Martin shared his knowledge with me. On top of this, I have learnt from Martin how to become a master of LISREL and MPlus and - even more important - how to have fun while running a model with second-order constructs and cross-national data. Martin, I am not only thankful for the fruitful discussions we had on various research topics, but also for your "Hi, it's I" (?) as well as for your good morning interruptions, and obligatory 30-minutes non-stop fun meetings (officially called lunches).

Special thanks go to my office mates and friends Sonja Wendel and Charlotte Rolef. Sonja, thanks for all your help and support during the last five years. You have not only been an excellent internship and master thesis supervisor, but also a $\mathrm{PhD}$ fellow with whom I could exchange my research ideas, questions, and preference for high quality shoes and coffee. Moreover, you helped me run $10 \mathrm{~km}$ within the hour and always backed me up when I needed it. Charlotte, I am very thankful for the lively experiences we shared 
- be it in our office, at conferences, or in the real world! It is good to know that I can count on you. I also would like to thank my office mates Roger, Linda, and Mirella for sharing enthusiasm for various activities such as for the champagne committee. Furthermore, I would like to thank Claudia, Charlotte, and Nina for having read and corrected critical parts of this thesis.

I would like to express my gratitude to my dissertation committee, Jos Lemmink, Paul Matthyssens, and Wilko Letterie for the time and effort they spent into reading my dissertation. Their valuable feedback and comments have enabled last refinements. I would also like to thank Luis F. Lages for his cooperation on one of the projects; his support at conferences, feedback and our meetings in Lisbon made it a pleasure to work with him. I also really appreciate the input of Christine Moorman, Vera Blazevic, and John Cadogan on various parts of the papers.

I would like to thank my whole family. My parents have supported me throughout my life and always backed me up in my career plans. They gave me the freedom to set my own goals and they offered me the opportunities to reach them without forgetting what really matters in life. Thanks to my aunt Liesel for being a real "Tante Liesel". Anke and Tim, I am also very thankful that you made and designed the cover of this dissertation. Henner and Christina, I am very grateful for your immense support during the last years.

Moreover, I would like to thank my friends. Katrin and Thomas, we still haven't managed to have ice barbecue with the Metro Stars. But except for that, we have already made a lot of other crazy dreams come true. Thanks for a decade of friendship and support. A big thanks also goes to my friends Anne, Katrin and Stefan, Mike, Hendrik, Jenny and Esther.

Ingrid Beckers

Maastricht, 2009 


\section{Table of Contents}

CHAPTER 1 INTRODUCTION

$1.1 \quad$ Export Marketing and the World Wide Web 2

1.2 The Web in a Theory of the Firm 3

1.3 Research Objectives 5

1.3.1 Research Objective 1: The Impact of

Web Capabilities on Export Marketing

Resources

1.3.2 Research Objective 2: Web Capabilities to Renew Export Marketing Resources

1.3.3 Research Objective 3: A Contingency Perspective on the Impact of Web Capabilities on Marketing Knowledge 6

1.4 A Database of Export Marketing Ventures 7

1.4.1 Data Collection 8

1.4.2 Sampling 8

1.4.3 Description of the Database 10

1.5 Dissertation Outline 12

CHAPTER 2 WEB CAPABILITIES AND EXPORT MARKETING PERFORMANCE 15

2.1 Introduction 16

2.2 Conceptual Framework 18

2.2.1 Web Capabilities 18

2.2.2 Web Capabilities and Export Marketing Capabilities

2.2.3 Web Capabilities and Declarative and Experiential Knowledge 20

2.2.4 Knowledge and Export Marketing Performance 21

2.2.5 Web Capabilities as Facilitators 23

2.3 Empirical Study 25

2.3.1 Measures 25

2.4 Analysis 26

2.4.1 Measure Validation 26

2.4.2 Measurement Invariance Tests 27

2.4.3 Structural Model Estimation 29 
2.5 Discussion

2.5.1 The Dynamic Nature of Web Capabilities

2.5.2 Post-Hoc Analysis on Long-Term Effect

2.5.3 Web Capabilities as Facilitators 33

2.6 Limitations and Further Research 34

2.7 Managerial Implications

\section{CHAPTER 3 LEVEL AND PROFILE OF WEB CAPABILITIES: EFFECTS OF WEB-INDUCED PROCESSES ON PERFORMANCE}

3.1 Introduction 38

3.2 Conceptual Model 39

3.2.1 Web Capabilities and Marketing Processes 39

3.2.2 Web-Induced Deployment 40

3.2.3 Web-Induced Upgrading 42

3.3 Empirical Study 45 3.3.1 Measures $\quad 45$

3.4 Analysis 47

3.4.1 Measurement and Structural Model Estimation 47

3.5 Discussion 50

3.6 Limitations and Further Research 51

3.7 Managerial Implications $\quad 52$

CHAPTER 4 DEVELOPING LOCAL MARKET KNOWLEDGE THROUGH VIRTUAL

INTERACTION: BRIDGING CULTURAL DISTANCE

4.1 Introduction 56

4.2 Conceptual Model 58

4.2.1 Interactive Web Capabilities 59

4.2.2 Export Market Knowledge 59

4.2.3 Cultural Distance 61

4.2.4 International Business Experience 62

4.2.5 Web Experience 64

4.3 Empirical Part 66

4.3.1 Measures 66 
4.3.2 Construct Validation $\quad 67$

4.4 Analysis 68

4.4.1 Results 69

4.5 Discussion 71

4.6 Limitations and Further Research 73

4.7 Managerial Implications 74

$\begin{array}{ll}\text { CHAPTER } 5 \text { CONCLUSION } & 77\end{array}$

5.1 Synopsis 78

5.2 Web Capabilities and Export Marketing
Performance

5.3 Level and Profile of Web Capabilities:

Processes on Performance 79

5.4 Developing Local Market Knowledge by Bridging the Cultural Distance Gap through Virtual Interaction $\quad 80$

5.5 Overall Conclusion 81

5.6 Some Suggestions for Future Research 82

$\begin{array}{ll}\text { APPENDICES } & 85\end{array}$

$\begin{array}{ll}\text { REFERENCES } & 101\end{array}$

CURRICULUM VITAE 121 

Chapter 1

Introduction 


\subsection{Export Marketing and the World Wide Web}

It is widely acknowledged that the World Wide Web (the Web) has significantly decreased the barriers of market-oriented internationalization, especially for small and medium-sized enterprises (Moen et al. 2003; Quelch and Klein 1996). For exporting companies, the Web has created affordable or even free opportunities for international data collection, foreign retailer selection, fast global communication and sales (Morgan-Thomas and Bridgewater 2004; Prasad et al. 2001). As a connection tool, it can help build and maintain effective and efficient communication with foreign customers, distributors, and suppliers and facilitate international exchange. Furthermore, search engines and electronic surveys provide useful tools for retrieving information about foreign customers (Loane et al. 2004). As such, the Web may act as a powerful market intelligence tool that permanently browses online data streams, filters what fits certain selection criteria and integrates data into useful and up to date information. Using the Web for marketing intelligence enables firms to access information about overseas markets with higher speed and at lower cost. More recently, Web technologies have turned online encounters with customers into lively interactions and increasingly unfurl precious opportunities such as social networking and benefiting from customers' creativity and engagement. In all, the Web has turned the world into an increasingly virtual marketplace, where foreign direct investments and physical exchanges become increasingly redundant. At the same time, the Web has boosted marketing opportunities in particular for companies without a local presence abroad and will continue to do so even more profoundly in the years to come (Chui et al. 2009). In comparison to entry modes such as foreign direct investment, exporting companies do not have the opportunity to learn from their markets abroad through a local presence. Next to this lack of proximity to the market, export is one of the entry modes that demands least involvement and commitment. Therefore, especially to exporting companies the Web represents a convenient tool providing plenty of opportunities to interact with foreign markets, eventually to gain market knowledge.

Extant academic literature has widely covered the role of the Web in marketing strategy and practice. In particular, the prevalence of the Web in today's international business arena has nurtured marketing research in three clusters. In a first cluster, researchers have scrutinized the instrumental marketing value of Web applications, for instance for retrieving market information (Schillewaert and Meulemeester 2005) and online advertising (Saeed et al. 2002). As such, this stream of research has contributed to understanding how the Web enhances the (mainly tactical) marketing toolbox (Prasad et al. 2001; Parasuraman 2002). In a second cluster, scholars have focused on online interactivity between market parties in the context of relationship marketing theory. There is growing consensus that the Web 
creates a valuable platform for social supplier-customer interaction (Wang et al. 2007), creating particular marketing opportunities for joint new product development (Melewar 2001; Sawhney 2005) and customer relationship management (CRM) (Srinivasan and Moorman 2005), among others. A third cluster of ongoing research mainly focuses on how the Web acts as an integrator to span diverse business functions within and across organizations to impact strategic decision-making (e.g., Karavdic and Gregory 2005). It embraces studies that shed light on, among others, institutional enablers such as the extent of coordination and management support on the assimilation of Web technologies (e.g., Chatterjee 2002). While research continues to unfold how the Web affects marketing from an instrumental, relational and integration perspective, a critical question largely remains unanswered: Does it all matter?

From a distance, the impact of the Web on firm performance seems straightforward: Web tools increase the efficiency and/or efficacy of the marketing toolbox in connecting with new customers and deepening out the relationship with existing customers. This, however, is an overly simplistic perspective as it ignores the open character of the Web, enabling competitors to imitate Web applications for export marketing goals almost without effort (e.g., McKinsey 2007a). The foundations for a potentially more nuanced and even stratified relationship with marketing are laid by acknowledging the multidimensional nature of the Web. To date, therefore, academia has not fully understood whether and how the Web encroaches upon the marketing-performance relationship. So far, we have limited knowledge regarding how the Web may impinge upon a firm's marketing strategies and operations mix, eventually to have a profound effect on a firm's marketing performance. The present thesis contributes to this quest in that it aims to disclose the Web's impact on marketing performance in an export context. To do so, we first set out for a theory of the firm as a point of departure.

\subsection{The Web in a Theory of the Firm}

This dissertation builds upon the Resource-Based View (RBV) as a theory of the firm which emphasizes the internal strengths of a company as the foundation of sustained competitive advantage and performance. More in particular, the RBV argues that competitive advantage is created by the valuable, rare, imperfectly imitable, and not substitutable resources a firm controls (Barney 1991; Barney 1996; Peteraf 1993). Broadly, there are two related types of resources that are necessary for creating competitive advantages: assets and capabilities (Day 1994; Dierickx and Cool 1989). In an export marketing context, studies have identified particular capabilities (e.g., informational and relationship-building capabilities) as crucial determinants 
of export marketing performance (Morgan et al. 2004; Morgan et al. 2003; Zou et al. 2003). Assets are the resource endowments a firm has accumulated (e.g., investments in production facilities), and capabilities are a firm's complex bundle of skills and accumulated knowledge, exercised through organizational processes, that enable the firm to coordinate activities and make the best use of its assets (Day 1994; Teece et al. 1997). In line with the RBV, we focus on an organization's Web capabilities as a point of departure to understand how the Web affects firm performance.

Echoing earlier calls to upgrade the RBV to a less static theory of the firm (Helfat and Peteraf 2003), this dissertation emphasizes the importance of a company's ability to update and upgrade its operant resources - more in particular its knowledge base and organizational capabilities (Vargo and Lusch 2004) - in an effort to meet (un)predictable challenges that may undermine the organization's competitive position. While core resources are critical, they can turn into core rigidities after some time (Leonard-Barton 1992). For this reason, companies regularly need to review the value of their resources and, if needed, upgrade their resource base (Eisenhardt and Martin 2000; Teece et al. 1997). This dynamic perspective entails that organizational resources evolve, are exchanged, grow, and are reproduced by building, integrating, and reconfiguring organizational assets (Luo 2000). In this thesis, we portray an organization's Web capabilities as a leverage to feed, update and upgrade an export firm's marketing resource base.

Among the organization's repertory of resources, we consider organizational knowledge to be the ultimate foundation of the resourcebased perspective (Kogut and Zander 1992) and endorse Grant (1996) in that: "At the heart [...] is the idea that the primary role of the firm, and the essence of organizational capability, is the integration of knowledge" ( $p$. 375). While former studies have indicated the potential of the Web for marketing knowledge management (e.g., Nguyen and Barrett 2006), this thesis is among the first to elaborate how and why a firm's Web capabilities are an important source of organizational knowledge creation, eventually to affect export marketing performance in the long term.

Building upon this dynamic Resource-Based View of the firm and recognizing organizational knowledge as the ultimate resource, this dissertation portrays the relationship between a firm's Web capabilities and its export marketing performance as a multifaceted picture of knowledge creation, marketing resource upgrading and advanced marketing instrumentation. We define the objectives of this dissertation along these epistemological lines. 


\subsection{Research Objectives}

To unfold the complex relationship between Web capabilities and export marketing performance, we present three research objectives. Each objective forms the basis of a particular study. Together, these studies characterize the multifaceted nature of how Web capabilities affect export marketing performance. In study 1, we provide a conceptualization of Web capabilities. An important result of this study is that we are able to observe how complex the phenomenon Web capabilities actually is. In study 2, we grasp the richness of the phenomenon Web capabilities by discerning between the abundance (level) and character (profile) of Web capabilities. As a result of study 2, we also know that the interactive trait of Web capabilities acts as a critical catalyst towards export performance. In study 3, we subsequently prove the stability of this finding by showing that the effect of interactive Web capabilities is not contingent on cultural distance. We set out these objectives hereafter.

\subsubsection{Research Objective 1: The Impact of Web Capabilities on Export}

\section{Marketing Resources}

The ambition of the first study is twofold. First, we develop a sound conceptualization of Web capabilities and present a valid operationalization of a (multidimensional) measure. Second, we rely on seminal literature on (dynamic) capabilities to conceptualize the relationship between Web capabilities and export marketing resources. A such, we extend the established resources-strategy-performance perspective as presented and tested in an export marketing context by Cavusgil and Zou (1994) and Morgan et al. (2004).

While extant research has shown the instrumental impact of Web applications on export performance (e.g., Morgan-Thomas and Bridgewater 2004), we set up a framework that reflects a more balanced perspective on how Web capabilities ultimately affect export marketing performance: not only through offering online instrumentation of an export marketing strategy yet also and even more profoundly by their impact on the export marketing resources; knowledge and capabilities of the firm. Especially the latter yields to enduring performance. In contrast to current literature which does not distinguish between short-and long-term effects (e.g., Zou et al. 2003), we provide evidence for long-lasting performance effects of the Web. In sum, we approach our first research objective by: 1) Defining and operationalizing Web capabilities, and 2) examining the impact of Web capabilities on the resources-strategyperformance chain in export marketing. 


\subsubsection{Research Objective 2: Web Capabilities to Renew Export}

\section{Marketing Resources}

Complementary to defining and measuring the effect of Web capabilities on an export firms' marketing resources, the second study focuses on the processes through which Web capabilities contribute to the renewal of marketing resources to achieve congruence with the changing business environment. For this purpose, we immerse into organizational learning processes that nourish and foster underlying marketing resources (Zollo and Winter 2002). More specifically, we conceptualize two specific processes and depict the role of Web capabilities in both marketing resource deployment and upgrading. As a consequence of Web-enhanced resource deployment firms increasingly exploit marketing assets in a profitable manner. In a complementary fashion, Web-enhanced resource upgrading results in amended and/or new marketing assets and capabilities. In contrast to existing literature focussing on general implications of the Web on international marketing (Varadarajan and Yadav 2002), we acknowledge the relevance of the interactive nature of Web capabilities to fully understand how the Web fosters resource deployment and upgrading. In sum, to understand the processes through which Web capabilities contribute to the updating and upgrading of relevant export marketing resources, we 1) fathom the scope of Web capabilities by discerning between effects of their abundance and nature, 2) identify how Web capabilities enbance resource deployment and upgrading, and 3) substantiate the pertinence of this process for immediate and long-term export marketing performance.

\subsubsection{Research Objective 3: A Contingency Perspective on the Impact of Web Capabilities on Marketing Knowledge}

As its relevance is acknowledged under Objective 1, we deepen out and contextualize the critical relationship between Web capabilities and marketing knowledge. We zoom into this relationship and identify particular export-related catalysts and obstacles that might affect the Web capabilitiesknowledge relationship (Wadhwa and Kotha 2006). While research has investigated cultural influences on knowledge creation (Michailova and Hutchings 2006), to the best of our knowledge no study has looked at the influence of cultural distance under consideration of the effect of Web capabilities. We show that distinct cultural inheritance and cultural backgrounds of exchange partners hardly impede Web-induced knowledge creation. As such, we highlight the relevance and power of Web-induced market learning, especially in an export context. In contrast, we present an organization's international business experience as well as its general Internet experience as important vehicles to leverage the aforementioned Web- 
knowledge relationship. In sum, we intend to 1) zoom into the Web-knowledge relationship, 2) understand how environmental obstacles such as cultural distance impede the Web-knowledge relationship, 3) show that export firms can rely on their international business experience and online experience to reinforce the effect of Web capabilities on knowledge creation.

\subsection{A Database of Export Marketing Ventures}

To pursue these research objectives, we set up three complementary studies. Each study elaborates a theoretical logic that builds upon seminal insights (mainly) from marketing, strategy and information systems research. To test the hypotheses that emanate from these three conceptual frameworks, we rely on a database of export marketing ventures of medium-sized manufacturing companies in The Netherlands and Portugal. This database was built between 2004 and 2008 .

The database consists of 337 export ventures and was built through secondary data collection and two surveys. We considered export ventures of manufacturing small- and (mostly) medium-sized enterprises (SMEs), which encompass the vast majority of European enterprises (OECD 2005a). According to the European Commission, almost one third of all European SMEs' products are exported to industrialized countries all over the world, illustrated by an export rate of $30.2 \%$ (Eurostat 2007). Furthermore, their characteristic resource constraints mandate that SMEs use export as an important path for firm growth (Lu and Beamish 2001). To many of these companies, the Web represents an easy and inexpensive way to access customers in export markets and promote products online instead of relying on sales personnel or brochures (Andersen 2005).

The Netherlands and Portugal provide an appropriate context for two reasons. First, both countries depend heavily on exports - with (at the time of the studies) export/GDP rates of $61.5 \%$ for the Netherlands (Economist 2007) and 58.2\% for Portugal (Instituto Nacional de Etastística 2008). To the contrary, the two countries differ largely with respect to their information and communication technology (ICT) infrastructure. In terms of the number of Web hosts, echoing the intensity of active usage of ICT in firms, Portugal reports $30 \mathrm{Web}$ hosts per 1,000 inhabitants in 2004, whereas the Netherlands boasts 70 Web hosts per 1,000 inhabitants (CBS 2005). The proportions of enterprises with broadband connections in 2006 amounted to $82 \%$ in the Netherlands, whereas only $66 \%$ of all Portuguese enterprises have a broadband connection, below the EU 25 average of 75\% (Eurostat 2006). As such, these countries are rather comparable with respect to their export dependency yet differ significantly with respect to the adoption of the Web as a business instrument and medium. This two-country perspective enhances the external validity of an empirical perspective on the Web-export marketing performance relationship. 
In line with previous research, we adopt the export venture (i.e., a product-foreign market combination) as the prime unit of analysis (Cavusgil and Zou 1994; Morgan et al. 2004). This level is appropriate since an exporting firm typically maintains a portfolio of products in several export markets, each of which might require different resources, strategies and eventually might lead to uneven marketing performance. Taking this venture-level approach has two particular advantages. First, it acknowledges an export firm's reality in which marketing strategies are to a large extent product and market specific. Therefore, it is valid to go after nonaggregated measures of export performance as performance may largely differ among export ventures of one firm (Cavusgil and Zou 1994). Second, it is easier for export managers to report on measures at the export venture level because individual products and markets typically define the scope of export managers' decision-making authority (Cavusgil and Zou 1994). Nevertheless, this unit of analysis largely precludes the availability of objective and factual data as firms simply do not have or at least typically do not report or share factual (performance) data on this business level.

\subsubsection{Data Collection}

As our unit of analysis is the venture level within the exporting firm, to the best of our knowledge no objective data exists to test our conceptual model. Moreover, the majority of the concepts in our model have been defined and operationalized as latent, multidimensional constructs. Therefore, we collected primary data mainly through two online surveys.

We preferred online data collection over traditional paper and pencil surveying, for four reasons. First, online surveys allow for large-scale data collection in a cost-effective manner, which is especially important because we have to collect the data on an international scale. Second, online surveys are appropriate for overcoming respondents' unwillingness to disclose apparently sensitive information, such as export performance (Schillewaert and Meulemeester 2005). Third, because of their convenience, online surveys help increase response rates; respondents can decide themselves when to reply and how much time they need to read and answer questions. Nevertheless, compared with mail surveys, online surveys yield equally reliable and valid analytical results (Deutskens et al. 2004). Finally, online data collection fits the sampling frame of the study.

\subsubsection{Sampling}

Our data collection procedure mirrors that of several previous export studies (Morgan et al. 2003). In the Netherlands, we draw a stratified random sample of 1,853 Dutch firms from the Dun \& Bradstreet database, based on standard industrialization classification (SIC) codes. Thus, we obtain a cross- 
section of industries including food and beverages (two-digit SIC code 20); tobacco, textiles, and clothing (SIC codes 21-23), machinery and transport equipment (SIC codes 35 and 37). Hence, our sampling frame features exporting firms from multiple industries in the manufacturing sector, which helps us increase the variance and generalizability of our findings.

All eligible firms had at least three years of export experience and a corporate Web site. The former criterion ensures that export is a structural activity of the firm or business unit, and the latter verifies that the companies have the potential to develop Web capabilities. We contacted all firms by telephone to check their qualifications, identify an appropriate key informant (usually export or marketing manager), and ask him or her to participate. Eventually, we identified 913 Dutch companies that met the aforementioned requirements and were willing to contribute to our database. Immediately after gaining their approval, we sent an e-mail message with a hyperlink to a first online questionnaire. At the beginning of this questionnaire, we asked respondents to identify a specific export venture that had existed for at least three years, as well as the export country, and answer all remaining questions with respect to this venture. Our data collection efforts in the Netherlands yielded 215 responses, though some respondents had excessive missing data on the measures (i.e., missing responses on three or more items for any single scale) Overall, this leaves us with a data set of up to 196 cases, for a response rate of $21.5 \%$.

The data collection in Portugal follows the same procedure. We draw a stratified (using the same industry codes as in the Dutch sampling frame) random sample from three different databases: Dun \& Bradstreet, Exportinfo 2000, and Portrade 2000/2001. Through phone calls to the sampling frame of 1,025 companies, identified in the same way as their Dutch counterparts, we obtained 736 e-mail addresses. However, 282 firms did not meet the prequisites; 78 did not conform to either the export- or Web-related requirements, 92 had other reasons for nonparticipation, and 112 provided incorrect contact details. Thus, the invitations and one reminder yield 122 key informants, of which 7 featured excessive missing data on the respective measures. After we delete these responses, we have a Portuguese data set that contains observations from 115 export ventures, for a response rate of $16.0 \%$. This dataset was only included in study 1 . We tested non-response bias for the Dutch and Portuguese data by assessing the differences between the early and late respondents with regard to the means of all the variables for both samples (Armstrong and Overton 1977). Early respondents were defined as the first $75 \%$ of the returned questionnaires, and the last $25 \%$ were considered to be late respondents. No significant differences were found, suggesting that non-response bias was not a significant problem in the study. 
In 2008, we recollected performance data four years after the first survey to check if these hypothesized performance effects remain stable over time. Accordingly, we approached all participating and identifiable Dutch and Portuguese companies once again with a request to report on their year+4 export marketing performance (EXPERF) in the same venture. Unfortunately, 70 of the Dutch companies and 50 of the Portuguese companies did not provide their contact details in the initial survey and therefore could not be identified or reached for year +4 follow-up survey. Eventually, though, we received responses from 84 Dutch companies $(67 \%$ of the reachable cases) and 49 Portuguese companies ( $75 \%$ of the reachable cases). We made use of the 2008 dataset in study 1 and 2 only.

\subsubsection{Description of the Database}

The goal of this section is to provide a first description of our database. We therefore highlight some critical key characteristics of both the ventures and firms in our samples. More sophisticated check-ups of the database and measures will follow later in this dissertation. Table 1.1 gives an overview of the most important characteristics of the Dutch and Portuguese ventures in our sample. The table compares the two ventures in terms of the countries they are most often exporting to, the number of years the product has been exported, and the venture's market potential the documented ventures from the two countries can be compared as follows. The figures in the table indicate that Dutch and Portuguese ventures are similar to each other with regard to these characteristics. 
Table 1.1 Venture Descriptives

\begin{tabular}{|c|c|c|}
\hline Venture Descriptives & $\begin{array}{c}\text { Dutch } \\
\text { Sample }(\%)\end{array}$ & $\begin{array}{l}\text { Portuguese } \\
\text { Sample (\%) }\end{array}$ \\
\hline \multicolumn{3}{|l|}{$\begin{array}{l}\text { Country product has been } \\
\text { exported to }\end{array}$} \\
\hline countries within EU & 73.5 & 75.8 \\
\hline countries outside EU & 26.5 & 24.2 \\
\hline Germany & 26.7 & 8.9 \\
\hline United Kingdom & 8.9 & 13.9 \\
\hline France & 5.9 & 19.0 \\
\hline Belgium & 5.0 & 2.5 \\
\hline United States & 6.9 & 5.1 \\
\hline Spain & 2.0 & 13.9 \\
\hline \multicolumn{3}{|c|}{$\begin{array}{l}\text { Number of years product has been } \\
\text { exported }\end{array}$} \\
\hline$>10$ years & 51.9 & 65.1 \\
\hline $4-10$ years & 40.6 & 24.6 \\
\hline$<4$ years & 7.5 & 10.3 \\
\hline \multicolumn{3}{|l|}{$\begin{array}{l}\text { Market potential of the export } \\
\text { venture }\end{array}$} \\
\hline Limited & 3.9 & 0.9 \\
\hline Rather limited & 10.8 & 8.0 \\
\hline Neither limited nor extensive & 31.5 & 29.5 \\
\hline Rather extensive & 36.9 & 37.5 \\
\hline Extensive & 16.7 & 25.0 \\
\hline
\end{tabular}

Table 1.2 gives an overview of the most relevant characteristics of the firms the ventures belong to. Each firm has reported on only one venture. The table compares the firms with respect to the following criteria: firm size (number of employees), annual sales volume, industry, and extent of international business experience. Based on these characteristics, we can infer that Portuguese and Dutch companies are similar in terms of their size, industry membership, and international business experience. They slightly differ with regard to the annual sales volume. More Portuguese companies indicate to have an annual sales volume of less than $€ 5$ million. Through additional investigation of the two nations' most important international trade statistics (CBS 2004; Instituto Nacional de Estastística 2004; Elk et al. 2005) and in line with prior export studies (Lages et al. 2008), we confirm the national representativeness of both samples. 
Table 1.2 Firm Descriptives

\begin{tabular}{lcc}
\hline Firm Descriptives & $\begin{array}{c}\text { Dutch } \\
\text { Sample (\%) }\end{array}$ & $\begin{array}{c}\text { Portuguese } \\
\text { Sample (\%) }\end{array}$ \\
\hline Firm size & & \\
$<=50$ employees & 10.6 & 14.9 \\
$>50$ I <=250 employees & 89.4 & 85.1 \\
Annual sales volume & & \\
$<€ 5$ million: & 10.0 & 45.7 \\
$€ 5-€ 30$ million: & 58.0 & 42.7 \\
$>€ 30$ million: & 32.0 & 11.6 \\
Industry & & \\
Machinery \& transport equipment & 38.1 & 24.3 \\
Tobacco, textiles, \& clothing & 28.0 & 26.7 \\
Food \& beverages & 24.5 & 34.6 \\
Other & 9.4 & 14.4 \\
International business experience & & \\
None & 0.5 & 0.9 \\
Minor & 6.4 & 2.6 \\
Some & 23.0 & 21.1 \\
Much & 57.8 & 44.2 \\
Considerable & 12.3 & 24.2 \\
\hline
\end{tabular}

\subsection{Dissertation Outline}

This dissertation contains three empirical studies each of which contributes to a dynamic perspective on the Web-performance relationship. Table 1.3 offers a summary of each study, its objectives, theory, and analysis. The table also makes clear that even though each of these studies contributes to the overall theme of this dissertation, they may be read separately.

Table 1.3 gives an overview of the outline of the chapters. 
TABLE 1.3 Overview of Chapters

\begin{tabular}{|c|c|c|c|}
\hline Chapter & Title & Objectives of the Studies & Theoretical Contribution \\
\hline 1 & Introduction & & \\
\hline 2 & $\begin{array}{l}\text { Web capabilities and } \\
\text { export marketing } \\
\text { performance }\end{array}$ & $\begin{array}{l}\text { Developing a sound conceptualization of Web } \\
\text { capabilities and examining the impact of Web } \\
\text { capabilities on the resources-strategy-performance } \\
\text { chain in export marketing. }\end{array}$ & $\begin{array}{l}\text { Integrating Web capabilities in the } \\
\text { established resources-strategy- } \\
\text { performance framework. }\end{array}$ \\
\hline 3 & $\begin{array}{l}\text { Level and Profile of } \\
\text { Web Capabilities: } \\
\text { Effects of Web- } \\
\text { Induced Processes on } \\
\text { Performance }\end{array}$ & $\begin{array}{l}\text { Fathoming the full scope of Web capabilities by } \\
\text { discerning between effects of their abundance (level) } \\
\text { and character (profile). Identifying deployment and } \\
\text { upgrading as two particular processes through which } \\
\text { Web capabilities affect the resource base. } \\
\text { Substantiating the pertinence of these processes for } \\
\text { immediate and long-term performance. }\end{array}$ & $\begin{array}{l}\text { Explaining the organizational processes } \\
\text { through which dynamic capabilities } \\
\text { contribute to the renewal of organizational } \\
\text { resources. }\end{array}$ \\
\hline 4 & $\begin{array}{l}\text { Developing Local } \\
\text { Market Knowledge } \\
\text { through Virtual } \\
\text { Interaction: Bridging } \\
\text { Cultural Distance }\end{array}$ & $\begin{array}{l}\text { Zooming into the Web-knowledge relationship. } \\
\text { Understanding if and how environmental obstacles } \\
\text { such as cultural distance impede the Web-knowledge } \\
\text { relationship. Showing that firms can rely on their } \\
\text { international business experience and online } \\
\text { experience to reinforce the effect of Web capabilities } \\
\text { on knowledge creation. }\end{array}$ & $\begin{array}{l}\text { Assessing the robustness of the impact of } \\
\text { dynamic capabilities on organizational } \\
\text { knowledge. }\end{array}$ \\
\hline 5 & Conclusion & & \\
\hline
\end{tabular}





\title{
Chapter 2
}

\section{Web Capabilities and Export Marketing Performance}

\begin{abstract}
Academic and managerial literature alike suggest a positive performance impact of virtual marketing applications in the World Wide Web. However, the nature and sustainability of this effect remain largely unexplored. In this chapter, the authors identify an organization's Web capabilities as a bundle of skills to transform material and immaterial resources into particular Web applications. Based on cross-national data from 311 middle-sized industrial exporting firms, we find that Web capabilities enhance export marketing knowledge as well as functional export marketing capabilities, which collectively spurs long-term export marketing performance. In addition, we observe how Web capabilities facilitate the implementation of export marketing strategies towards short-term export marketing performance. This joint effect confirmes the dynamic nature of Web capabilities as a leverage for sustainable export marketing performance.
\end{abstract}




\subsection{Introduction}

The Word Wide Web (Web) has affected export marketing considerably, in that it offers global market visibility, facilitates international market entry, and enables worldwide data collection at relatively low cost (Gregory et al. 2007). To enjoy these benefits, export firms invest in Web applications for online information sharing, customer interactions, transaction handling, and relationship management (Eid et al. 2006). In general, industry reports and empirical studies alike confirm that a more intense usage of the Web for marketing purposes spurs export performance (Greenspan 2002).

However, increasing evidence suggests that the performance impact of the Web is neither unequivocally straightforward nor sustainable. Industry reports point to potential pitfalls of treating the Web as a panacea for a wide range of problems (The Economist 2006). The open character of the Web and the highly competitive nature of export environments enable competitors to copy Web applications for export marketing purposes almost effortlessly, so initial competitive advantages fade quickly (Carr 2003; McKinsey 2007a; Wade and Hulland 2004). Moreover, the strengthening of enduring competitiveness becomes particularly relevant as increased globalization of trade transforms benefits related to the Web into necessities (Gregory et al. 2007). Therefore, researchers and practitioners alike require in-depth insights into the impact of the Web on export performance.

The role of the Web in export marketing has appeared on research agendas for more than a decade (Quelch and Klein 1996), with a dominant focus on the drivers of and barriers to Web-based export marketing, Webbased global distribution, or the integration of the Web with export marketing strategies and tactics (e.g., Avlonitis and Karayanni 2000; Dou et al. 2002; Gregory et al. 2007; Hamill 1997; Javalgi and Ramsey 2001; Varadarajan and Yadav 2002). Yet research to date has failed to establish an unequivocal relationship between a firm's Web applications and its export marketing performance (Morgan-Thomas and Bridgewater 2004; Prasad et al. 2001). Inconsistencies in empirical evidence may exist because previous studies focus on diverging aspects of the Web, ranging from perceptions of the productive development of Web sites for international use (Seilheimer 2004) to the architecture of individual Web applications (e.g., Slaughter et al. 2007). To assess the role of the Web in export marketing, we posit that sustainable competitive advantage cannot be derived solely from access to the Web but largely depends on the firm's relevant capabilities; competencies, skills and routines that affect sustainable competitive advantage (Samiee 1998). A recent global study highlighted the importance of Web capabilities and concluded that insufficient Web capabilities represent one of the most important barriers to successful performance across all electronic marketing domains (McKinsey 2007b). Therefore, we 
focus on a firm's Web capabilities and contribute to the emerging literature by examining three critical issues.

First, we develop a conceptualization of Web capabilities by relying on the RBV, which defines capabilities as a collection of specific resources that are valuable to the firm and have the potential to spur competitive advantage (Teece et al. 1997). Existing research in the field of information systems has categorized a set of e-commerce metrics to better assess the contribution of Web-based activities and identifies them as a novel technological resources that may transform ways in which performance goals can be achieved (Zhu and Kraemer 2002). Yet, it is still not obvious how marketers might use Web-related initiatives to reach unique competitive advantages. Therefore, the aim of this study is to develop a sound conceptualization of Web capabilities that incorporates the skills necessary to build up Web-related information, transaction, interaction, and connection applications.

Second, to assess the dynamic nature of Web capabilities, we focus on how they (re)configure the firm's export marketing resource base. Knowledge is a substantive and integral part of this resource base, because ultimately through knowledge, firms realize enduring competitive advantage (Grant 1996). To attain these advantages, the firm must continually update and reconfigure its knowledge stocks. These stocks commonly consist of declarative (know-what) and experiential (know-how) knowledge (Eriksson et al. 1997; Morgan et al. 2004). We posit that Web capabilities support both information and social exchanges, so that exporting firms can better accumulate, evaluate, and adapt their export-related knowledge stocks (Nguyen and Barrett 2006). As such, we develop a framework that reflects the critical role of Web capabilities in the creation of declarative and experiential knowledge as a valuable resource base for export marketing. Extant research convincingly demonstrates that market knowledge fuels export marketing performance indirectly (Morgan et al. 2003). Whether market knowledge eventually leads to export performance depends on how the organization translates this resource into its marketing capabilities and strategies (Souchon and Diamantopoulos 1996; Zou et al. 2003). Thus, the ultimate performance impact of Web capabilities hinges on important intermediate export resources.

Third, and complementary to the impact of Web capapbilities on the resource base of the firm, we postulate that Web capabilities can also play a functional role when they facilitate the implementation of marketing strategies. We hence put forward that Web capabilities are also more immediately linked to performance on the basis of the notion that IT-related capabilities commonly represent rent-generating resources that directly benefit a firm's strategic marketing (Bharadwaj 2000). Therefore, we expect Web capabilities to enhance the implementation of a marketing strategy, 
such as through improved customer service and more efficient communication between buyers and suppliers. We examine this moderator effect, taking into consideration two important issues. On the basis of the so-called IT productivity paradox (Brynjolfsson 1993), some studies refute the short-term rents of Web capabilities (Spithoven 2003), and others emphasize that the short-term gains of the Web fade out quickly (Yamin and Sinkovics 2006). Therefore, we distinguish between short-term and longterm export marketing performance and investigate this moderator effect in both time frames. Moreover, ample evidence indicates that Web capabilities should align with the strategic course of the export firm if investments are to reach the optimal level and to avoid the "virtuality trap" (Fisher et al. 2007; Henderson and Venkatraman 1999; Yamin and Sinkovics 2006). Therefore, we expect Web capabilities to enhance performance up to a certain optimal point. In summary, we postulate a curvilinear effect of Web capabilities on the direct relationship of export marketing strategy and short-term and longterm export marketing performance.

The increasing ubiquity of Web-based export marketing, despite the scarce, inconsistent, and sometimes contradictory findings about its performance impacts, creates the need for more definitive research that investigates the foundation of export marketing performance in a Webendowed marketing environment. Therefore, we focus on a firm's Web capabilities and their effects on the firm's export marketing basis, as well as on immediate and enduring export marketing performance. We test the theoretical and empirical validity of our propositions and detail the implications across samples of medium-sized industrial firms from two European countries.

\subsection{Conceptual Framework}

In this section, we refer to strategic marketing and information systems literature to define Web capabilities and position them alongside export marketing capabilities as critical antecedents of export performance in a Web-endowed export marketing environment.

\subsubsection{Web Capabilities}

According to the RBV (Grant 1991), a firm's resources consist of assets and capabilities that provide the substructure for sustainable competitive advantage (Barney 1991; Peteraf 1993). Assets are the resource endowments the firm has accumulated, whereas capabilities are the firm's complex bundles of skills, exercised through organizational processes that enable the firm to coordinate its activities (Amit and Schoemaker 1993; Grant 1991). Various domains attempt to conceptualize capabilities (e.g., Bhatt and Grover 2005; Moorman and Slotegraaf 1999), and insights into the 
functional activities of market-driven organizations (e.g., Day 1994) inspire conceptual and empirical work on export marketing capabilities, especially with respect to informational, relational, and product development skills (Morgan et al. 2004). Export marketing capabilities thus have been unequivocally established as pivotal antecedents of export marketing strategy, tactics, and performance (Morgan et al. 2004; Zou et al. 2003).

Export marketing takes place in an environment that is increasingly virtual, which creates a strategic imperative to manage the export firm's Web presence. Web-related skills refer to an organization's Web capabilities as they increase its ability to repeatedly generate Web applications that create value (Zhu 2004). If underdeveloped, Web capabilities significantly hinder Internet marketing performance, which means that in addition to export marketing capabilities, Web capabilities need to be developed as a complementary driver of marketing performance. Web capabilities constitute both technical (e.g., integration of software tools) and nontechnical (e.g., graphical design of a Web site) skills and can transform material (e.g., hardware) and immaterial (e.g., knowledge of programming languages) resources to make them useful for performance (Zhu and Kraemer 2002).

In addition to their functional role as a platform for the creation of Web applications, Web capabilities may affect the (re)configuration of a firm's organizational routines (Chatterjee et al. 2002), other functional capabilities (Biswas and Krishnan 2002), and knowledge base (Tanriverdi 2005; Zhu and Kraemer 2002). A dynamic perspective of the RBV suggests that the (re)configuration and dynamic use of functional capabilities, especially knowledge stocks, represents the cornerstone of sustainable competitive advantage (Cepeda and Vera 2007; Eisenhardt and Martin 2000; Teece et al. 1997). As higher-order or dynamic capabilities, Web capabilities would help firms achieve enduring competitive advantages in changing environments because they can deploy and (re)configure export marketing capabilities and knowledge stocks (Zander and Kogut 1995).

\subsubsection{Web Capabilities and Export Marketing Capabilities}

Dynamic capabilities provide value by (re)configuring functional capabilities to match changing market prerequisites (Eisenhardt and Martin 2000). When firms are too slow to (re)configure their functional capabilities, they miss the connection with evolving business practice in dynamic export markets, and core rigidities arise (Leonard-Barton 1992). Core rigidities reflect the flip side of functional capabilities. In export marketing, typical core rigidities include product specifications, market information, and relationship strategies that have served the firm well in the past but become inappropriate for current and new environmental requirements (Morgan et al. 2004). To avoid core rigidities and gain optimal value from export marketing capabilities, exporting firms use the dynamic potential of Web capabilities to feed their 
export marketing capabilities. This dynamic potential exists in the form of day-to-day routines, processes, and simple rules (Zhu and Kraemer 2002). In summary, a firm's ability to develop and coordinate Web-based activities should enhance its timely upgrades of informational, relational, and product development skills. Accordingly, we hypothesize:

$\mathrm{H}_{1}$ : Web capabilities positively affect export marketing capabilities.

\subsubsection{Web Capabilities and Declarative and Experiential Knowledge}

Recent research emphasizes the importance of knowledge management for exporting firms (Morgan et al. 2003), but the extent to which the Web affects an exporting organization's knowledge stocks and eventually influences longterm export marketing performance has been presumed rather than explored (Nguyen and Barrett 2006). To clarify this phenomenon, we discern two types of export marketing knowledge: declarative and experiential. Focusing on both is necessary, because they have separate relevance with regard to the internationalization of the firm (Eriksson et al. 1997) and international business performance (e.g., Morgan et al. 2003).

Declarative knowledge denotes a firm's understanding of the export market through codified, factual information that is readily available from various sources (Cohen and Bacdayan 1994). This type of knowledge can be acquired easily through standardized methods of collecting and transmitting information and transferred to or replicated by other organizations. By increasing Web capabilities, exporting firms likely gain access to Web sources that contain relevant declarative information about export marketing (Nguyen and Barrett 2006). The current prevalence of Web-based marketing activities in international companies means that more and more firms acquire more advanced Web applications that facilitate information gathering, validation, and integration across multiple information sources (Gregory et al. 2007; McKinsey 2007b).

The Web facilitates interactions between the firm and its markets and thus generates more accurate, factual information about the export marketing environment. The interface used to exchange information also enables exporting companies to store and internalize information, such as by integrating intra- and extra-net applications (Liesch and Knight 1999). Firms look for declarative information to reduce the uncertainty associated with the foreign export market (Bergh 1998; Johanson and Vahlne 1977), then enter search processes to combine and compare different bodies of information. Once they acquire, sort, and add enough information, they translate it into new explicit and actionable knowledge (Nonaka 1994). Thus, with their Web capabilities, companies obtain greater exposure to factual information from 
the Web and then internalize this information, which increases their stock of declarative knowledge. Hence, we hypothesize:

Web capabilities positively affect an exporting firm's stock of declarative knowledge.

Unlike the "know-what" character of declarative knowledge, experiential knowledge primarily pertains to "know-how", that is, a firm's potential to perceive concrete opportunities in the market and understand how these opportunities should be taken, as well as how they fit into current and future activities (Eriksson et al. 1997). Generating experiential knowledge is costly, because it requires frequent and extensive interactions with the field (Lam 2000). Although extant literature points to the need for regular physical interactions between exporters and market(s) (e.g., learning by doing) to create experiential knowledge (Cavusgil and Zou 1994), recent findings in relationship marketing and information systems research indicate that virtual interaction has advanced to the stage that it offers a suitable context for creating experiential knowledge on a large scale (Devaraj and Kohli 2003). Specifically, the increased reach and richness of virtual interactions enable firms to acquire new customers without a physical presence. As a result of the Web's development into a social medium, personal and professional networking opportunities abound and even extend to entire virtual worlds (Nambisan and Baron 2007). Electronic communities for product/service support, manufacturer-reseller programs for online training, and Web-enhanced selling and buying options represent just some examples of how extended, virtual interactions between exporters and stakeholders in physically distant markets is now a reality (Sawhney et al. 2005). Firms retrieve information from this interactionally rich media environment to reduce their ambiguity and confusion about opportunities (Daft and Lengel 1986). In summary, the present-day Web channel offers increasing possibilities for customization and personalization (e.g., real-time communication, instant feedback mechanisms) (Devaraj and Kohli 2003). With these Web capabilities, firms can combine information exchange with social exchange and thus accumulate, evaluate, and adapt their know-how. In turn, they minimize ambiguity and maximize their understanding of concrete opportunities. Accordingly, we hypothesize:

$\mathrm{H}_{3}$ : Web capabilities positively affect an exporting firm's stock of experiential knowledge.

\subsubsection{Knowledge and Export Marketing Performance}

The relationship between organizational knowledge and performance has been extensively discussed and corroborated in the strategy, organization, international business and marketing literature. We build on this rich theoretical and empirical basis and on its exponent in export marketing 
literature more in particular to shortly discuss how declarative and experiential knowledge and export marketing capabilities relate to export marketing performance. As such, we develop four baseline hypotheses through which we relate Web capabilities to export marketing performance.

Following the KBV, declarative and experiential knowledge provide two fundamental sources of a firm's functional capabilities (e.g., Grant 1996; Kogut and Zander 1996). These knowledge-capabilities relationships receive ample empirical support in export marketing literature (e.g., Morgan et al. 2003; Souchon and Diamantopoulos 1996). Furthermore, strategic management and export marketing literature reveal that the capabilitiesstrategy link represents an important path to (export) performance (Barney 1991; Zou et al. 2003). An export marketing strategy pertains to a firm's deliberate exploitation of internal resources and adequate response to the external forces and opportunities of an export product-market combination (Varadarajan and Yadav 2002). In general, research supports the proposition that companies with a clearer, more intense strategic course outperform competitors (Morgan et al. 2003). Finally, empirical studies confirm the positive effects of strategy on financial (e.g., Pelham and Wilson 1996) and nonfinancial (e.g., Jaworski and Kohli 1993) performance. Strategyperformance effects have also been substantiated in the export marketing literature (Cavusgil and Zou 1994; Hunt and Morgan 1996). Extant research defines export marketing performance as the degree to which an export venture achieves its most important financial and nonfinancial marketing goals (Diamantopoulos and Kakkos 2007). Hence, we propose four baseline hypotheses:

$$
\begin{array}{ll}
\mathrm{H}_{4 a}: & \text { The stock of declarative knowledge positively } \\
& \text { affects export marketing capabilities. } \\
\mathrm{H}_{4 \mathrm{~b}}: & \text { The stock of experiential knowledge positively } \\
& \text { affects export marketing capabilities. } \\
\mathrm{H}_{4 \mathrm{c}}: & \begin{array}{l}
\text { Export marketing capabilities positively affect } \\
\text { export marketing strategy. }
\end{array} \\
\mathrm{H}_{4 \mathrm{~d}, \mathrm{e}}: & \begin{array}{l}
\text { Export marketing strategy positively affects (d) } \\
\text { short-term export marketing performance and (e) } \\
\text { long-term export marketing performance. }
\end{array}
\end{array}
$$

We use these baseline hypotheses to integrate Web capabilities into the established thread that theoretically links market knowledge, export marketing capabilities, and strategy to export marketing performance. If we can empirically confirm this integration, these structural relationships present a promising perspective on the dynamic nature of Web capabilities. 


\subsubsection{Web Capabilities as Facilitators}

In addition to considering the dynamic nature of Web capabilities and their associated indirect effect on export marketing performance, information systems research focuses on the more functional impact of IT on firm performance (Zhu and Kraemer 2002). More in particular, it is argued that IT-related capabilities create functionalities that increase operational efficiency, reduce transaction and production costs, and enhance product differentiation (Jean 2007). Web capabilities in turn enrich the portfolio of export marketing instruments and offer opportunities for faster global communication, international data collection, foreign retailer selection, and better service to existing customers (Fisher et al. 2007). That is, Web capabilities offer a wide range of means to facilitate and strengthen the effect of export marketing strategy on export marketing performance. Therefore, we conceive Web capabilities as a moderator that strengthens the relationship between export marketing strategy and performance and examine the relationship while taking into account two important issues: the "IT productivity paradox" and the "virtuality trap".

First, academia has not reached consensus about the time scope of the functional effect of Web capabilities. On the one hand, the need to embed Web capabilities in the patchwork of complementary organizational capabilities and the related learning process suggest a significant time lag before the functional benefits of Web capabilities become manifest (Spithoven 2003). On the other hand, the transparency of the Web (e.g., open source software) reduces ambiguity about best practices and facilitates copies of successful Web tools, so the immediate benefits of Web capabilities may fade out quickly (Yamin and Sinkovics 2006). As this "IT productivity paradox" remains unsolved (Brynjolfsson 1993), we investigate the moderating effect of Web capabilities both in short- and in the longrun.Second, a firm's Web activity may fall short of or outpace its strategic course. Empirical studies illustrate the high risks and costs associated with improperly aligned Web applications (Ghose and Dou 1998; Liu and Shrum 2002). Firms may overestimate the role of the Web, overinvest in Web capabilities, and get caught in the "virtuality trap" (Yamin and Sinkovics 2006), which prompts them to underutilize or even ignore nonvirtual sources of information. We contend that increasing Web capabilities are functional up to a certain level and therefore propose an inverted U-shaped effect. Beyond an optimal point, extra investments in Web capabilities grow increasingly misaligned with the strategic course of the exporting firm, so they are expected to attenuate rather than enhance the positive effect of export marketing strategy on performance. Taking into account both issues, we hypothesize: 
$\mathrm{H}_{5 \mathrm{a}, \mathrm{b}}$ : Web capabilities have an inverted U-shaped effect
on the positive relationship between export
marketing strategy and (a) short-term export
performance and (b) long-term export marketing
performance.

The conceptual framework in Figure 2.1 summarizes our constructs and hypotheses.

\section{FIGURE 2.1 Conceptual Framework}

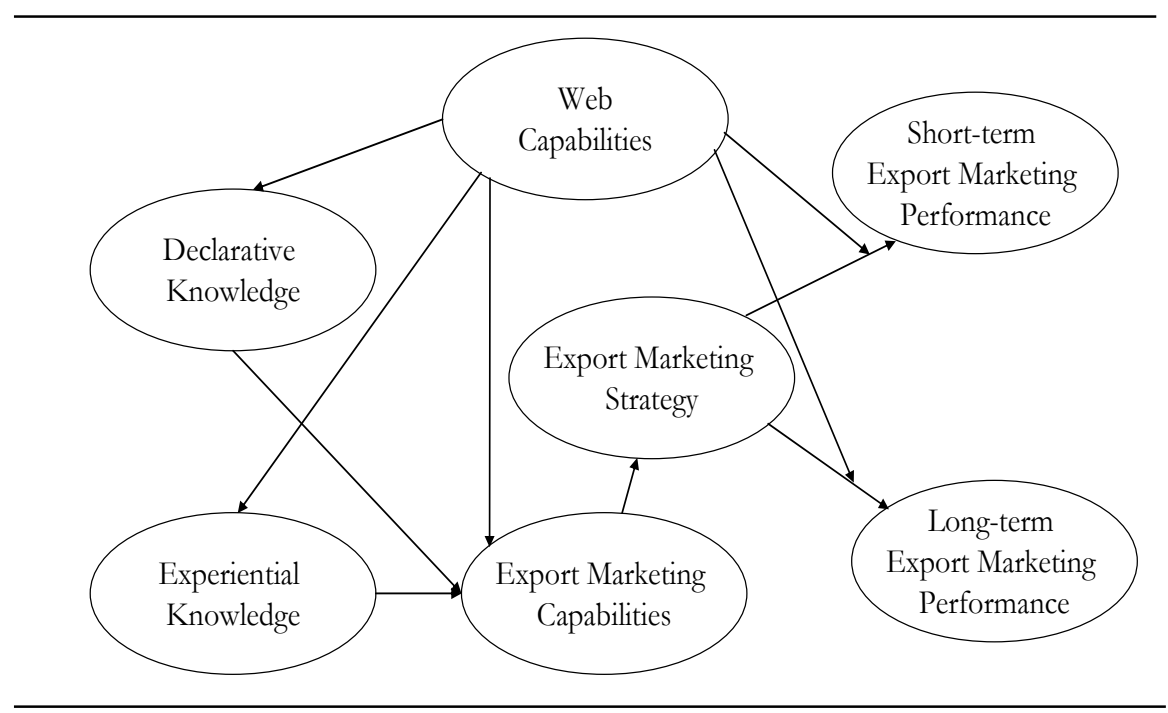

We thus take a dual perspective toward the relationship between Web capabilities and export marketing performance. Dynamic in nature, Web capabilities affect export marketing capabilities, mainly through their impact on the relevant knowledge base of the exporting firm. Concurrently, Web capabilities facilitate the manifestation of export marketing strategy. 


\subsection{Empirical Study}

As described in Chapter 1 and to test our hypotheses in this study, we rely on a database of 311 export ventures from Dutch and Portuguese manufacturing companies.

\subsubsection{Measures}

By combining fieldwork with insights from international marketing and information systems literature, we verify the relevance and adequacy of each construct. Furthermore, to ensure that the original meaning of the constructs does not change, we apply double back-translation, such that the original English version of the questionnaire was translated to Dutch and Portuguese by three academics in international marketing (one Portuguese and two Dutch native speakers). We draw the measurement scales from articles published in established journals in information systems, (international) marketing, and strategy. Respondents could complete the Portuguese, Dutch, or English versions of the questionnaire. The items in our scales, references, and reliability estimates appear in Appendix A, and we discuss them next.

Declarative and Experiential Knowledge. We measure declarative and experiential knowledge with three-item scales adapted from Morgan and colleagues (2003).

Web Capabilities. We assess Web capabilities by adapting a measure based on Zhu and Kraemer (2002), whose items tap the degree to which the export venture provides information (4 items), transaction (5 items), interaction (5 items), and supplier connection (5 items) capabilities.

Export Marketing Capabilities. We adapt Morgan et al.'s (2004) measure to operationalize the export marketing capabilities scale with an instrument that focuses on informational capabilities (5 items), relationshipbuilding capabilities ( 3 items), and product development capabilities (3 items). These items reflect the most important types of capabilities, widely used as indicators of export marketing capabilities (e.g., Calantone et al. 1996; Souchon and Diamantopoulos 1996).

Export Marketing Strategy. We assess the extent to which export ventures embrace an export marketing strategy by adapting a nine-item measure from Morgan et al. (2004). This measure reflects three underlying dimensions - cost leadership, market differentiation, and service differentiation —operationalized with three items each.

Short-term and Long-term Export Marketing Performance. We measure short-term export marketing performance satisfaction with Lages and Lages's (2004) 10-item STEP scale, which reflects the following dimensions: extent to which the export venture achieved satisfaction with 
short-term performance improvement (4 items), immediate export intensity improvement (2 items), and expected short-term performance improvement (4 items). Finally, to assess long-term export marketing performance, we borrow Zou et al.'s (1998) EXPERF scale, which captures financial and strategic export performance, as well as overall satisfaction with the export venture, with three items each. We use this overall, timeless scale, which is appropriate for gathering long-term performance assessments from respondents. According to Diamantopoulos and Kakkos (2007), if the scale does not refer to a timeframe for export marketing, respondents tend to think about the long term. We provide more details about the measures in Appendix A.

\subsection{Analysis}

Except for declarative and experiential knowledge, we operationalize the remaining constructs in our model using multidimensional measures.

\subsubsection{Measure Validation}

To test the hypotheses, we use a first-order partial aggregation model (Bagozzi and Heatherton 1994), in which the underlying dimensions are parceled and load on the higher-order construct. For instance, for export marketing capabilities, the informational, relationship-building, and product development capabilities items aggregate into three item parcels that constitute the indicators for that construct. Item parceling is appropriate for nonnormally distributed and coarsely categorized data (Bandalos 2002); it allows for less complex models and reduces the number of parameters to be estimated (Bagozzi and Heatherton 1994).

However, item parceling should be considered only when the parceled items exhibit unidimensionality (Bandalos 2002). Unidimensionality can be defined in the context of structural equation modeling as having measurement models with manifest variables which only load on one hypothesized construct (Anderson and Gerbing 1988; Kumar and Dillon 1987). To assess unidimensionality, we conduct confirmatory factor analyses of all possible pairwise combinations of the measures at the disaggregate level for the Dutch and Portuguese samples. Specifically, we test each possible combination of the 18 dimensions (including declarative and experiential knowledge) using a nested model approach, which yields 153 pairwise analyses for each sample. For each two-factor model, we compare two nested models: one in which the interfactor correlation is constrained to unity, and another in which the factor correlation remains unconstrained (Anderson and Gerbing 1988). The constrained model is equivalent to a onefactor model and should yield inferior model fit compared with the unconstrained model if the two measures are truly unidimensional (e.g., 
Rindskopf and Rose 1988). Moreover, this approach also allows us to assess within-method convergent and discriminant validity (Anderson and Gerbing, 1988; Steenkamp and van Trijp, 1991).

To assess violations of the assumption of multivariate normality, we conduct Mardia's omnibus test of multivariate normality using PRELIS 2.80 (Mardia 1985). For both samples, the test rejects the null hypothesis, which implies our data are not normally distributed. Therefore, we use the SatorraBentler scaled (SB) $\chi^{2}$ (Satorra and Bentler 2001) and corresponding robust standard errors to adjust for the deviations from multivariate normality, as suggested by Curran and colleagues (1996). When conducting the pairwise analyses we omitted 10 indicators, as they exhibited large standardized residuals and/or significant Lagrange multiplier tests (i.e., modification index). For the remaining indicators we found that all loadings $(\Gamma)$ exceeded .7 for both samples thus supporting within-method convergent validity (Steenkamp and van Trijp 1991). The results using the SB $\chi^{2}$ difference test (Satorra and Bentler 2001) reveal that the constrained model causes a substantial and significant decrease in model fit $(\alpha=.05)$ compared with the unconstrained model for all pairwise comparisons. Therefore, the two-factor model provides a better fit with the data than the one-factor model thus providing support for unidimensionality and discriminant validity. All measures exhibit sufficient reliability, with coefficient alphas ranging from .71 to .95 . Finally, we partially aggregated the items at the first-order level for all constructs except declarative and experiential knowledge.

\subsubsection{Measurement Invariance Tests}

In testing for measurement invariance between the Dutch and Portuguese samples, we first propose a baseline model using the first-order partially aggregated model, which we then subject to a series of increasingly restrictive models to demonstrate measurement invariance (Vandenberg and Lance 2000). The measurement invariance analysis demonstrates the extent to which the scaling and representativeness of the indicators are similar across the two samples. We adopt Steenkamp and Baumgartner's (1998) approach to test measurement invariance in cross-national research and estimate one constrained model simultaneously across the two samples, with an equality constraint imposed on the factor loadings. In turn, we test these models against the relevant unconstrained model. To determine the impact of the equality constraint, we compare the $\mathrm{SB} \chi^{2}$ for the constrained model with the $\mathrm{SB} \chi^{2}$ for the relevant unconstrained model using a SB $\chi^{2}$ difference test. We opt for the SB $\chi^{2}$ and the corresponding robust standard errors, because the null hypothesis for Mardia's (1985) omnibus test of multivariate normality is rejected for the first-order, partially aggregated model in both samples. 
In line with recent studies on measurement invariance (Steenkamp and Baumgartner 1998; Vandenberg 2002; Vandenberg and Lance 2000), we select two additional absolute fit indices: root mean squared error of approximation (RMSEA) and standardized root mean square residual (SRMR), along with two incremental fit indices: the Tucker-Lewis (1973) index (TLI) and the comparative fit index (CFI), following the guidelines suggested by Hu and Bentler (1998) and Marsh et al. (2004). In addition, we obtain a more detailed evaluation of fit by inspecting the normalized residuals and modification indices.

Except for one item of the declarative knowledge construct, we find no source of misfit in our baseline model ( $\mathrm{SB} \chi^{2}=589.8$ [df $=419, p<.01$ ], $\mathrm{CFI}=.975$, TLI $=.970, \mathrm{RMSEA}=.051, \mathrm{SRMR}=.078)$. For the configural invariance model, we freely estimate the loadings in both samples, omitting one item, and obtain an excellent model fit $\left(\mathrm{SB} \chi^{2}=515.6\right.$ [df $=376, p<$ $.01]$, CFI $=.977$, TLI $=.971$, RMSEA $=.049$, SRMR $=.071)$, which provides clear evidence of configural measurement invariance. Moreover, the fit indices for the full metric invariance model $\left(\mathrm{SB} \chi^{2}=537.2[\mathrm{df}=391, p<\right.$ $.01]$, CFI $=.976$, TLI $=.971$, RMSEA $=.049$, SRMR $=.074$ ) are more than acceptable (Marsh et al. 2004). Although Vandenberg and Lance (2000) recommend less stringent cut-off values for high model complexity, all our fit indices meet $\mathrm{Hu}$ and Bentler's (1998) recommended values. A nonsignificant $\mathrm{SB} \chi^{2}$ difference test $\left(\mathrm{SB} \Delta \chi^{2}=21.6, \Delta d f=15, p>.05\right)$ also indicates metric invariance, and none of the items show modification indices that indicate item loading differences across groups (e.g., Cheung and Rensvold 1999). That is, respondents from the two samples appear to use equivalent conceptual frames of reference when responding to the scale items. In Appendix D, we list the higher-order factors and standardized loadings of their respective items in the full measurement equivalence model. We provide an overview of the outcomes of the measurement invariance tests and internal consistency estimates in Table 2.1. 
TABLE 2.1 Measurement Model Results

Measurement Invariance Tests

\begin{tabular}{lccccccccc}
\hline Models & SB $\chi^{2}$ & $\mathbf{d f}$ & SB $\Delta \chi^{2}$ & $\Delta$ df & $p$ & CFI & TLI & RMSEA & SRMR \\
\hline $\begin{array}{l}\text { Baseline } \\
\text { model }\end{array}$ & 589.8 & 419 & - & - & - & .975 & .970 & .051 & .078 \\
$\begin{array}{l}\text { Con- } \\
\text { figural } \\
\text { invariance } \\
\text { model }\end{array}$ & 515.6 & 376 & - & - & - & .977 & .971 & .049 & .071 \\
$\begin{array}{l}\text { Full metric } \\
\text { invariance } \\
\text { model }\end{array}$ & 537.2 & 391 & 21.6 & 15 & .12 & .976 & .971 & .049 & .074 \\
\hline
\end{tabular}

\subsubsection{Structural Model Estimation}

Establishing structural invariance is necessary before conducting comparisons across groups, so we explore the structural invariance of all relationships. We take a multiple-group approach (e.g., Netemeyer et al. 2004), as we show in Table 2.2. In the first step, we estimate the baseline model, and all paths across samples are freely estimated (SB $\chi^{2}=750.91$, df $=415)$. We then compare the model with a model in which we constrain all paths to be equal across groups, that is, a full structural invariance model (SB $\left.\chi^{2}=764.70, \mathrm{df}=424\right)$. The difference in fit between the two models is not significant (SB $\Delta \chi^{2}=13.79, \Delta d f=9, p>.05$; cf. Satorra and Bentler 2001), in support of the structural invariance of all paths in our model. The fit indices for the model $\left(\mathrm{SB} \chi^{2}=764.70, d f=424, p<.001\right.$, CFI $=.953$, TLI $=.949$, RMSEA $=.065)$ indicate excellent model fit. 
Chapter 2

TABLE 2.2 Structural Model Results, Standardized Path Estimates, tValues, and Interaction Effects

Structural Model Results

\begin{tabular}{lcccccccc}
\hline Models & SB $\chi^{2}$ & df & SB $\Delta \chi^{2}$ & $\Delta$ df & p & CFI & TLI & RMSEA \\
\hline $\begin{array}{l}\text { Baseline model } \\
\begin{array}{l}\text { (all paths } \\
\text { freely estimated) }\end{array}\end{array}$ & 750.91 & 415 & - & - & - & .954 & .948 & .066 \\
$\begin{array}{l}\text { Full structural } \\
\text { invariance } \\
\text { model }\end{array}$ & 764.70 & 424 & 13.79 & 9 & .13 & .953 & .949 & .065 \\
\hline
\end{tabular}

Standardized Path Estimates and t-Values

\begin{tabular}{|c|c|c|}
\hline Direct Effects & $\begin{array}{l}\text { Standardized } \\
\text { Coefficients } \\
\end{array}$ & t-Values \\
\hline $\mathrm{H}_{1}$ : Web capabilities $\rightarrow$ export marketing capabilities & $.11^{* *}$ & 2.10 \\
\hline $\mathrm{H}_{2}:$ Web capabilities $\rightarrow$ declarative knowledge & $.21 * *$ & 2.88 \\
\hline $\mathrm{H}_{3}:$ Web capabilities $\rightarrow$ experiential knowledge & $.15^{* *}$ & 2.28 \\
\hline \multicolumn{3}{|l|}{ Baseline Hypotheses: } \\
\hline $\begin{array}{l}\mathrm{H}_{4 a} \text { Declarative knowledge } \rightarrow \text { export marketing } \\
\text { capabilities }\end{array}$ & $.61 * *$ & 7.94 \\
\hline $\begin{array}{l}\mathrm{H}_{4 \mathrm{~b}} \text { Experiential knowledge } \rightarrow \text { export marketing } \\
\text { capabilities }\end{array}$ & $.45^{* *}$ & 7.56 \\
\hline $\begin{array}{l}\mathrm{H}_{4 \mathrm{c}} \text { Export marketing capabilities } \rightarrow \text { export marketing } \\
\text { strategy }\end{array}$ & $.74^{* *}$ & 5.87 \\
\hline $\begin{array}{l}\mathrm{H}_{4 \mathrm{~d}} \text { Export marketing strategy } \rightarrow \text { short-term export } \\
\text { marketing } \\
\text { performance }\end{array}$ & $.17^{* *}$ & 2.02 \\
\hline $\begin{array}{l}\mathrm{H}_{4 \mathrm{e}} \text { Export marketing strategy } \rightarrow \text { long-term export } \\
\text { marketing performance }\end{array}$ & $.56^{* *}$ & 8.36 \\
\hline \multicolumn{3}{|l|}{$\begin{array}{l}* \text { Significant at } p<.05 . \\
* * \text { Significant at } p<.01 \\
\end{array}$} \\
\hline Interaction Effects & $\Delta \chi^{2}$ & df \\
\hline $\begin{array}{l}\mathrm{H}_{5 a}: \text { Web capabilities x export marketing strategy } \rightarrow \text { short- } \\
\text { term export marketing performance }\end{array}$ & 15.54 & 2 \\
\hline $\begin{array}{l}\mathrm{H}_{5 b}: \text { Web capabilities } \mathrm{x} \text { export marketing strategy } \rightarrow \text { long- } \\
\text { term export marketing performance }\end{array}$ & .45 & 2 \\
\hline
\end{tabular}


All proposed path coefficients and t-values are significant and in the expected direction. The squared multiple correlations confirm the explanatory power; they range from .39 for export marketing strategy to .64 for export marketing capabilities. In Table 2.2, we also present the structural model results and standardized coefficients for all direct relationships. Web capabilities positively affect export marketing capabilities $\left(\mathrm{H}_{1}\right)$ (standardized coefficient .11, t-value 2.10), declarative knowledge $\left(\mathrm{H}_{2}\right)$ (standardized coefficient .21, t-value 2.88), and experiential knowledge $\left(\mathrm{H}_{3}\right)$ (standardized coefficient .15, t-value 2.28). Besides, Table 2.2 shows support for our baseline hypotheses 4 a,b,c,d,e.

Our analysis also confirms that the indirect effect of Web capabilities on export marketing capabilities is significant through both declarative and experiential knowledge (standardized coefficient .13, t-value 2.76). The indirect effect of Web capabilities on export marketing capabilities is stronger than the direct effect (standardized coefficient .11, $\mathrm{t}$-value 2.10). Furthermore, export marketing capabilities and strategy mediate the effect of Web capabilities on both short-term and long-term export marketing performance (standardized coefficients: short-term .06, t-value 1.85; longterm .10, t-value 2.80). Finally, we control for the effects of IT infrastructure on Web capabilities with a two-sample median split test but find no significant effects.

In a final step, we test $\mathrm{H}_{5 a}$ and $\mathrm{H}_{5 \mathrm{~b}}$ using a three-sample median split (Bagozzi and Yi 1989). A chi-square difference test $\left(\Delta \chi^{2}=15.54\right.$, df $=2, p<$ .05) confirms the significant, inverted, U-shaped moderating effect of Web capabilities on the relationship between export marketing strategy and shortterm export marketing performance (standardized coefficients $\beta_{\text {Low }}-.14$, $\mathrm{t}$ value $-.75 ; \beta_{\text {Medium }} .32$, $t$-value 3.77 ; $\beta_{\text {High }}-.29$, $t$-value -1.70 ). We check for the same effect with regard to long-term export marketing performance, but this effect turns out to be insignificant $\left(\Delta \chi^{2}=.45, \mathrm{df}=2, p>.05\right)$.

\subsection{Discussion}

This study attempts to advance marketing literature by untangling the complex relationship between a firm's Web activity and its export marketing performance. Therefore, we proposed three research objectives: conceptualize Web capabilities, develop a framework that reflects the dynamic nature of Web capabilities in the creation and renewal of export marketing resources, and explore Web capabilities as facilitating the materialization of export marketing strategy towards performance.

The measurement model and invariance analysis confirm a higherorder conceptualization of Web capabilities and demonstrate the equivalence of the construct across Dutch and Portuguese samples. Exporting firms should develop technical and nontechnical skills to reinforce their Web activity in the export arena. In particular, Web capabilities enable exporting 
firms to transform and integrate their material and immaterial resources, which makes them useful for providing information, enhancing transactions, facilitating interactions, and connecting to suppliers through the Web (Zhu and Kraemer 2002).

\subsubsection{The Dynamic Nature of Web Capabilities}

We find a direct, positive effect of Web capabilities on export marketing capabilities and on declarative and experiential knowledge. This finding confirms the dynamic nature of Web capabilities as a prime antecedent of the renewal of export marketing resources. Although previous research outlines the potential impact of dynamic capabilities on functional marketing capabilities and eventually on performance, our study is among the first to provide empirical evidence of this relationship (e.g., Cepeda and Vera 2007; Schreyögg and Kliesch-Eberl 2007). Moreover, the results show that the indirect effect of Web capabilities, through knowledge, on export marketing capabilities outperforms the direct effect. The effect of Web capabilities on experiential knowledge is almost as strong as the effect on declarative knowledge. This finding strengthens our presumption that the Web represents an interface for not only the exchange of factual information with export markets but also social exchange, such that exporting firms can create up-to-date marketing knowledge. These findings also match recent studies that report on the use of social cues to enhance customers' perceptions of human connection and the formation of emotional bonds (Wang et al. 2007) and extend previous research with respect to the impact of the Web on a firm's export marketing knowledge (Nguyen and Barrett 2006).

Because our findings corroborate the mediating role of both export marketing capabilities and strategy (cf. Morgan et al. 2004), the data largely support our theoretical framework, in which we relate Web capabilities through knowledge to export marketing resources and eventually, indirectly, to export marketing performance.

\subsubsection{Post Hoc Analysis on Long-Term Effect}

The long-term performance measure (EXPERF) in the model represents a forward looking respondent's perspective. However, for the dynamic nature of Web capabilities to hold, a more rigorous assessment is appropriate. Therefore, as mentioned in Chapter 1, we collected performance data four years after the first survey to check if these hypothesized performance effects remain standing over time. Prior research in this context suggests that a longitudinal approach with a lag period of four years is appropriate (Grant et al. 1988; Hult et al. 2008).

To test this post hoc hypothesis, we replaced export marketing performance $\left(\right.$ Year $\left._{t}\right)$ with export marketing performance $\left(\right.$ Year $\left._{t+4}\right)$ in the 
model specified in Figure 1. We used maximum likelihood estimation to calculate this model, because of the missing values for our export marketing performance $\left(\right.$ Year $\left._{t+4}\right)$ scale. Therefore, this model does not account for non-normality yet shows still good yet inferior fit indices compared to the main model $\left(\chi^{2}=667.80, d f=497, p<.001\right.$, CFI $=.871$, TLI $=.868$, RMSEA = .078). Most important, though, our results confirm the significant effect of export marketing strategy on long-term export marketing performance $\left(\right.$ Year $\left._{\mathrm{t}+4}\right)$ (standardized coefficient .20, $\mathrm{p}<.05$ ). Furthermore, the results show that Web capabilities impact declarative knowledge (standardized coefficient .27, $\mathrm{p}<.05$ ) and experiential knowledge (standardized coefficient .20, $\mathrm{p}<.05$ ). Moreover, both declarative and experiential knowledge significantly affect export marketing capabilities (standardized coefficient .63, $\mathrm{p}<.01$ and $.65, \mathrm{p}<.01$, respectively). Finally, export marketing capabilities influence export marketing strategy (standardized coefficient .94, $\mathrm{p}<.01$ ). Therefore, this model confirms that Web capabilities affect export marketing performance in the long run through declarative and experiential knowledge, export marketing capabilities, and export marketing strategy.

\subsubsection{Web Capabilities as Facilitators}

Finally, the results largely confirm a complementary effect of Web capabilities on export marketing performance. That is, Web capabilities moderate the direct, positive effect of export marketing strategy on shortterm performance, which implies that they strengthen the implementation of an export marketing strategy with immediate performance effects. However, this effect fails to remain significant in the long run. Thus, the facilitating role of Web capabilities does not reflect on long-term export marketing performance, which is consistent with previous research findings and recent managerial judgment indicating that tactical performance benefits of Web applications may fade quickly (Carr 2003; Wade and Hulland 2004). Moreover, this moderation effect shows an inverted U-shape, as hypothesized. Beyond a moderate level, additional investments in Web capabilities become increasingly ineffective or even minimize the immediate performance impact of the strategic course. This finding confirms recent studies that call for aligning Web capabilities with the firm's strategic course (Ghose and Dou 1998; Liu and Shrum 2002). Overall, the results provide broad support for our conceptual model and largely confirm the dual nature of Web capabilities and their contributions to export marketing performance. 


\subsection{Limitations and Further Research}

This study has several limitations that must be taken into consideration to judge its merits. At the same time, these limitations have implications for further theory development. First, we use cross-sectional data, which prevent us from testing causal relationships. A more extended longitudinal analysis might reveal a more complex interaction (including feedback loops) among Web capabilities, knowledge, and export marketing capabilities (e.g., Schreyögg and Kliesch-Eberl 2007). Furthermore, a longitudinal approach with a larger data set would allow for deeper insights in the short-term and long-term performance effects of Web capabilities (Lages and Lages 2004).

Second, the study's generalizability remains restricted, because our sample is limited to manufacturing firms. Although representative of typical exporting firms in the Netherlands and Portugal, our findings cannot simply be generalized to larger or service firms. Nevertheless, we collect data in two countries that differ with respect to their Web environment, the focal issue of this paper. As such, we enhance the external validity of the model, but further research including multiple segments and countries is warranted.

Third, the complexity of the model, not least due to the higherorder nature of most constructs, enabled us to include only a limited number of variables. Further research should introduce additional explanatory variables; for example, the interaction between Web capabilities and export marketing capabilities might depend on the integration of both capabilities within the organization (e.g., Prasad et al. 2001). Furthermore, the relationship among knowledge, export marketing capabilities, and performance might be extended to include other export resources and additional export-related processes (e.g., Morgan et al. 2004).

\subsection{Managerial Implications}

This research provides several clear recommendations for export managers. First, exporting firms should invest in developing Web capabilities. Beyond the indispensable IT infrastructure, through their Web capabilities, exporting firms can translate their presence on the Internet into export marketing performance. This ability seems particularly important in the context of a recent market report that indicates export managers believe that investments in advanced Web capabilities have lagged (McKinsey 2007a). Therefore, exporting organizations should enhance their technical and nontechnical skills with respect to online information, transaction, interaction, and supplier connection management.

Second, the development of Web capabilities is a time-consuming and complex process, so noncompetitive benchmarking can be a useful tool to identify gaps in the current portfolio of Web capabilities and paths for future development (Bharadwaj 2000). Our results show that the 
performance outcomes of Web capabilities may be short lived, as might the competitive relevance of modern skills. A regular evaluation and, if needed, rejuvenation of Web capabilities appears required to safeguard their relevance and maintain up-to-date export marketing resources.

Third, our empirical findings corroborate the importance of Web capabilities for shaping and renewing the export knowledge base of the firm. Exporting firms should manage their knowledge stocks with an open mind about the Web. To date, exporting firms generally use the Internet as a cheap and easy medium for searching factual knowledge about export markets (Nguyen and Barrett 2006) but largely fail to see the potential of the Web for transforming facts that have been gathered into real business intelligence and eventually better strategic decision-making (McKinsey 2009). Linking the Web to firm internal IT systems such as SAP can help companies collect, analyze, and interpret online information so that this information can eventually be used to achieve cost-efficiencies or to improve customer relationship management.

Fourth, our findings confirm that the development of Web capabilities should be aligned with the export strategy of the firm, in line with Gregory et al. (2007), who argue that Web capabilities enhance the successful implementation of an export marketing strategy as long as they are sufficiently embedded in the current business tactics of a particular venture. Both internal and external credibility are at stake if a firm's Web activity fails to match its market positioning or reputation among local export partners. Moreover, misaligned Web capabilities cannot contribute to export performance, because the firm will lack the marketing instruments that can help Web capabilities materialize. Because export strategies differ among ventures, Web capabilities should align in a venture-specific context. To safeguard this alignment, boundary-spanning middle management, the champions of particular export ventures who operate close to the market (McKinsey 2007b), should take charge of developing Web capabilities. Although support from top management and corporate IT departments is necessary, successful Web capabilities cannot be mandated from outside the business context in which they should excel. 



\title{
Chapter 3
}

\section{Level and Profile of Web Capabilities: Effects of Web- Induced Processes on Performance}

\begin{abstract}
The impact of the Web on export management repeatedly takes the label "revolutionary". Surprisingly though, the performance impact of a firm's Web activity remains largely unexplored. In this chapter, we fathom the full scope of Web capabilities by distinguishing between their level and profile and investigate the effect of Web capabilities as a driver of export marketing processes. On the basis of longitudinal data from industrial exporting firms, we find that Web capabilities advance the deployment and upgrading of export marketing resources to enhance short-term and long-term performance, respectively. Our data also show how the interactive trait of Web capabilities buttresses performance. This chapter therefore reveals the complex yet profound effects of Web capabilities on marketing processes and performance.
\end{abstract}




\subsection{Introduction}

The World Wide Web heralds a new era of export marketing. In many industries, it helps firms counter the liability of physical and mental distance to their markets, resellers, and foreign end customers (Prasad et al. 2001). Although the Web has decreased barriers to internationalization, export marketers also have learned that investing in Web technologies alone is not enough to foster marketing performance. Specifically, neither developing a Web site (Samiee 1998) nor dedicating budget and time to Web activities (Manyika et al. 2008) and relentlessly upgrading hard- and software to gather and process information (Quelch and Klein 1996) is sufficient to spur export marketing performance. Increasing managerial and academic evidence indicates the key to successful marketing performance is rarely Web technology per se (Morgan-Thomas and Bridgewater 2004). Rather, competitive advantage derives from the skillful and proprietary ways in which companies use Web technologies (Samiee, 1998). Recently, this statement has received confirmation from a large-scale, global survey that concluded that without an understanding of Web capabilities and their integration into relevant marketing activities, investments in Web technologies will not be effective (McKinsey 2007a). To date though, a paucity of knowledge clarifies these Web capabilities and how they eventually might enhance export marketing performance.

Literature amply supports the notion that firms can realize and sustain competitive advantage to the extent that they have the capabilities to deploy and upgrade their marketing-related resources regularly (Day 1994; Teece et al. 1997; Eisenhardt and Martin 2000). This dynamic capabilities perspective appears in international marketing contexts (e.g., Luo 2000), for which the preliminary findings support the idea that Web capabilities contribute to a more productive use and allocation of resources (e.g., Prasad et al. 2001). Therefore, we argue that Web capabilities possess dynamic potential if they spur the deployment and upgrading of other organizational resources (Teece et al. 1997). Both resource deployment and upgrading foster sustainable competitive advantage, because they entail the efforts needed to extract returns from current resources and create new resources with future-return earning potential (Luo 2000). We contribute to emerging literature in two ways.

First, we take a dynamic capabilities perspective to investigate how the level of Web capabilities drives critical marketing processes and eventually affects performance. We define and operationalize these relationships in an export marketing context and depict the impact of Web capabilities on performance through both resource deployment and resource upgrading. More precisely, as a result of deploying resources, firms create, allocate, and leverage critical marketing assets profitably. Resource upgrading entails investments in new marketing knowledge as a platform for revised or 
new marketing assets and capabilities. We argue that only resource upgrading has the potential to affect long-term performance.

Second, we examine the interactivity trait of Web capabilities, which has led to the conceptualization of the Internet as a social medium (also referred to as Web 2.0). Overall, firm-market interactivity drastically affects firm performance (Song and Zinkhan 2008), and research convincingly illustrates that interactivity constitutes a valuable attribute of Web applications (Albert et al. 2004). Web interactivity gives firms more opportunities to communicate with important stakeholders such as customers. Online interactions for instance enable firms to better assess the potential of products to satisfy customer needs and if necessary to change service offerings accordingly. However, it remains largely unexplored whether enhanced online interactivity leads to performance (Varadarajan and Yadav 2002). Therefore, we investigate how the interactive trait of Web capabilities affects export marketing performance in the short and the long run and explore the extent to which this influence depends on how the organization links interactivity to its current export marketing behavior.

In the remainder of this chapter, we conceptualize Web capabilities and elaborate a model that depicts a dynamic perspective on Web capabilities. In related hypotheses, we formalize the relationships we anticipate among Web capabilities, the deployment and upgrading of export marketing resources, and short-term and long-term performance. We test these hypotheses with a sample of 175 exporting firms across medium-sized manufacturing industries. Finally, we discuss the findings, some routes for further research, and managerial recommendations.

\subsection{Conceptual Model}

Building on recent advances in strategy, marketing, and information systems literature, we expand on how the level of Web capabilities feeds recurrent resource deployment and upgrading to enhance short-term and long-term export marketing performance. Furthermore, we explain how the interactive trait of Web capabilities reinforces these strategic processes.

\subsubsection{Web Capabilities and Marketing Processes}

This chapter relies on the same conceptualization and definition of Web capabilities we developed in Chapter 2. Hence, also in this chapter, we use Web-based initiatives to refer to an organization's Web capabilities when they increase its ability to generate Web applications that create value (cf. Zhu 2004). Web capabilities constitute both technical (e.g., integration of software tools) and nontechnical (e.g., graphical design of a Web site) skills and can transform material (e.g., hardware) and immaterial (e.g., software 
knowledge) assets to make them useful for the organization (Zhu and Kraemer 2002). On top of the findings in Chapter 2, this chapter highlights the role of underlying organizational capabilities that mobilize and deploy other resources to explain performance (Tanriverdi 2005). Although an important prerequisite, the mere possession of Web capabilities is insufficient to enhance marketing performance (Grewal and Slotegraaf 2007). Today, marketing managers must master the balancing act among operationalizing, optimizing, and building organizational resources, including Web capabilities (Lages et al. 2005; Grewal and Slotegraaf 2007). Therefore, a more dynamic perspective on Web capabilities may better enable the appropriate deployment and timely upgrading of resources in the context of export marketing performance (Teece et al. 1997; Winter 2003). This way, the competitive relevance of Web application receives safeguarding in the short and long run.

\subsubsection{Web-Induced Deployment}

The deployment of export marketing resources is a complex activity, the outcome of an exploitation process that involves decision making and implementation such that resources produce the maximum risk-adjusted net return (Luo 2002). Returns on resource deployment, however, are rather short lived (Benner and Tushman 2002), because the use of pertinent assets and capabilities implies a depreciation of their competitive value (Teece et al. 1997). We define export marketing deployment as a process that spurs the extension and optimization of existing paradigms, competencies, and technologies with respect to export marketing management. In the following, we elaborate on how Web capabilities may enhance export marketing deployment to the firm's advantage.

The Web supports economic and increasingly social exchanges between the exporting firm and its local partners and makes business behavior transparent and accessible. In online communities, for example, both companies and customers can observe their own contributions as well as those of other business partners. Thus, by managing and using online tools, firms can gain insights not only about their customers but also about their own behavior. Compared with real-life, verbal chats, information displayed on Web sites is easy to comprehend, because it can be saved, printed, and quickly passed on to colleagues. Therefore, firms with the skills to manage online tools will obtain a better understanding of their own export marketing conduct. The interface used to mirror the firm's behavior also provides insights into the venture's value drivers and value drains (Nguyen and Barrett 2006). Furthermore, to spur export marketing deployment, firms look for exchanges with business partners, which enables them to learn from past mistakes and experiences as well as optimize existing marketing competencies (Huber 1991). In a traditional sense, the exporter 
might, for example, set up a relatively static Web site to provide information about the company and its products to the export market. A more innovative approach would use the Web as a social medium and facilitate direct interaction with and between customers through virtual communities, social (business) networks, and videoconferencing. Hence, the Web represents a very rich interface that perfectly mirrors exporters' current export behavior and gives them more opportunities to optimize their current activities and feed export marketing deployment. Therefore,

$\mathrm{H}_{1}$ : Web capabilities positively affect export marketing deployment.

Export marketing deployment also enhances the action repertoire of the export manager instantly, because it activates obtainable, trustworthy, and reliable marketing assets, knowledge, and competencies (Moorman and Miner 1997). As such, it helps strengthen the value proposition(s) and marketing performance in the export venture (Sethi and Iqbal 2008). Extant research defines export marketing performance as the degree to which an export venture achieves its most important financial and nonfinancial marketing goals (Diamantopoulos and Kakkos 2007). However, the benefits of resource deployment may be only short lived, because the advantages of exploiting existing resources are limited and expected to fade (Luo 2000). By relying too much on its own internal strengths, the exporter runs the risk of becoming short-sighted and neglecting changes in customers' preferences or competitive moves that necessitate greater modifications to the marketing mix. Hence, the strength of resource deployment is absolute focus and commitment to the current marketing mix, though this focus simultaneously entails a lack of flexibility to adjust to trends and make revolutionary changes. Therefore, we expect that deployment affects performance only in the short run.

$\mathrm{H}_{2}$ : $\quad$ Export marketing deployment positively affects short-term export marketing performance.

The creation of competitive advantages largely is contingent on resource traits (Black and Boal 1994). Accordingly, in addition to just the stock of Web capabilities, their characteristics should affect short-term export marketing performance. In this respect, we focus on interactivity as a predominant trait of Web applications, based on the increasing relevance of interactivity for firm performance (Ramani and Kumar 2008). In a Webmediated environment, interactivity denotes the degree to which communication is bidirectional, timely, mutually controllable, and responsive (McMillan and Hwang 2002). We contend that Web capabilities without the potential to enhance interactive Web tools only allow for unidirectional contact from the firm to customers, which implies that information merely 
flows from the company to the market and does not take account of any feedback mechanisms (Liu and Shrum 2002). In contrast, Web capabilities with interactive potential can create and manage interactive Web-based interfaces. Especially increasing bandwidth facilitates the use of Web 2.0 tools (Cooke and Buckley 2008; Manyika et al. 2008). Information systems literature characterizes a Web 2.0 environment as interactive, facilitating active sharing and participation (Hoffman 2008; Metz 2008). As such, Web 2.0 tools may help bridge the gap between an exporter and its markets. However, isolated from the firm's export marketing conduct, Web 2.0 tools cannot yield competitive advantages. To spur performance, the Web-based interface should underpin the firm's current export marketing conduct. Therefore, we concentrate on how the interactive trait of Web capabilities fosters export marketing deployment and upgrading.

The interactive trait of Web capabilities should enhance the deployment of export marketing resources by offering practical features for, among other things, faster global communication, international data collection, foreign retailer selection, and better service to existing customers (Fisher et al. 2007). Furthermore, recent findings show that companies that can handle interactive Web tools, such as blogs and communities (Barwise and Farley 2005), are better at discovering, differentiating, and networking with individual customers, as well as building customized product offerings (Bernoff and $\mathrm{Li}$ 2008). These applications result in more lively communication and active dialogues with customers to promote products or services. As such, they help companies emphasize the key benefits of their offerings and increase their market awareness and local sales (Sicilia et al. 2005). Therefore:

$\mathrm{H}_{3}$ : The interactive trait of Web capabilities enhances the positive effect of export marketing deployment on short-term export marketing performance.

Web capabilities should underpin the deployment of export marketing resources, yet eventual success reduces the causal ambiguity about the existence and impact of resources, even across the organization's boundaries. As a consequence, the profits from resource deployments fade. To understand how Web capabilities can spur long-term performance effects, we also must recognize how Web capabilities help upgrade export marketing resources (Luo 2000; 2002).

\subsubsection{Web-Induced Upgrading}

Resource upgrading results from an exploration process and involves searching, experimentation, discovery, and innovation outside current paradigms and competences (March 1991; Voss 2008; Zhan and Luo 2008). Through exploration and experimentation, firms eventually shift their 
learning curves, which can provide a broader mindset and greater ability to respond to changes in the environment (Brouthers et al. 2008). In turn, they build new technologies, market offerings, and skills that become the basis for their future performance (Luo 2000). We define export marketing upgrading as a process that entails the creation and internalization of new insights and procedures with respect to export marketing management. In the following, we elaborate on how Web capabilities may enhance upgrades of export marketing resources and thus future performance.

The Web facilitates an open window between the firm and its markets and thus enhances a firm's ability to retrieve information about the export marketing environment. This information interface also enables exporting companies to store and internalize information, such as by integrating intranet and extranet applications (Sharp 1998). Furthermore, virtual communities enable firms to bring together users with common interests or let these users express common attitudes or opinions about the products online (Sawhney et al. 2005). Firms look for information to reduce uncertainty about the foreign export market (Johanson and Vahlne 1977; Bergh 1998), then enter into search processes to combine and compare different bodies of information. New information becomes internalized to feed the firm's knowledge stocks (Nonaka 1994), which may reduce risk perceptions about uncharted possibilities, because the new information improves the exporter's capability to assess the consequences of opportunities, such as changing the brand name of a product for a particular market. Thus, through their Web capabilities, companies obtain greater exposure to new knowledge, which spurs upgrades of export marketing resources. Hence,

$\mathrm{H}_{4}$ :

Web capabilities positively affect export marketing upgrading.

Export marketing upgrading also entails the acquisition of knowledge and skills that differ from those used previously. Therefore, export marketing upgrading should increase a company's palette of available export marketing skills and competencies (Sidhu et al. 2007). Furthermore, resource deployment must be fueled with different ingredients, because the ways in which existing resources can be (re)used and allocated are limited (Luo 2002). As we hypothesized previously, export marketing deployment should result in immediate performance improvements. Because many companies attempt to guarantee short-run profitability to their stakeholders, we expect that the company uses the benefits of upgrading to feed deployment instantly. That is, resource upgrading results in new insights and expands the room available for strategic maneuvering. Firms likely instantly apply their upgraded resources, such that: 
A second, easily neglected, yet crucial benefit of export marketing upgrading pertains to the potential to enhance an exporter's future strategic flexibility and marketing options (Paik 1992), which can result in flexibility in the resources available (i.e., slack) and enhanced flexibility in the use of resources for new strategic options. For example, an upgraded resource base may enable companies to develop new products, new partnerships with distinct suppliers, and/or better customer-centered strategies (Eisenhardt and Martin 2000; Swink et al. 2005). Although flexibility may help firms improve their long-term competitive advantage, it also represents a strategic route that requires planning (Grewal and Tansuhaj 2001). To be effective, strategic flexibility requires other parts of the company, such as manufacturing technology and organizational design, to be aligned (Bello and Gilliland 1997). Some companies tend to ignore these strengths of upgrading, because it takes time and effort before they can turn them into profitable outcomes. Yet if they invest in upgrading, they benefit in the long run.

$\mathrm{H}_{6}: \quad$ Export marketing upgrading positively affects longterm export marketing performance.

In line with $\mathrm{H} 3$, we argue that the interactive trait of Web capabilities enhances the effects of export marketing upgrading. Interactivity pays off when it can foster relationships with particular (future) customer groups, which becomes particularly relevant for influentials or lead-users in specific export markets (Franke et al. 2006). Interactive Web tools enable exporters to build a joint information network and even cocreate with lead users; through interactive virtual modes, users can help design and develop new products (Urban and Hauser 2004). Therefore, we argue that:

$\mathrm{H}_{7}: \quad$ The interactive trait of Web capabilities enhances the positive effect of export marketing upgrading on long-term export marketing performance.

The conceptual framework in Figure 3.1 summarizes our hypotheses and depicts how Web capabilities might affect export marketing deployment and upgrading. Moreover, the model indicates the role of the interactive trait of Web capabilities. 


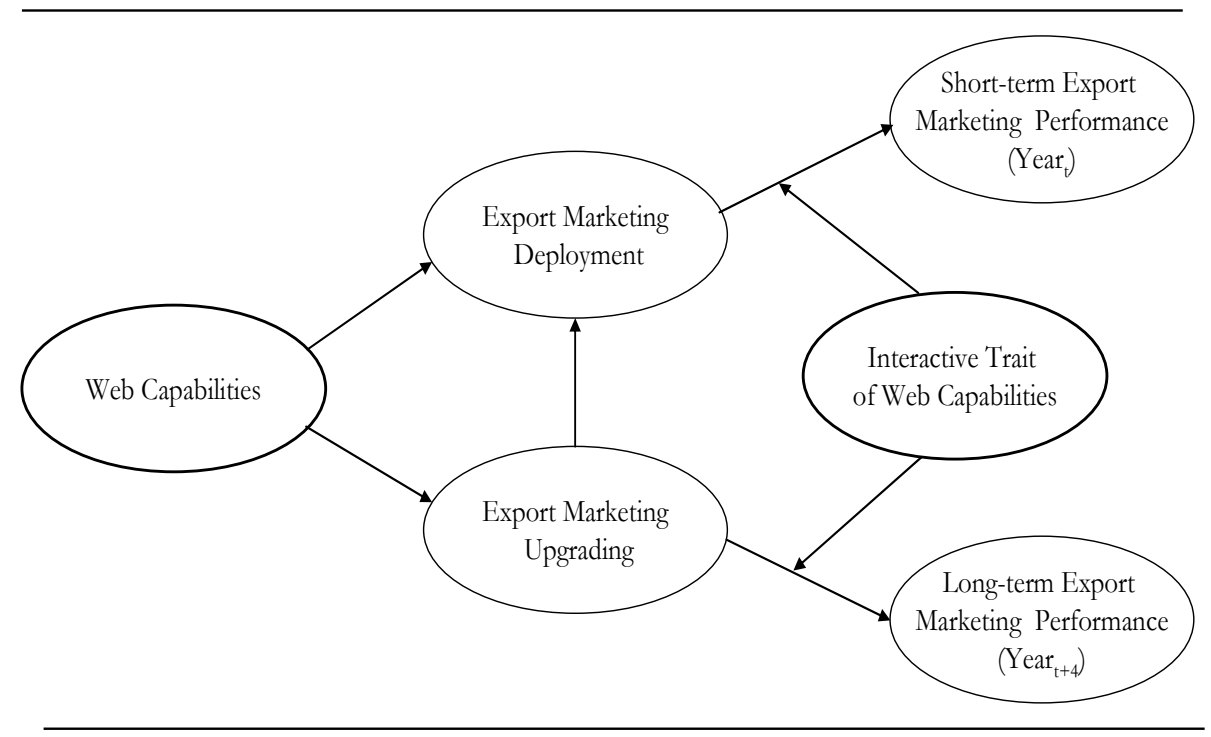

\subsection{Empirical Study}

To test these hypotheses and as described in Chapter 1, we first of all used the data for all measures that were collected in the Netherlands in 2004. After deletion of 21 additional cases with missing values on the respectives scales needed for this study, we based our analysis on a dataset consisting of 175 cases. Second, we used responses on the 2008 survey for the long-term export marketing performance measure $\left(\mathrm{Year}_{\mathrm{t}+4}\right)$ from 84 companies.

\subsubsection{Measures}

We draw the measurement scales from articles published in established journals in information systems, (international) marketing, international business, and strategy. By combining fieldwork with findings from international marketing and information systems literature, we verify the relevance and adequacy of each construct. Respondents could choose the Dutch or English versions of the questionnaire. Double-back translation ensured consistency between the two questionnaires. The items of our scales, references, and reliability estimates appear in Appendix B. We discuss them shortly hereafter.

Web Capabilities. We assess Web capabilities by developing a higher-order conceptualization that consists of four dimensions that tap the 
organization's capability to offer information (4 items), enable transactions (5 items), allow interactions (5 items), and facilitate supplier connections (5 items) through Web applications. We adopt items for each of these four dimensions from an elaborate list of e-commerce metrics identified by Zhu and Kraemer (2002).

Interactive Trait of Web Capabilities. Emphasizing their potential to generate interactive Web applications, we capture the extent to which Web capabilities allow for interactivity by subtracting the average summated scores of the non-interactive items ( 9 items) from the average summated score of the interactive items (10 items) of the Web capabilities scale. Higher scores on this difference score imply that the profile of Web capabilities is disproportionately interactive.

Export Marketing Deployment and Upgrading. Export marketing deployment represents a process that spurs the extension and optimization of existing paradigms, whereas export marketing upgrading entails the creation and internalization of new insights and procedures. We review relevant literature on strategy, marketing, and dynamic capabilities to produce an adequate item list (e.g., Eisenhardt and Martin 2000; Luo 2000). With regard to export marketing deployment, we develop an item set that includes statements regarding the exploitation of the current marketing mix and the optimization of existing knowledge. For export marketing upgrading, the items reflect the firm's search for new insights, such as monitoring new competitive products and understanding new customer requirements. Item generation precedes the item edition phase (Churchill 1979), in which we carefully evaluate the item list to ensure that it contains slightly different shades of meaning. These procedures lead to a four-item measurement instrument for each construct. Four peers inspected the instruments to assess item redundancy, specificity, and non-ambiguity.

Short-term Export Marketing Performance. We measure shortterm export marketing performance satisfaction with Lages and Lages's (2004) 10-item STEP scale, which reflects the following dimensions: extent to which the export venture achieved satisfaction with short-term performance improvement (4 items), immediate export intensity improvement (2 items), and expected short-term performance improvement (4 items). The STEP scale forms part of our questionnaire in 2004, so we collect data for this measure at the same point in time as all preceding measures. Accordingly, in Figure 1, we refer to short-term export marketing performance $\left(\right.$ Year $_{\mathrm{t}}$ ).

Long-term Export Marketing Performance. We measure longterm export marketing performance using Zou and colleagues' (1998) EXPERF scale, which captures financial and strategic export performance, as well as overall satisfaction with the export venture, with three items each. The data for this item were collected four years after the first data collection 
to account for the typical time it takes for upgrading processes to take effect. Furthermore, prior research suggests that a longitudinal approach with a lag period of four years is appropriate (Grant et al. 1988; Hult et al. 2008). Figure 1 depicts this particular time frame by incorporating long-term export marketing performance $\left(\mathrm{Year}_{\mathrm{t}+4}\right)$.

In addition to these constructs, we add some control variables to our model, namely, export marketing resources, IT infrastructure, and competitive intensity.

Export Marketing Resources. We adapt Morgan and colleagues' (2004) measure to operationalize the export marketing resources construct with an instrument that focuses on experiential resources (4 items), scale resources (3 items), financial resources ( 2 items), and physical resources (3 items). These items reflect the most important types of traditional resources, widely used as indicators of the export marketing resource base (e.g., Cavusgil and Zou 1994; Morgan et al. 2004).

IT Infrastructure. Zhu and colleagues (2003) use a seven-item scale to tap the sophistication of a company's IT infrastructure. We adapt this scale slightly to measure the extent to which a company makes use of typical information technology tools, such as intranets, electronic data interchange (EDI), or electronic groupware tools.

Competitive Intensity. Similar to Morgan and colleagues (2004), we apply a five-item scale to assess the extent of competition in the particular export market. Examples of the items employed include the degree to which price competition is a hallmark and the frequency of competitive actions such as promotion wars.

\subsection{Analysis}

Except for export marketing deployment, export marketing upgrading, and the interactive trait of Web capabilities, we operationalize the constructs in our model using multidimensional measures.

\subsubsection{Measurement and Structural Model Estimation}

As an initial step, we check for common method variance (CMV), because using a single data collection method might exert a systematic influence on the observed correlation between the measures (Podsakoff et al. 2003). To check for the potential effect of common method bias, we adopt the approach suggested by Lindell and Whitney (2001). First, we calculate the correlations among all variables. Second, we subtract the lowest correlation across all possible pairs of variables from the total correlation between each pair. The smallest correlation among variables thus serves to represent the maximum amount of CMV possible, partialled out of the remaining 
correlations to remove the effect of CMV. Significant t-statistics for the majority of our constructs indicate that CMV does not bias the results. A detailed overview of these results appears in Appendix E. To assess violations of the assumption of multivariate normality, we conduct Mardia's (1970) test of multivariate kurtosis $(\mathrm{N}(\mathrm{b} 2 \mathrm{p})=7.93, p<.001)$ and Small's test (Looney, 1995) of multivariate normality (VQ3 $=137.02, p<.001)$. For both tests, we reject the null hypothesis, which implies that our data are not normally distributed (DeCarlo 1997). Next, we started to analyze the measurement and structural models with partial least squares (PLS) regression analysis. The deviations from multivariate distribution of one of our constructs, the ability to detect and accurately estimate the strength of interaction effects, and the limited number of cases for our long-term performance measures motivated our choice of PLS (Chin et al. 2003).

We used nonparametric bootstrapping, as implemented in PLS Graph 3.0, with 500 replications (Chin, 2001). To generate the higher-order latent variables, we repeated the use of the manifest variables of the lowerorder variables (Wetzels et al. 2008). Specifically, we constructed the firstorder latent variables by relating them to their respective block of manifest variables using mode A (reflective). To construct the second-order latent variables, we related them to the blocks of the underlying first-order latent variables using mode A (reflective). Furthermore, as Chin and colleagues (2003) suggest, we used the two-step score construction procedure to test our two interaction effects. This approach ensures the explicit estimation of latent variable (LV) scores; after saving the standardized LV scores (cf. Tenenhaus et al. 2005), we calculate the interaction terms and include them in the model.

All item loadings $(\lambda)$ exceed .60 , which supports within-method convergent validity. Our measures exhibit sufficient reliability, with coefficient alphas greater than .70 (Hulland, 1999). In addition, our constructs display discriminant validity. The square root of the average variance extracted of each construct is greater than the variance shared between the construct and other constructs in the model (Fornell and Larcker 1981). In Appendix F, we list the higher-order factors and standardized loadings of their respective items.

All proposed path coefficients are significant and in the expected direction. The R-squares confirm the explanatory power: .57 and .38 for export marketing deployment and export marketing upgrading, respectively. In Table 3.1, we also present the standardized coefficients for all direct relationships. 


\begin{tabular}{|c|c|}
\hline Direct Effects & $\begin{array}{l}\text { Standardized } \\
\text { Coefficients }\end{array}$ \\
\hline $\mathrm{H}_{1}:$ Web capabilities $\rightarrow$ export marketing deployment & $.23^{* *}$ \\
\hline $\begin{aligned} \mathrm{H}_{2}: & \text { Export marketing deployment } \rightarrow \text { short-term export } \\
& \text { marketing performance }\end{aligned}$ & $.23^{*}$ \\
\hline $\begin{array}{l}\mathrm{H}_{3}: \text { Interactive trait of Web capabilities x export marketing } \\
\text { deployment } \rightarrow \text { short-term export marketing performance }\end{array}$ & $.16^{*}$ \\
\hline $\mathrm{H}_{4}:$ Web capabilities $\rightarrow$ export marketing upgrading & $.14^{*}$ \\
\hline $\begin{array}{l}\mathrm{H}_{5}: \text { Export marketing upgrading } \rightarrow \text { export marketing } \\
\text { deployment }\end{array}$ & $.43^{* *}$ \\
\hline $\begin{array}{l}\mathrm{H}_{6}: \begin{array}{l}\text { Export marketing upgrading } \rightarrow \text { long-term export marketing } \\
\text { performance }\end{array}\end{array}$ & $.16^{*}$ \\
\hline $\begin{array}{l}\mathrm{H}_{7}: \text { Interactive trait of Web capabilities x export marketing } \\
\text { upgrading } \rightarrow \text { long-term export marketing performance }\end{array}$ & $.20^{*}$ \\
\hline $\begin{array}{l}* \text { Significant at } p<.05 . \\
* * \text { Significant at } p<.01\end{array}$ & \\
\hline
\end{tabular}

As expected, Web capabilities positively affect export marketing deployment $\left(\mathrm{H}_{1}\right)$ (standardized coefficient $.23, p<.01$ ) and export marketing upgrading $\left(\mathrm{H}_{4}\right)$ (standardized coefficient .14, $p<.05$ ). These effects of Web capabilities are significant even in presence of the significant effects of export marketing resources on both deployment (standardized coefficient $.40, p<.01$ ) and upgrading (standardized coefficient .60, $p<.01$ ). Export marketing deployment only affects export marketing performance in the short run $\left(\mathrm{H}_{2}\right)$ (standardized coefficient .23, $p<.05$ ), whereas export marketing upgrading has long-term effects on export marketing performance $\left(\mathrm{H}_{6}\right)$ (standardized coefficient .16, $p<.05$ ). Furthermore, export marketing upgrading has a positive effect on export marketing deployment $\left(\mathrm{H}_{5}\right)$ (standardized coefficient $.43, p<.01$ ) and therefore also feeds short-term performance indirectly.

With regard to the interaction effects between the interactive trait of Web capabilities, and deployment and upgrading towards export marketing performance (i.e., $\mathrm{H}_{3}$ and $\mathrm{H}_{7}$ ), we find significant results for deployment on short-term performance (standardized coefficient .16, $p<.05$ ), and for upgrading on long-term performance (standardized coefficient .20, $p<.05$ ). Moreover, we do not find a direct effect from the interactive trait of Web capabilities to export marketing performance, deployment, or upgrading. The direct effects of export marketing deployment on long-term export marketing performance (standardized coefficient .08, $p>.05$ ) and those of export marketing upgrading on short-term export marketing performance 
(standardized coefficient .13, $p>.05$ ), as expected, turn out to be insignificant.

Although not hypothesized, we consider potentially confounding effects and test for the impact of additional variables that appear in related prior studies (Zhu and Kraemer 2002; Morgan et al. 2004). In addition to the direct influence of more traditional organizational, financial, and physical export marketing resources on export marketing deployment and upgrading, we control for export firms' investments in IT infrastructure and the competitive intensity in the industry and export market. No significant interaction effects emerge between Web capabilities and IT infrastructure or export marketing deployment and competitive intensity. These findings again emphasize the importance of the significant results of the interaction effects with respect to the interactive trait of Web capabilities.

\subsection{Discussion}

The aim of this study has been to reveal the complex relationship between a firm's Web activity and its export marketing performance. Therefore, we propose two research objectives: (1) a framework that characterizes the role and performance of Web capabilities through the deployment and upgrading of export marketing resources, and (2) an exploration of the interactive traits of Web capabilities as potential catalysts of export marketing performance.

For the first research objective, we propose a dynamic perspective on Web capabilities. Web capabilities positively influence both resource deployment and upgrading. This finding confirms our argument that the Web represents an interface that spurs crucial marketing processes. This interface encourages the deployment of resources by increasing a company's insights into the market and spurs short-term performance by heightening the company's commitment to export. We thus support prior research regarding the relationship between internal management forces and immediate performance outcomes (e.g., Lages et al. 2008). We complement previous findings by incorporating long-term performance effects and proposing that Web capabilities affect performance in the long run through the upgrading of export marketing resources. Companies benefit in the long run, because resource upgrading reinforces their strategic marketing flexibility and action repertoire. Moreover, these effects of Web capabilities strikingly persist even in the presence of an extended range of wellestablished export marketing assets. The results support previous findings that argued that a dynamic perspective on capabilities is neither vague nor tautological if it explicates the relationship of capabilities to the deployment and upgrading of particular resources (Eisenhardt and Martin 2000). Moreover, our findings confirm the importance of social interactions for export marketing and advance existing research by illustrating potential ways 
in which specific capabilities may help spur social interactions (Zhou et al. 2007).

Second, the results largely confirm that the interactive degree of Web capabilities plays a special role in export marketing performance. That is, the interactive trait of Web capabilities moderates the direct, positive effects of resource deployment on short-term export marketing performance by enhancing the range of practical tools available to perform export marketing in a more efficient and effective manner. Moreover, this interactive trait matters in the long run, because of its power for fostering knowledge exchange, commitment, and cocreation with lead users. This finding contributes to recent studies that highlight the long-term effects of online interactivity (e.g., Cooke and Buckley 2008) and the fundamental effect of commitment and trust between partners on export performance (Styles et al. 2008). In all, the results provide broad support for our conceptual model and largely confirm the link between Web capabilities and strategic marketing processes, as well as their contributions to export marketing performance.

\subsection{Limitations and Further Research}

This study has a few limitations. First, we use data from single informants. Although a multi-informant approach is often preferable, pragmatic reasons, such as gaining collaboration from the participating firms, motivated us to rely on single respondents. Although the single-informant technique is widely applied in export marketing research (Morgan et al. 2006), its possible limitations warrant continued reflection. For example, because we gather data at the export venture level, data from single informants could raise concerns about response accuracy. However, we take care to allay this concern by verifying that respondents are experts in key export positions and asking them to provide a description of their current position and responsibilities.

Second, we only contacted manufacturing SMEs. Even though these firms are characteristic of typical exporting firms in the Netherlands, our findings cannot simply be generalized to larger or service firms. Nevertheless, we control for the effects of additional, relevant variables such as IT infrastructure. Thus, we augment the external validity of the model, but further research including data from multiple segments and countries would be beneficial.

Third, the complexity of the model, not least due to the incorporation of interaction effects, restricts us to incorporating only the most important variables. Further research should add more explanatory variables; for instance, the interaction between Web capabilities and export marketing activities might depend on the export marketing orientation of the company (Cadogan et al. 1999; Cadogan et al. 2002). Furthermore, the 
export performance measure might be extended to include objective measures (e.g., Morgan et al. 2004). Nevertheless, extant research provides evidence of a strong correlation between objective and subjective performance measures (Dess and Robinson 1984).

\subsection{Managerial Implications}

The World Wide Web benefits almost every exporting firm, because it offers critical advantages such as decreasing the geographical and psychic distance to markets. Sustainable competitive advantages, however, can be derived only from the ways in which companies use Web capabilities.

First, in addition to the effects of the level of Web capabilities which we investigated in Chapter 2, the empirical findings of Chapter 3 corroborate the importance of looking closely at the interactive trait of Web capabilities for reinforcing the export marketing activities-performance relationship. Exporting firms should try to use interactive technologies such as blogs, podcasts, and online social networks to reinforce the effectiveness of their marketing strategies. To date, exporting firms generally use the Web as a cheap and easy medium for gathering factual knowledge about export markets (Nguyen and Barrett 2006), but many fail to see the potential of Web 2.0 tools for instigating intense dialogues with customers and partners (McKinsey 2007b). To address this deficiency, we suggest that export firms should make use of interaction-related Web capabilities. For example, export managers could set up a cocreation-related online community; open to all foreign partners in a particular business. Firms could invite customers to propose new product extensions interactively and then (financially) reward those customers whose ideas proved marketable. Research amply documents the importance of online communities as instruments of fast and efficient communication to customers and business partners (Von Hippel and von Krogh 2003; Wiertz and de Ruyter 2007; Bughin et al. 2008).

Second, and in line with the results of Chapter 2, we reveal in this study that the performance outcomes of Web capabilities may be immediate or long lasting. Yet. in addition to Chapter 3, we do not only reveal that the long-term performance impact is indirect, but also present upgrading as a process through which companies can control future outcomes. This result is interesting, because it offers export managers power over the exact timing of the effect of Web capabilities. By deciding if they will use Web capabilities for deployment or to upgrade export marketing resources, these managers can set the priorities regarding short-term or long-term effects, respectively. Moreover, they can eventually employ the interactive trait of Web capabilities to strengthen the effects of export marketing strategies on performance. Thus, the profile of Web capabilities can facilitate both shortterm and long-term performance goals. 
Third, in addition to Chapter 2, we show in this study which specific, dynamic processes within an export venture spur performance. By mapping these processes in more detail companies can more easily identify the most valuable steps that form part of these processes. In turn, managers can assign key performance indicators (KPIs) to employees to emphasize these elements of upgrading and deployment which are fundamental for their short-term and long-term profitability. The KPIs will make the processes more tangible to the organization and its employees and in turn motivate everyone to focus on these tasks that matter most in terms of financial and non-financial performance. 



\section{Chapter 4}

\section{Developing Local Market Knowledge through Virtual Interaction: Bridging Cultural Distance}

Academics and marketers alike have pointed to the benefits of collaboration and interactions for knowledge creation. In fact, the Web seems to be a markedly valuable tool to foster online interactions with business partners worldwide. So far, however, international marketers tend to favor contractual agreements to facilitate interactions and the literature today does not yet provide clear evidence for the effectiveness of online interactivity. With data from 165 Dutch companies, we reveal that firms can make use of their interactive Web capabilities to spur the creation of market knowledge. While we provided evidence for a positive Web-knowledge relationship in Chapter 2, this chapter re-examines this effect by incorporating cultural distance as well as international business and Web experience into our model. This way, we investigate more closely to which extent information is organized and accessed in foreign markets and prove the robustness of the Web-knowledge relationship. 


\subsection{Introduction}

Interorganizational networks may leverage to the creation of new resources (Powell et al. 1996; Zaheer and Bell 2005). Best practice and research in domains such as new product development (Rindfleisch and Moorman 2001) and customer relationship management (Palmatier 2008), illustrate the relevance of interaction with stakeholders as a platform for the creation of unique resources that reside in the interstices of the interaction (Gulati 1999; Hardy et al. 2003). Eventually, interconnected firms manage to extract longlasting value from resources that would not have emerged if no interaction outside the organization occurred (Dyer and Singh 1998; Palmatier et al. 2007). The creation of these network-enabled resources mirrors complex learning that builds not only on firms' past experience, but also on the relational platform in which a firm's interaction with business partners is embedded (Powell et al. 1996; Uzzi and Lancaster 2003). As a consequence, topical research has addressed issues, such as relational embeddedness, goal congruency, and knowledge redundancy of partners, investigating both contractual and informal relations (Bonner and Walker Jr. 2004; Gulati and Singh 1998; Park and Russo 1996; Rindfleisch and Moorman 2001; Uzzi 1997). Overall, these authors concur that apart from the partnering firms' stocks of knowledge, the nature of inter-organizational relations affects the eventual outcome and type of new network-enabled capabilities (Uzzi and Lancaster 2003).

Two important global trends currently affect the nature of these relations: (1) globalization and (2) the development of the World Wide Web. In relation to the former, an increasing share of inter-firm relations now occurs between foreign firms. Extant research has pointed to the importance of viewing learning as a social process, in which trustful cooperative behavior is more relevant for knowledge creation than impersonal exchanges motivated by instrumental profit seeking. As a consequence of globalization, this social process cannot be understood without considering the background of firm partners and in particular their culture. However, relatively little is known about how partners' cultural predispositions affect relational aspects and to which extent this subsequently impacts the ways in which information is organized and accessed in foreign markets.

Second, during the last decade the Web has become a truly virtual equivalent to face-to-face firm interactions. Therefore, scholars have expanded their scope to include virtual relations (Jap 2007; Sun 2006), thereby revisiting interactions in the context of virtual relations (Nambisan and Baron 2007). Best practice and academia alike herald the immense potential of virtual interactive tools (e.g. weblogs, video-conferencing, online communities virtual social networks and entire 3D virtual worlds) and their impact on interorganizational relations (Wu et al. 2003). It is often emphasized that the essence of the potential lies in recognition of the fact 
that virtual interactions now are of an inherently social nature (Holzwarth et al. 2006; Moon 2000; Parasuraman and Zinkhan 2002).

In the wake of these two contingencies, we propose to focus on the creation of market knowledge through virtual interaction in an export marketing context. Extant literature has demonstrated abundantly the critical role of export marketing knowledge - a firm's understanding of the most important business partners and procedures in a foreign market -for enduring firm performance (De Luca and Atuahene-Gima 2007; Edmondson et al. 2003) as well as for the firm's internationalization process itself (Morgan et al. 2003). Concurrently, however, it has been demonstrated that the development of export marketing knowledge becomes increasingly complicated as the (cultural) distance between interacting parties increases (Griffith et al. 2006). Overall, cultural distance tends to raise barriers for understanding international partners (Lyles and Salk 1996; Michailova and Hutchings 2006), which may impede flows of information and learning (Parkhe 1993). In turn, this may disturb partners' behavior, perturbing the expected train of affairs (Bush et al. 2001; Lyles and Salk 1996). In response, it has been argued that virtual interaction may overcome aforementioned barriers as the Web as a social medium may be used as a safeguard against the liabilities of cultural distance while fostering the development of export marketing knowledge (Tam and Ho 2006).

In the present paper, we investigate the viability of this claim. An important assumption is that concurrent interactive Web capabilities enable companies to provide highly personalized offerings and social interaction with geographically dispersed customers. By fine-tuning the medium as well as the message to the appropriate socio-cultural context, companies can overcome cultural distance by taking into account idiosyncratic customer preferences (Tam and Ho 2005). Furthermore, we investigate how a firm's relevant international experience - in itself a cognitive antecedent of new knowledge - impacts knowledge creation through virtual interaction under cultural restraints. In addition, we study the impact of a firm's virtual experience as an increasingly commonplace and pertinent yet unidentified type of asset for marketing knowledge creation that transcends national borders.

More specifically, we aim to contribute to the literature in threefold. First, we capture the complementary role of a firm's international business experience and the firm's capability to interact over the Web on the creation of export market knowledge. We provide a conceptualization of interactive Web capabilities that encompasses the skills needed to deploy Web-based interactions for knowledge creation. While prior research has pointed to the potential of online interactions for fostering the creation of foreign market knowledge (Nguyen and Barrett 2006), to the best of our knowledge no study has empirically investigated this link. As such, in a KBV, we provide 
evidence for the decisive impact of cognitive (i.e., international business experience and Web experience) and strategic (i.e., Web capabilities) antecedents of organizational knowledge creation in an international as well as virtual context.

Second, we extend topical research by re-examining the negative impact of cultural distance on physical interaction and cross-border knowledge creation to a virtual context. We propose that cultural distance may be less problematic as a result of unleashing the potential of online capabilities. Firms across the globe possess interactive tools to collect and analyze Web behavior and transactions to generate highly adaptive content for different users (Komiak and Benbasat 2006; Simonson 2005). However, our premise is that only by turning commercial transactions into social exchanges, they develop a sound basis for knowledge creation. Thus, we contribute to ongoing research that focuses on the social nature and impact of interaction and extend the relevance of their findings to the international and virtual context.

Third, we focus at how and to what extent the cognitive platforms of future learning - a firm's international business experience and its experience with the Web - facilitate knowledge creation from interactive Web capabilities. Even though international experience appears to be too broad to solve market-specific problems at first sight, we posit that it helps companies to assess the value of new market knowledge better. Furthermore, while existing research has identified Web experience as a crucial marketing resource (e.g., Chatterjee et al. 2002), there is lack of evidence for its pertinence with regard to knowledge creation in culturally remote markets. We reveal that elaborate Web experience leads to the development of a social network, in which members easily exchange ideas and information because of a common language and shared customs. Thus, we show that Web experience holds up in culturally distant markets.

\subsection{Conceptual Model}

The RBV focuses on assets and capabilities that provide companies with a unique, competitive advantage (Barney 1996). According to the RBV, firms achieve strategic goals by possessing and controlling an inimitable bundle of accumulated resource stocks that are internal to the firm. Recently, the strategic management literature has highlighted the importance of external resources available to the company through its network (e.g., McEvily and Markus 2005). More specifically, authors such as Zaheer and Bell (2005) underline that firms with superior network structures are better at exploiting internal resources. While interactions per se are beneficial for performance, this is particularly true if firms possess the capabilities that allow them to identify knowledge resources in their network. 
Since Web applications are typically characterized by high levels of interactivity, firms increasingly use them to facilitate inter-firm exchanges (Cooke and Buckley 2008, Manyika et al. 2007). In an increasingly virtual world, an interactive Web environment may expand a firm's potential to create new knowledge (Johnsen and Ford 2006; Johnson et al. 2005). Information systems scholars define an interactive Web environment as facilitating active sharing and participation among online participants (Hoffman 2008; Metz 2008).

\subsubsection{Interactive Web Capabilities}

In the present paper, we focus on a firm's capabilities to create and manage interactive Web tools, an ability that offers firms the opportunity of more closely linking to (foreign) markets (Sicilia et al. 2005). Extant research in information systems identifies elaborate sets of e-commerce metrics and captures effects of interactive Web applications that might determine firms' degree of online interactivity (Zhu and Kraemer 2002). Although several studies report a linear, positive association between a firm's extent of interactional initiatives and firm performance, others report insignificant findings (Morgan-Thomas and Bridgewater 2004; Prasad et al. 2001). More recent studies underpin the role of underlying firm capabilities that activate and exploit other resources to improve performance (Tanriverdi 2005). Web capabilities constitute both technical (e.g., integration of interactive tools) and nontechnical (e.g., user-friendliness of a Web site) skills and can transform material (e.g., hardware) and immaterial (e.g., software knowledge) assets to be beneficial for firm performance (Zhu and Kraemer 2002). Interactive Web capabilities enable companies to create and use interactive tools to foster bi-directional, direct, and mutually controllable communication with customers and other business partners across time and space (Haeubl and Trifts 2000).

\subsubsection{Export Market Knowledge}

Export market knowledge denotes a firm's understanding of the most important foreign business partners and procedures that form part of a particular export market (De Luca and Atuahene-Gima 2007). Existing studies have underlined the importance of knowledge of the market, clients, problems, and opportunities abroad (Eriksson and Chetty 2003; Eriksson et al. 1997). A firm's export market knowledge varies across markets and contextual factors are likely to influence the extent to which knowledge is created (Morgan et al., 2003; Zou and Stan 1998).

An important source of export market knowledge is direct, face-toface interactions with local business partners. Yet, studies increasingly point to the equality of online and offline media for knowledge creation. More in 
particular, online tools characterized by high levels of interactivity are very similar to a direct experience with a business partner (Banker et al. 2006). For instance, Sussman and Siegal (2003) illustrate that online interactions which are perceived to be useful and credible ultimately result in information adoption and exchange. Web sites offer the advantages of being constantly available and accessible to all business partners at low cost and worldwide. Despite these benefits, the literature largely remains silent on the potential of virtual Web sites. Therefore, we investigate if Web interactivity is relevant for market knowledge creation.

Interactive Web capabilities facilitate several methods of interactive communication between the company and its users. These include blogs, online communities, as well as feedback and discussion forums to answer user questions. Furthermore, in real-life settings customers of products whose usage is sensitive to their personal needs might not be willing to share insightful information. Similarly, companies developing highly innovative products also tend to protect information to avoid imitation by competitors. Companies increasingly set up online client service areas to solve this problem. Only registered users have access to these special online areas. As a consequence, both companies and customers can be certain that information exchanged is not revealed to third parties. Besides, information rich environments such as interactive Web sites positively affect motivation to learn from feedback (Bono and Colbert 2005). Feedback immediacy permits the rapid updating and/or clarification of the information being conveyed (Froehle 2006). The interface used to exchange market information also enables firms to store and internalize information, such as by connecting to suppliers' inventory databases and matching inventory to on-and offline customer demand. The Web is a useful medium to capture and internalize information about customers and feedback from business partners. Processed by other technologies in back-end systems, the information that has been captured shall be translated into knowledge on customer behavior.

Thus, with their interactive Web capabilities, companies can enable the timely, regular, and secure sharing of meaningful information and subsequently gain users' commitment (Gupta et al. 2004). The more users regularly communicate via these tools, the more benefits they will retrieve and the higher their willingness of providing companies with information about their needs (Li et al. 2006). Arnott and Bridgewater (2002), among others, reveal that interactivity increases marketers' ability to understand customer behavior which can help them offer products or services according to what customers want. Richer media facilitate social perceptions and perceived ability to evaluate others' deception and expertise. All in all, the synchronicity and enhanced security of online exchanges as well as the possibility to customize content and store feedback enabled by interactive Web capabilities are likely to enhance source credibility and to stimulate 
communication that results in enhanced understanding of market needs. Subsequently, we argue that interactive Web capabilities enhance companies' market-related knowledge.

$\mathrm{H}_{1}$ :

Interactive Web capabilities positively affect export market knowledge.

Although we expect the linkage between interactive Web capabilities and export market knowledge to be considerable, we cannot ignore that knowledge is sticky (De Luca and Atuahene-Gima 2007). This means that its characteristics make it difficult, costly, and uncertain to create and transfer. Simonin (1999), among others, notes that market knowledge is usually difficult to codify because of its contextual and socially complex nature (Wadhwa and Kotha 2006). Particular export market characteristics, such as cultural distance (Bhagat et al. 2002; Tse et al. 1988), have often been underlined as an obstacle to the creation of market knowledge. Nevertheless, organizational memory and experience with Web technologies or with international business in general are likely to stimulate a firm's absorptive capacity which smoothens knowledge creation (Smith et al. 2005; Van den Bosch et al. 1999). In the following, we compare the contrary impact of obstacles such as cultural distance and vantages such as international and Web experience.

\subsubsection{Cultural Distance}

Research indicates that cultural distance influences export marketing practices, particularly with regard to the development of market knowledge (Murray et al. 2007; Souchon et al. 2003). We define cultural distance as the heterogeneity of dynamically changing contacts and characteristics that separates one group from another (Shenkar 2001). High levels of cultural distance are likely to cause tension between business partners and to obstruct the flow of information between the firm and its market.

Cultural distance matters to market knowledge creation for several reasons. Cultural distance raises barriers for understanding partners (Lyles and Salk 1996; Michailova and Hutchings 2006). In this regard, the lack of fluency in a partner's native language and unavailability of the partners' Web site may constitute only two examples of obstacles (Romano 2003). Moreover, cultural distance creates uncertainty about understanding partners' business practices and performance goals (O'Grady and Lane 1996). The culture in which people are raised affects ways of thinking and behaving. Although it does not hinder the ability to manage within one's own country, where business practices are relatively homogeneous, it can affect the ability to manage in other countries. Business people are often not aware of the assumptions that underlie their actions. These assumptions can 
lead to cross-cultural misinterpretations and parochialism. Such difficulties are equally relevant in offline and online contexts and might lead to unexpected problems which eventually restrain customers from providing information via interactions. Thus, in line with research on offline interactions (van Oudenhoven and van der Zee 2002), we argue that chances of misunderstanding between cultures increase as the degree of intercultural differences increases. Therefore, belonging to a different cultural environment may limit partners' motivation and ability to benefit from on online information exchange. This in turn restrains companies' reliance on interactive Web capabilities to enrich their knowledge base.

$\mathrm{H}_{2}$ : Cultural distance attenuates the positive effect of interactive Web capabilities on export market knowledge.

While cultural distance confronts companies with unforeseen obstacles and uncertainty, experience endows companies with routine and confidence. Accordingly, earlier studies on knowledge creation have often pointed to past experience as an important backbone of companies, particularly when they face unexpected difficulties (Cockburn and Henderson 1998; Cohen and Levinthal 1990). For instance, Zahra and George (2002) corroborate that both the extent to which know-how has been acquired and the variety of sources from which knowledge has been collected stimulate a firm's propensity to acquire new knowledge. We expect two types of experiences to matter most with regard to the interactive Web capabilities - market knowledge relationship: international business experience and Web experience.

\subsubsection{International Business Experience}

We define international business experience as the extent to which companies have accumulated internationalization knowledge from previous foreign market entries (Cavusgil and Zou 1994; Eriksson et al. 1997). Experience is gained by environmental scanning, interactions with customers, and learning-by-doing (Nonaka and Takeuchi 1995), which altogether ease the acquisition of new knowledge (Eriksson and Chetty 2003; Eriksson et al. 2000). Under some circumstances, experience might trigger companies to fall for rigid routines and therefore cause inertia (LeonardBarton 1992). At the same time, however, experience can enhance a company's openness to new ideas and is therefore acknowedged as an important knowledge source.

Although it remains debatable if more "general" market experience across the world enhances the creation of export market knowledge in a particular market, empirical studies confirm the relevance of knowledge gained in similar markets to new market entries (Calantone et al. 2004; Mitra 
and Golder 2002). For instance, Barkema et al. (1996) show that when doing business with a new customer, a firm accumulates a more realistic view of doing business from previous experiences with customers. Furthermore, Chetty and colleagues (2006) underpin that firms which diversify into various cultural clusters become better at evaluating what type of existing knowledge is important for the ongoing business. Thus, firms with more international business experience are better at generating knowledge relevant to new foreign markets.

$\mathrm{H}_{3}: \quad$ International business experience positively affects export market knowledge.

Next to this direct effect on knowledge, experience also has a more indirect impact by shaping up the processes related to knowledge acquisition and assimilation (Zahra and George 2002). First, acquisition refers to firm's ability to identify and obtain externally generated knowledge that is critical to its operations. With more international business experience, companies are more aware of gaps in what they ought to know to be successful in a market and what they actually do know. Companies with more experience abroad have developed benchmarks and criteria, based on which they are able to assess the sufficiency of their export market knowledge (Barkema et al. 1996; Barkema et al. 1997). Second, assimilation refers to the firm's routines that allow it to analyze, interpret, and apply their information obtained from external sources (Szulanski 1996). Experience is closely connected to organizational memory and facilitates a firm's ability to store and manage incoming knowledge (Van den Bosch et al. 1999). A better memory also ensures that firms have accumulated more know-how with regard to scrutinizing and evaluating the value of information from external sources.

The diversity of accumulated know-how increases a firm's range of ideas and this way helps it to cope with various environmental circumstances. Firms that deal with relatively many products, markets, and customers have a broader range of mental models (Luo and Peng 1999). As a consequence, more experienced firms are more open to innovative solutions such as using new online interactive tools to extend their knowledge base. For these reasons, we expect international business experience to strengthen the use of interactive Web capabilities for export market knowledge.

$\mathrm{H}_{4}$ :

International business experience strengthens the impact of interactive Web capabilities on export market knowledge.

Although international business experience fuels companies' knowledge base, it is not clear if these effects remain relevant in culturally distant environments. Experienced companies might face cultural misunderstandings in a particular market which they could not foresee. 
Lacking routines for the solutions of new problems, managers search in the neighborhood of their past experiences. The ability to use such experiences is also much dependent on the extent of the firm's commitment to internationalization. For instance, Barkema and colleagues (1996) found that prior experience weights more in cases of high commitment (e.g., acquisitions) compared to low commitment (e.g., start-ups). More recently, Shenkar et al. (2008) point out that the actual impact of cultural distance is much dependent on the degree of actual encounter and potential friction. From this perspective, actors embedded in national identities and possessing divergent positions continuously create and recreate culture. Hence, the routines that companies developed from international business experience might turn out to be irrelevant in instances where they need dynamic processes to overcome cultural barriers. Therefore, we propose a tree way interaction between cultural distance, international business experience and interactive Web capabilities so that:

$\mathrm{H}_{5}$ :

Cultural distance attenuates the strengthening effect of international business experience on the relationship between interactive Web capabilities and export market knowledge.

\subsubsection{Web Experience}

Research has pointed to the importance of cumulative experience with a technology as a critical factor for generating knowledge (Zander and Kogut 1995). Today, companies increasingly build up experience with Web technologies in particular. So far, however, researchers have not investigated the impact of Web experience on knowledge creation. We define Web experience as the extent to which a company is actively using the Web.

More Web experience entails that a company has more knowledge about its Web-related infrastructure that can help transform and exploit information. Whereas transformation indicates a firm's capability to refine processes that combine existing and newly acquired knowledge, exploitation refers to the application of knowledge (Zahra and George 2002). With enhanced Web experience companies have set up common rules and maybe even a language with regard to how information on a Web site should be structured so that it is easily accessible and understandable to employees and business partners. On a very elaborate level, they have developed a "Web culture" (Collins and Smith 2006; Nicovich and Cornwell 1998), which eases exchange, communication and internalization of newly acquired knowledge. A common Web culture elicits employee behavior and practices and therefore makes employees better aware of how to act in the best interest of the company and its partners. For this reason, a company with a higher Web culture possesses a stronger ability of incorporating cultural differences and idiosyncrasies into a company's Web site design. This will in turn lead to 
more advanced Web sites, including appropriate interactional interfaces, which are well-adapted to the needs of the business partners in the export market. As a consequence, business partners abroad will be more motivated to share information with the company, which can in turn increase its knowledge about the export market. Hence:

$\mathrm{H}_{6}$ : Web experience strengthens the impact of interactive Web capabilities on export market knowledge.

Despite the aforementioned strengths of Web experience, it is not clear whether the impact of Web experience prevails in culturally distant markets. More specifically, although Web experience refines particular processes and routines related to transforming and applying knowledge, these processes might not be suited to overcome cultural obstacles. Similar to the case of international business experience, Web experience feeds the creation of routines that in turn reduce the firm's flexibility and creativity needed to react adequately to cultural problems. In the face of cultural changes, institutionalized routines may lead to inertia (Lieberman and Montgomery 1998; Lieberman and Montgomery 1988). Skills and managerial thought that served the company well in the past might be experienced as core rigidities in new situations (Leonard-Barton 1992). For this reason, we verify if the effect of Web experience holds in markets with high cultural distance. Accordingly, we posit a three way interaction:

$\mathrm{H}_{7}$ :

Cultural distance attenuates the strengthening effect of Web experience on the relationship between interactive Web capabilities and export market knowledge.

Figure 4.1 provides an overview of our conceptual framework. This conceptual model pictures how interactive Web capabilities may affect export market knowledge. Besides, the model shows how cultural distance, international and virtual experience come in. 
FIGURE 4.1 Conceptual Framework

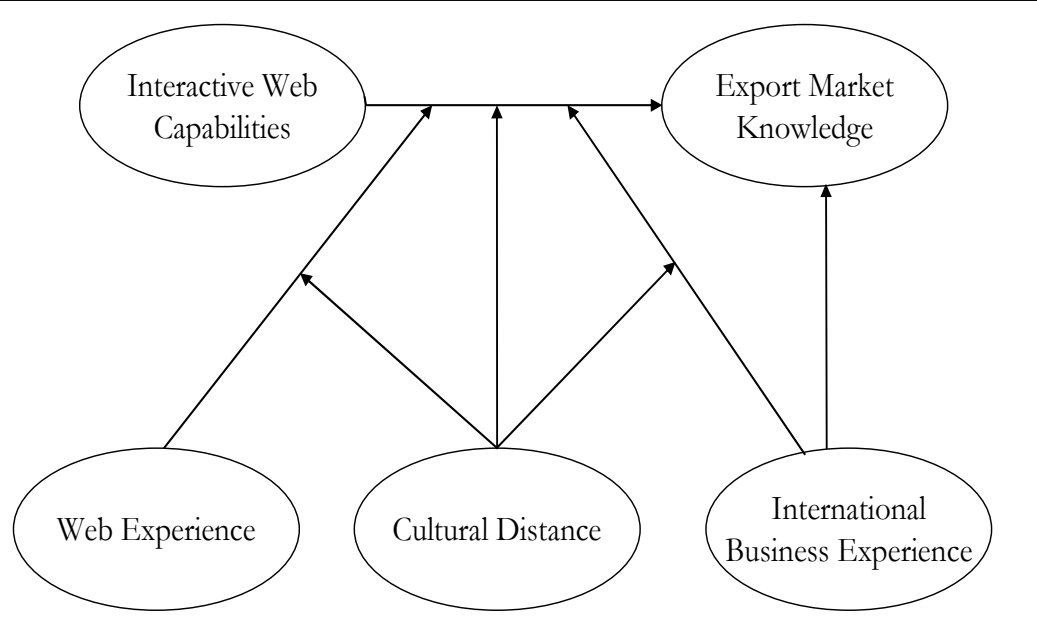

\subsection{Empirical Part}

To test these hypotheses and as described in Chapter 1, data for all measures were collected from Dutch manufacturing companies in 2004. After deletion of additonal 31 cases with missing values, we used a dataset comprising 165 cases for this study.

\subsubsection{Measures}

To assess potential nonresponse bias, we compare early and late respondents with regard to diverse firm characteristics, including age of the venture, number of employees, and annual sales volume. We found no significant differences between early and late respondents in our data.

By combining fieldwork with findings from international marketing and information systems literature, we verify the relevance and adequacy of each construct. We have drawn the measurement scales from articles published in established journals in information systems, (international) marketing, and strategy. Respondents were free to choose the Dutch or English versions of the questionnaire. Double-back translation ensured consistency between the two questionnaires. The items of our scales and references appear in Appendix C. We discuss them shortly hereafter.

Interactive Web Capabilities. We adapt Zhu and Kraemer's (2002) measure to operationalize the interactive Web capabilities construct with an instrument that captures interactions with business partners such as customers and suppliers (10 items). Examples of the items used are the degree to which companies have the capability of enabling customers to 
customize the content of their Web site and the capability of having suppliers check and adapt their inventory online.

Export Market Knowledge. We assess export market knowledge by adapting a scale from Morgan et al. (2003). This scale consists of four items in total and measures a company's knowledge of customers, competitors, distributors, and business information.

Cultural Distance. We followed Kogut and Singh's approach (1988). A composite index was formed based on the deviation along each of Hofstede's four cultural dimensions (e.g., power distance, uncertainty avoidance, masculinity/femininity, and individualism) of each export country from the Dutch ranking. The deviations were corrected for differences in the variance of each dimension and then arithmetically averaged. For 30 companies in our dataset, we were not able to calculate this index, since their values for all of the four Hofstede dimensions are not known. For example, some respondents in our sample indicated to have exports to countries which have not been investigated by Hofstede (e.g., Ukrania, Angola), or to countries, especially in Eastern Europe (e.g., Serbia-Montenegro) which do not exist anymore and for which indices are not available.

Web Experience. To develop an adequate measure for Web experience we formed an index by using a scale from Zhu and Kraemer (2002) comprising eight items in total. While item 1 consists of an open question which captures the numbers of years the company has a Web site, items 2 to 8 consist of continuous scales measuring the extent to which companies have gained experience with different Web tools such as EDI, the Internet, and electronic groupware tools.

International Business Experience. We assessed international business experience in an equivalent way to Web experience. Accordingly, we set up an index based on a five-item continuous scale from Cavusgil and Zou (1994). While the first is measured on a continuous scale measuring the strength of a firm' international business experience, item 2 to 5 incorporate open questions with regard to (2) the number of years the firm has been involved in international business, (3) the number of markets the firm has been involved in, (4) and the percentage of sales and (5) profits derived from foreign sales.

Competitive Intensity. We adapted a five-item measurement scale from Morgan et al. (2004) to control for the effect of competitive intensity in the export market. This scale enabled us to capture the degree of competition in the export market.

\subsubsection{Construct Validation}

Latent variables with multiple items can be reflective or formative measures. When indicators of a construct correspond to distinctive characteristics of the construct, the construct can be regarded as a sum of the individual 
indicators (Bagozzi 1994; Bollen and Lennox 1991). The constructs cultural distance, Web experience, and international business experience reflect such a total across different, unique sources and are hence operationalized in a formative manner (Howell 1987). For instance, cultural distance is measured along four principal dimensions: individualism vs. collectivism, masculinism vs. feminism, uncertainty avoidance and power distance. Cultural distance is a sum of the individual indicators and is therefore a formative construct. Since each of these items measures a specific dimension of the underlying construct, they need not correlate significantly, but they still contribute to the total value of the corresponding construct. The validity and reliability of formative scales cannot be estimated by conventional statistical techniques such as coefficient alpha and confirmatory factor analysis (Bagozzi 1994), which are based on the assumption of high interitem correlation. Although a large number of studies in export marketing research have largely relied on reflective conceptualizations of measures, formative operationalizations have become more widely used. For these reasons, reliability estimates in Appendix $\mathrm{C}$ are neither provided for international business experience nor for Web experience.

\subsection{Analysis}

Before the hypothesis testing, we applied Harman's single-factor, a widely approved technique, to check for common method variance that may reduce internal validity (Podsakoff et al. 2003). According to this method, common method variance exists if one factor accounts for the majority of the covariance in the total set of variables. Harman's single-factor test was carried out using exploratory factor analysis without any rotation. No dominant factor was found emerging from the factor analysis and the extracted factors explained 47.5 percent of the variance, implying that common method variance was not a serious problem.

To examine the role of interactive Web capabilities, cultural distance, Web experience, and competitive intensity in export market knowledge creation, we used regression analysis in STATA 10.0. We estimate our model with STATA for several reasons. First, it is very well suited for regression analysis and interactions (e.g., Miller and Eden 2006; Trevor and Nyberg 2008). Second, this estimation method allows for the integration of different types of variables ( $\mathrm{Lu}$ and Xufei 2008; Trevor and Nyberg 2008). The following equation presents the model we tested:

$$
\begin{aligned}
\mathrm{EMK}= & \mathrm{c}_{1}+\beta_{1}(\mathrm{IWC})+\beta_{2}(\mathrm{CD})+\beta_{3}(\mathrm{CI})+\beta_{4}(\mathrm{IWE})+\beta_{5}(\mathrm{IBE}) \\
& +\beta_{6}(\mathrm{IWC} C \mathrm{CD})+\beta_{7}\left(\mathrm{IWC} \mathrm{CWI}^{*}+\beta_{8}\left(\mathrm{IWC} \mathrm{IWIB}^{*}\right)\right. \\
& +\beta_{9}\left(\mathrm{IWC} \mathrm{IWE}^{*}\right. \\
& +\beta_{10}\left(\mathrm{IWC} \mathrm{CD}^{*} \mathrm{WWE}\right)+\beta_{11}\left(\mathrm{IWC} \mathrm{CWD}^{*} \mathrm{IBE}\right) \\
& +\beta_{12}\left(\mathrm{IWC} \mathrm{IWE}^{*} \mathrm{CI}\right)+\beta_{13}\left(\mathrm{IWC} \mathrm{IBE}^{*} \mathrm{CI}\right)
\end{aligned}
$$




$$
\begin{aligned}
& +\beta_{14}(\mathrm{IWC} * \mathrm{IBE} * \mathrm{WW}) \\
& +\varepsilon_{1}
\end{aligned}
$$

where

$\mathrm{c}=$ constant,

IWC $=$ interactive Web capabilities,

$\mathrm{CD}=$ cultural distance,

$\mathrm{CI}=$ competitive intensity,

$\mathrm{WE}=$ Web experience,

$\mathrm{IBE}=$ international business experience,

$\varepsilon=$ disturbance term.

As suggested by Cohen et al. (2003), we mean-centered all variables to reduce non-essential collinearity. These transformed measures were subsequently used for the regression analysis. Variance inflation factors (VIFs) below 2 provide no indication of multicollinearity (Neter et al., 1985).

\subsubsection{Results}

All proposed path coefficients and t-values are significant and in the expected direction. The adjusted $\mathrm{R}^{2}$-square $(0.28)$ confirms the explanatory power for our dependent variable export market knowledge. Table 4.1 gives an overview of all standardized path estimates. Our first hypothesis $\left(\mathrm{H}_{1}\right)$ examines the positive effect of interactive Web capabilities on export market knowledge. The results show a beta-coefficient of .18 and a t-value of 1.72 ( $p$ $<.05)$ Thus, interactive Web capabilities significantly contribute to export market knowledge creation.

In $\mathrm{H}_{2}$ we predict that cultural distance diminishes the relationship between interactive Web capabilities and export market knowledge. Support for this hypothesis is just not in evidence (standardized coefficient $-.18, \mathrm{t}-$ value $-1.64, p>.05$ ). Furthermore, consistent with $\mathrm{H}_{3}$, international business experience has a direct, positive influence on export market knowledge. We find strong evidence for this hypothesis (standardized coefficient .39, t-value $4.45, p<.01$ ). Further, our results reveal that both international business experience (standardized coefficient .15, t-value 1.72, $p<.05$ ) and Web experience (standardized coefficient .18, t-value 1.81, $p<.05$ ) significantly strengthen the impact of interactive Web capabilities on export market knowledge. The effect of Web experience $\left(\mathrm{H}_{6}\right)$ is even stronger than the moderating effect of international business experience $\left(\mathrm{H}_{4}\right)$.

Hypothesis 5 states that cultural distance attenuates the strengthening effect of international business experience on the relation between interactive Web capabilities and export market. We included a three-way interaction test in our equation to investigate this hypothesis. Accordingly, we examined if high or low cultural distance has an impact on 
the interaction between international business experience and interactive Web capabilities (IWC*IBE*CD). Cultural distance does not influence the strengthening effect of international business experience (IWC*IBE*CD) (standardized coefficient .12, t-value: $1.34, p>.05$ ). Next, we tested hypothesis 7 by adding a three-way interaction effect between Web experience, interactive Web capabilities and cultural distance (IWC*WE*CD). Again we find nonsignificant results for this three-way interaction test (standardized coefficient .12, t-value: 1.24, $p>.05$ ). Irrespective of high or low cultural distance, Web experience enhances the impact of interactive Web capabilities on export market knowledge.

Finally, we controlled for additional three-way interaction effects in a similar way for competitive intensity. Competitive intensity does not affect the strengthening impact of Web experience on the relation between interactive Web capabilities and export market knowledge (IWC*WE*CI) (standardized coefficient -.11 , t-value $-1.23, p>.05$ ). Surprisingly, we find a positive, significant effect for competitive intensity with regard to international business experience (IWC*IBE*CI) (standardized coefficient $.21, \mathrm{t}$-value: $2.62, p<.05)$. This implies that the effect of international business experience is dependent on competitive intensity. More specifically, the strengthening effect of international business experience is particularly strong in export markets that are characterized by high levels of competitive intensity.

We further controlled for the direct effects of cultural distance, competitive intensity, and Web experience on export market knowledge. Except for cultural distance (standardized coefficient -.25 , t-value $-2.27, p<$ $.01)$ and in line with prior research studies, we do not find any significant, direct effects.

In table 4.1, we also present the standardized coefficients for all direct relationships and interaction effects. 
TABLE 4.1 Standardized Path Estimates and t-Values

\begin{tabular}{|c|c|c|}
\hline Direct Effects and Interaction Effects & $\begin{array}{l}\text { Standardized } \\
\text { Coefficients }\end{array}$ & Results \\
\hline $\begin{array}{l}\mathrm{H}_{1} \text { : Interactive Web capabilities positively affect } \\
\text { export market knowledge }\end{array}$ & $.18^{*}$ & Supported \\
\hline $\begin{array}{l}\mathrm{H}_{2}: \text { Cultural distance attenuates the positive } \\
\text { relationship between interactive Web } \\
\text { capabilities and export market knowledge }\end{array}$ & -.18 & $\begin{array}{l}\text { Not } \\
\text { Supported }\end{array}$ \\
\hline $\begin{array}{l}\mathrm{H}_{3} \text { : International business experience positively } \\
\text { affects export market knowledge }\end{array}$ & $.39 * *$ & Supported \\
\hline $\begin{array}{l}\mathrm{H}_{4} \text { : International business experience strengthens } \\
\text { the impact of interactive Web capabilities on } \\
\text { export market knowledge }\end{array}$ & $.15^{*}$ & Supported \\
\hline $\mathrm{H}_{5}:$ Cultural distance attenuates this effect & .12 & $\begin{array}{l}\text { Not } \\
\text { supported }\end{array}$ \\
\hline $\begin{array}{l}\mathrm{H}_{6} \text { : Web experience strengthens the impact of } \\
\text { interactive Web capabilities on export market } \\
\text { knowledge }\end{array}$ & $.18^{*}$ & Supported \\
\hline $\mathrm{H}_{7}:$ Cultural distance attenuates this effect & .12 & $\begin{array}{l}\text { Not } \\
\text { supported }\end{array}$ \\
\hline $\begin{array}{l}* \text { Significant at } \mathrm{p}<.05 \\
* * \text { Significant at } \mathrm{p}<.01\end{array}$ & & \\
\hline
\end{tabular}

\subsection{Discussion}

The ambition of this study was to empirically address three major research gaps. The first is linked to the impact of online interactivity on export market knowledge. Research gap two concentrates on the unidentified role of cultural distance in online interactions. Filling research gap three, we reveal how the potentially strong - yet so far uninvestigated - effects of virtual and international experience influence the interactivity-knowledge relationship.

When solving research gap one, we rely on the KBV which underlines the important role of capabilities in the deployment of networkenabled resources for knowledge creation (Grant 1996). While information systems research (e.g., Zhu and Kraemer 2002) identified essential metrics that reflect a full range of options to interact on the Web, our study is among the first that focuses exclusively on the capabilities necessary to manage Web-based interactions and their link to market knowledge. We identify interactive Web capabilities as the skills to create and manage interactive Web-based interfaces and empirically validate their relevance with regard to 
knowledge creation in an export marketing context. Our results extend prior findings emphasizing the equal relevance of both user-medium (e.g., synchronicity) and user-message (e.g., customization of content) elements of online interactivity to an international B2B context (Liu and Shrum 2002; Novak et al. 2000). Furthermore, we take into account the direct effect of international business experience and reveal that experience and capabilities constitute complementary resources rather than substitutes (e.g., Heimeriks and Duysters 2007).

In reference to our second research gap and contrary to our hypothesis, we find that cultural distance does not significantly harm the capabilities-knowledge relationship. In an offline context, cultural distance has been shown to raise barriers for understanding international partners (Lyles and Salk 1996) which may impede partners' willingness to share information (Parkhe 1993). Today, virtual interaction among parties in the international arena may overcome these obstacles, because it may safeguard from the liabilities of cultural distance (Tam and Ho 2006). Firms across the world are using the Web to interact with customers with diverse cultural backgrounds for product marketing and after-sales support. This is accomplished by deploying interactive tools to collect and analyze Web behavior and transactions to generate highly adaptive content for different users (Komiak and Benbasat 2006; Simonson 2005). Furthermore, by adding cues based on social characteristics into Web sites, companies may improve the perception of employee presence and hence intensify consumers' online experiences. Our results confirm recent findings in the literature which underpin the importance of using social cues in Web sites to interact with customers (Wang et al. 2007).

We tackle research gap three by incorporating international business and Web experience as two catalysts into our conceptual model. Our findings show that both types of experience matter - even in culturally distant or highly competitive markets. We draw two primary conclusions from these results. First, Web experience amplifies the capabilitiesknowledge effect, because it may encourage the formation of a Web culture (Nicovich and Cornwell 1998), which facilitates information sharing through the creation of a new, common language and routines that unite Web users worldwide. Companies go to a site, browse, surf, find a link and leave it eventually (Weinberger 2002). Thus, our results support recent research findings which point to the emergence of IT values and culture next to national culture (Leidner and Kayworth 2006). Second, our findings corroborate that international business experience does not mislead companies and make them rest on formerly acquired insights. By contrast, companies with international experience are aware of the fact that gaining market insights matters and tend to adapt more easily to competitive circumstances. This view is in line with earlier studies suggesting that 
cumulative knowledge provides strategic options to expand in new but uncertain markets in the future (Kogut and Zander 1992). This perspective is equally relevant in an increasingly virtual marketplace and puts forward that what a firm has done offline determines what it can do online. Hence, international business experience equips companies with more room for maneuver and this way encourages the usage of interactive Web capabilities for knowledge creation.

\subsection{Limitations and Further Research}

The results suggest several future research avenues. First, one key benefit noted in our study is that interactive Web capabilities enhance companies' understanding of business partners' needs. This might entail that companies reduce their reliance on traditional ways of communication (e.g., phone contact, face-to-face business meetings). By bypassing these traditional communication modes, a firm can reduce potential inefficiencies that arise from relying on individuals to perform key activities (Lohrke et al. 2006). In specific situations, however, it might still be important for a firm to capitalize on its employees' social skills. By looking at the specific purpose of interactions between companies and business partners, future studies could help gain a richer understanding of the online interactivity-knowledge relationship.

Second, despite the large number of variables considered in this study, not all potentially relevant antecedents have been investigated. We examined cultural distance of the export market and controlled for the effect of competitive intensity. Other market characteristics, such as government intervention, technological and environmental turbulence, should be studied in the future. Similarly, the effects of industry classification, which is not assessed in this study because of the intragroup heterogeneity of the sample in terms of competitive intensity of the industry or lack of measures, should be explored in the future.

Third, further research designed to replicate or extend this study should also examine ways to improve measurement of the cultural distance construct. In the current study, as in most related prior studies (Morosini et al. 1998) an index of the cultural distance measure based on Hofstede (1983) and Kogut and Singh (1988) was developed. Many studies have criticized the usage of this index (e.g., Shenkar 2001) to estimate cultural values between countries and have failed to find support for it. Further research could benefit from a richer conceptualization and operationalization of cultural distance that additionally incorporates the dimensions of geographic distance and business distance (Ojala and Tyrväinen 2007). 


\subsection{Managerial Implications}

Our study results in key insights for managers, and should help managers better understand the conditions that affect the creation of knowledge in and through virtual interaction.

First, our findings underline- the expected benefits of the interactional richness of Web sites and how companies can employ these benefits for knowledge creation. Managers considering building knowledge from online devices should assess the extent to which online interactions are supported by customers, suppliers, and other business partners in their export market. The degree of business partners' support and willingness to share information in online interactions will substantially influence what firms can realize from extending their interactive Web capabilities. In particular, those coordinators responsible for the smooth development of online interactional devices such as communities must clearly communicate the advantages of these tools to potential users. This includes actions such as the provision of incentives to early adopters, who are likely to experience problems and bugs as well as the establishment of rewards that motivate knowledge sharing to reinforce perceptions of trust right from the start.

Second, this study also adds deeper insights into the Webknowledge relationship which we investigated in Chapter 2 by taking into account factors that might strengthen or obscure knowledge creation. For instance, our study confirms that in a virtual context the importance of cultural distance is limited. From classic internationalization process theory we learned that concentric international growth - starting with nearby markets first - is most appropriate for the creation of market knowledge (Johanson and Vahlne 1977). With the emergence of the Web and online interactivity, however, the effect of risks coinciding with cultural distance fade out. In fact, firms even do not have to operate in foreign markets to establish relationships with crucial business partners. Although we show that cultural distance may hamper the creation of market knowledge by means of Web-based interactions, it does not act as an insurmountable barrier. In addition, managers can use their Web experience to counterbalance the influence of cultural remoteness. For instance, companies can do this by storing information gathered through online interactions with the help of devices such as their intranet platform. Based on these data, they can subsequently gain better insights into customers' profiles and customize information they exchange online. Furthermore, companies with high amounts of Web experience are likely to possess a mature IT infrastructure, which is part of their daily business and which helps them store and retrieve customer data for their Web-based efforts. 


Chapter 5

\section{Conclusion}




\subsection{Synopsis}

This dissertation has focused on the impact of the Web on marketing performance in an export context. By taking a dynamic Resource-Based View of the firm and recognizing knowledge as the ultimate resource, we examined the Web-performance relationship from a multifarious view and thereby captured the comprehensive link between the Web and marketing resources, knowledge creation, marketing processes, and ultimately performance. More specifically, we head for three research objectives and we addressed each objective by means of one specific study. Research objective 1 consisted of developing a sound conceptualization of Web capabilities and seizing the relationship between Web capabilities and export marketing resources. Research objective 2 immersed into three sub-goals: capturing the full scope of Web capabilities by discerning between effects of their abundance (level) and character (profile), identifying deployment and upgrading as two particular processes, and substantiating the importance of this process for immediate and long-term performance. Finally, research objective 3 was to zoom into the Web-knowledge relationship, to understand if and how environmental obstacles impede the Web-knowledge relationship, and to show that firms can use their international business and online experience to strengthen the effect of Web capabilities on knowledge creation.

We conducted three interrelated research projects to achieve each objective. Hence, each chapter of this dissertation corresponds to one study and covers one particular research objective. In this final chapter, we will first provide an overview of each project's outcomes. After that, we will draw a general conclusion about the results of the three chapters. Finally, the chapter concludes with suggestions for future research.

\subsection{Web Capabilities and Export Marketing Performance}

Exporting companies nowadays are using the Web to profit from the benefits the Web offers. For example, companies are investing in an elaborate and well-functioning Web site and hire IT specialists to develop extranets and intranets. Although all these Web-related initiatives are crucial, most of them can be easily imitated by competitors. The big advantage of Web capabilities is that they are less obscure. Web capabilities constitute both technical and nontechnical skills and can transform material (e.g., hardware) and immaterial (e.g., knowledge of programming languages) resources. At first sight, Web capabilities also seem to be complex. However, their complexity entails a second advantage: it makes them valuable and applicable for a wide array of marketing goals. 
Our first study has shown that the complex yet multifaceted character of Web capabilities is an advantage when it comes to performance. In contrast to existing literature that investigated the instrumental marketing value of Web applications such as online advertising (Saeed et al. 2002), the scope of our study is much broader by incorporating a much more comprehensive performance measure. More specifically, this study uncovered that Web capabilities do not only improve financial and nonfinancial performance outcomes (e.g., strategic results and satisfaction), but they also spur performance across different time periods (immediate, longterm). All in all, companies should focus on Web capabilities as a dynamic driver of resource creation and upgrading. Besides, unlike former research studies which focused on direct effects of the Web on e.g. selling performance (Luk et al. 2002), we investigate alternative routes. Overall, there are two main routes which companies can follow to achieve these effects. First, they can use Web capabilities to enhance their knowledge base. For instance, firms can use Web 2.0 for enhancing their understanding about customers' and partners' needs worldwide. Second, Web capabilities can underpin the effectiveness of an exporting company's marketing strategy under the condition that they are adequately aligned with the current business tactics of a particular venture. The results of this study show that the performance outcomes of Web capabilities may be short lived. Consequently, a regular evaluation and adaptation of Web capabilities appear required to safeguard their relevance and to keep export marketing resources up-to-date.

\subsection{Level and Profile of Web Capabilities: Effects of Web-}

\section{Induced Processes on Performance}

While study 1 (Chapter 2) focuses on Web capabilities as a dynamic precursor that affects the resource base, study 2 (Chapter 3) considers the organizational processes that underpin the relationship between Web capabilities and export marketing resources. To a greater extent than the current literature (e.g., Ray et al. 2004), we conceptualize two specific processes and we identify resource deployment and upgrading to be particularly relevant. Web capabilities hold long-lasting potential if they spur the deployment and upgrading of other organizational resources. More precisely, as a result of deploying resources, critical marketing assets are created, allocated and leveraged in profitable ways. Firms with the skills to manage online tools will receive a better understanding of their own export marketing conduct. Resource upgrading entails investments in new marketing knowledge as a platform for revised or new marketing assets and capabilities. Furthermore, through their Web capabilities, companies can 
build a social interface with the export market, obtain greater exposure to new knowledge, and thereby spur the upgrading of export marketing resources. Thus, companies benefit in the long run, since resource upgrading reinforces a firm's strategic marketing flexibility and action repertoire. In comparison to the current IS literature which looked at the effects of ISrelated resources per se (e.g., Ravinchandran and Lertwongsatien 2005), this study also incorporates other critical marketing resources. It is important to emphasize that these effects of Web capabilities sustain even in the presence of an extended range of well-established export marketing assets.

The results of the second study largely confirm that a distinction between level and profile of Web capabilities in export marketing is relevant. In this respect, we focus on interactivity as a predominant trait of Web applications. In excess of the current literature that predominantly examined direct effects of online interactivity (e.g., Sawhney 2005), we show that the interactive trait of Web capabilities moderates the direct, positive effects of resource deployment on short-term export marketing performance. It does so by enhancing the range of practical tools to perform export marketing in a more efficient and effective manner. Moreover, we demonstrate that the interactive trait of Web capabilities also matters in the long run, and explain this effect by referring to the power of the interactive trait of Web capabilities with regard to fostering knowledge exchange, commitment, and co-creation with lead-users. In all, the results provide broad support for our conceptual model and largely confirm the link between Web capabilities and marketing processes as well as their contributions to export marketing performance.

\subsection{Developing Local Market Knowledge by Bridging the}

\section{Cultural Distance Gap through Virtual Interaction}

While the results of our first study suggested that firms' knowledge is a crucial resource and intermediary variable between Web capabilities and performance, the third study (Chapter 4) looks more closely into the effect of interactive Web capabilities on export market knowledge. We point to the relevance of managing online interaction with stakeholders as a platform for the creation of unique market knowledge that is located in the interstices of the interaction. We find that online interactions affect market knowledge, especially due to their increasingly inherent social nature. Besides, we take into account that the Web-knowledge relationship is also sensitive to other internal strengths and external obstacles. While existing research has investigated cultural influences on knowledge creation, most of the studies did not consider the influence of the Web (Michailova and Hutchings 2006). Therefore, we incorporate the direct effect of international business experience and reveal that experience and capabilities constitute 
complements rather than substitutes in knowledge creation. Moreover, we do not detect a diminishing effect of cultural distance on the Web capabilities - knowledge relationship. Subsequently, in an online context dynamic and interactive Web capabilities may help overcome the barriers of cultural distance. This is accomplished by deploying interactive tools to collect and analyze Web behavior as well as customizing content to users who stem from different cultural backgrounds. Finally, our results reveal the relevance of Web experience as well as international business experience with regard to market knowledge creation. Even in culturally distant and highly competitive markets, both types of experience act as catalysts towards the online interactivity - knowledge relationship.

\subsection{Overall Conclusion}

Existing research has contributed essentially to unfurl the Web's potential from an instrumental, relational and integration view. Despite these pivotal efforts, we emphasized in the introduction chapter that one crucial question still needs to be answered: Does it all matter? Does the Web ultimately affect performance? In contrast to former research that mainly conceptualized the Web as an instrument that directly affects performance (e.g., Zhu and Kraemer 2002), this dissertation offers a far more nuanced approach. More specifically, this thesis is among the first to acknowledge the multidimensional nature of the Web relationship and thereby follows an alternative way to disclose the Web's impact on marketing performance. This dissertation aimed at the following goal: to depict the relationship between a firm's Web capabilities and its marketing performance as a multifaceted picture of knowledge creation, marketing resource upgrading and advanced marketing instrumentation. Throughout this thesis, the dynamic ResourceBased View of the firm and organizational knowledge accompanied us and made this achievement possible.

We begin with offering a conceptualization of Web capabilities which enables us to look at the capabilities that companies need to use the Web for the creation and integration of other resources. Based on this conceptualization, we are able to incorporate Web capabilities in the established resources-strategy-performance framework. This way, we provide evidence for the fact that Web capabilities are dynamic capabilities which mainly influence performance by creating knowledge and spurring strategies that ultimately enhance performance. In comparison to functional capabilities whose impact has been shown to be rather short-lived (Cepeda and Vera 2007), these dynamic capabilities have the power to affect performance in the long and short run. After that, we immerse more deeply into the organizational processes through which dynamic capabilities contribute to the renewal and exploitation of organizational resources. By identifying deployment and upgrading as two critical processes and linking 
them to short-and long-term performance, we were able to demonstrate how firms can control the timing of these effects. Besides, in this chapter we learn a lot more about dynamic capabilities by differentiating between their profile and level and by illustrating that the interactive capabilities act as a catalyst towards performance. Eventually, we additionally consider that other external and internal factors might obscure the relationship between dynamic capabilities and knowledge. Taking a more contingent view, we acknowledge that knowledge created by dynamic capabilities can be sensitive to external impediments such as cultural distance. Furthermore, we also account for a company's international business and online experience. At the end, we can conclude that the capabilities-knowledge relationship is robust against cultural distance and fostered by experience.

Taken the results of this thesis together, we can say much more than "yes, it matters". We do not only prove that dynamic capabilities spur performance in the short and long run, but even more important we reveal different ways in which they matter. First, through their effect on the established resources-strategy-performance thread. Second, as a pivotal driver of processes and interactive catalyst towards performance. Third, as a robust source of knowledge creation and even under consideration of external obstacles.

\subsection{Some Suggestions for Future Research}

At the end of each chapter in this dissertation we put forward directions for future research. In this section, we would like to give suggestions for future research which encompass the findings from all three chapters with regard to the role of Web capabilities in export marketing.

In this dissertation, we have elaborated on the influence of the Web on export marketing performance from a dynamic RBV perspective. More specifically, we investigated this link by looking at Web capabilities and how they can be integrated into the acknowledged export marketing knowledgecapabilities-performance thread. Hence, while we found out that Web capabilities lead to knowledge and export marketing capabilities and therefore spur typical outcomes of learning processes, we did not capture the learning processes per se. Thus, future research might also investigate to which extent higher-order learning processes are preeminent over other resources in export (Baker and Sinkula 1999). Learning theory could benefit from studies that investigate the influence of Web-induced higher-order learning processes and their subsequent effect on international marketing performance.

We have also examined the effect of Web capabilities on strategy and look at the extent to which Web capabilities underpin export marketing strategy. Future research might enrich these findings by looking at different strategy typologies, such as standardization versus adaptation (Calantone et 
al. 2004) and customer-level strategies (Kumar and Petersen 2005). Such investigations would provide insights into those strategies that are most relevant and fit best to the export marketing context. On top, future research might focus on strategic alignment and develop suggestions regarding how information technology could be leveraged for transforming organizations (e.g., Henderson and Venkatraman 1999).

We have also illustrated that a very high level of Web capabilities diminishes the effect of marketing strategy on performance. We explained this result by pointing to the danger of the "virtuality trap" (Yamin and Sinkovics 2006), which implies that too high investments in the Web mislead companies and make them neglect nonvirtual information sources. In this respect, the degree to which companies are market-oriented in their export operations is likely to counterbalance this effect (Cadogan et al. 2001). More specifically, how does a company's overall commitment with regard to export market intelligence generation, dissemination, and responsiveness activities, influence the usage of Web capabilities? Furthermore, how do other export market orientation related factors such as export coordination and export structures facilitate or impede the integration of Web capabilities?

Finally, in the three empirical studies, we confirmed the crossnational validity of crucial export performance measures (Lages and Lages 2004). For example, we measured both short-term and long-term export performance by using subjective, financial, and non-financial performance outcomes. Ideally, future research might substantiate our findings by taking into account more recently developed relationship quality as well as annual performance measures (e.g., Lages et al. 2005). The latter could also be used as a motivation tool and help companies set up suitable rewards when export employees achieve concrete annual goals. This aspect also hints to the idea that performance outcomes might influence a company's willingness and ability to invest in Web capabilities and points to the possibility of recursive effects. Eventually, we collected data on all measures asking key informants such as export managers. Although Web capabilities reside within the company, it might be interesting to see if customers' perceptions of a company's Web capabilities are equivalent to key informants' perceptions. 

Appendices 


\title{
Appendix A: Constructs, Measurement Items, and Reliabilities, Chapter 2
}

\author{
Construct and Measurement Items \\ Declarative Knowledge (adapted from Morgan et al. 2003) \\ ("Much worse" and "Much better" compared with competitors are \\ scale anchors) \\ MK_1: Our customer knowledge in this export market is \\ MK_2: Our knowledge of competitors in this export market is \\ MK_4: Our knowledge of business information in this export \\ market is
} Reliabilities

Experiential knowledge (adapted from Morgan et al. 2003)

("Much worse" and "Much better" compared with competitors are scale anchors)

EK_1: Our company's experience with operating this export

venture is

EK_2: The international orientation of our company's culture is

EK_3: Our company's international experience is

Export Marketing Capabilities (adapted from Morgan et al. 2004)

("Much worse" and "Much better" compared with competitors are scale anchors)

Our capability of...

A. Informational

INFO_1: identifying prospective customers is

INFO_2: capturing important market information is

INFO_3: acquiring export market-related information is

INFO_4: making contacts with potential partners is

INFO_5: monitoring competitive products is

B. Relationship Building

REL_1: understanding overseas customer requirements is

REL_2: establishing and maintaining close supplier relationships is

REL_3: establishing and maintaining close overseas distributor

relationships is

C. Product Development

PROD_1: developing new products is

PROD_2: adapting the product to designated or revised specifications is

PROD_3: adopting new methods and ideas in the manufacturing process is

Export Marketing Strategy (adapted from Morgan et al. 2004)

("No emphasis at all" and "Great emphasis" compared to competitors are scale anchors)

A. Cost Leadership

CL_1: Improving production/operating efficiency

CL_2: Maintaining experienced and trained personnel 
CL_3: Adopting innovative manufacturing methods and/or technologies

\section{B. Market Differentiation}

MD_1: Improving/maintaining advertising and promotion activities

MD_2: Building brand identification

MD_3: Adopting new/innovative marketing techniques

C. Service Differentiation

SD_1: Achieving/maintaining prompt response to customer orders

SD_2: Improving/maintaining quick product delivery

SD_3: Offering extensive customer service

Web Capabilities (adapted from Zhu and Kraemer 2002)

("Strongly disagree" to "strongly agree" are scale anchors)

A. Information (Our capability of...)

IN_1: offering product information online

IN_2: offering product-based online search capabilities for assisting customers in finding specific products quickly

IN_3: providing potential customers with online $3^{\text {rd }}$ party reviews or customer ratings of our products

IN_4: providing information on product updates online

B. Transaction (Our capability of...)

TR_1: enabling our customers to place their orders through our Web site

TR_2: enabling customers to $\log$ into our Web site to view the status of their orders

TR_3: offering a simplified procedure for registered users to complete online transaction fast

TR_4: facilitating product returns online

TR_5: offering sufficient information on our Web site about the security of transactions and customers' sensitive data

C. Interaction (Our capability of...)

INT_1: allowing customers to configure product features on our Web site so that products can be built-to-order on the basis of their preferences

INT_2: allowing users to register through our Web site to gain access to personalized accounts or private messages

INT_3: offering dynamic real-time product recommendations for our customers on our Web site

INT_4: enabling online visitors to customize the content viewed on our Web site

INT_5: offering real-time technical support through our Web site

D. Supplier Connection (Our capability of...)

SCON_1: allowing for Web-enabled procurement of raw material, supplies and parts by our importing partners

SCON_2: using electronic data interchange (EDI) or the extranet

for supply chain management 
SCON_3: offering an online community dedicated to suppliers SCON_4: facilitating shipment and logistics management through our Web site

SCON_5: facilitating inventory and information updates through our Web site

\section{Short-Term Export Marketing Performance (adapted from} Lages and Lages 2004)

A. Satisfaction with Short-Term Performance Improvement

("Much less satisfied in 2003" to "Much more satisfied in 2003

than 2002" are scale anchors)

SSTPI_1: Export sales volume

SSTPI_2: Export profitability

SSTPI_3: Market share in the importing market

SSTPI_4: Overall export performance

B. Short-Term Export Intensity Improvement

("Large decrease from 2002 to 2003" and "Large increase from 2002 to 2003" are scale anchors")

STEII_1: Percentage of this export venture to total sales volume

STEII_2: Percentage of this export venture to total profitability

\section{Expected Short-Term Performance Improvement}

("Much less satisfied in 2003" to "Much more satisfied in 2003

than 2002" are scale anchors)

ESTPI_1: Export sales volume

ESTPI_2: Export profitability

ESTPI_3: Achievement of the objectives

ESTPI_4: Satisfaction

Long-term Export Marketing Performance (adapted from Zou et al. 1998)

("Strongly disagree" to "Strongly agree" are scale anchors)

Overall this export venture...

\section{A. Financial Export Performance}

FEP_1: has been very profitable

FEP_2: has generated a high sales volume

FEP_3: has achieved rapid growth

B. Strategic Export Performance

SEP_1: has improved our global competitiveness

SEP_2: has strengthened our strategic positioning

SEP_3: has significantly increased our global market share

C. Satisfaction with Export Venture

SEV_1: turned out to be very satisfactory

SEV_2: has been very successful

SEV_3: has fully met our expectations 


\section{Appendix B: Constructs, Measurement Items, and Reliabilities, Chapter 3}

Construct and Measurement Items

Reliabilities

Web Capabilities (adapted from Zhu and Kraemer 2002)

("Strongly disagree" to "strongly agree" are scale anchors)

A. Information (Our capability of...)

IN_1: offering product information online

IN_2: offering product-based online search capabilities for assisting customers in finding specific products quickly

IN_3: providing potential customers with online $3^{\text {rd }}$ party reviews or customer

ratings of our products

IN_4: providing information on product updates online

B. Transaction (Our capability of...)

TR_1: enabling our customers to place their orders through our Web site

TR_2: enabling customers to log into our Web site to view the status of

their orders

TR_3: offering a simplified procedure for registered users to complete

online transaction fast

TR_4: facilitating product returns online

TR_5: offering sufficient information on our Web site about the security

of transactions and customers' sensitive data

C. Interaction (Our capability of...)

INT_1: allowing customers to configure product features on our Web

site so that products can be built-to-order on the basis of their preferences

INT_2: allowing users to register through our Web site to gain access to

personalized accounts or private messages

INT_3: offering dynamic real-time product recommendations for our customers on our Web site

INT_4: enabling online visitors to customize the content viewed on our

Web site

INT_5: offering real-time technical support through our Web site

D. Supplier Connection (Our capability of...)

SCON_1: allowing for Web-enabled procurement of raw material, supplies and parts by our importing partners

SCON_2: using electronic data interchange (EDI) or the extranet for

supply chain management

SCON_3: offering an online community dedicated to suppliers

SCON_4: facilitating shipment and logistics management through our

Web site

SCON_5: facilitating inventory and information updates through our Web

site 

1998)

("Strongly disagree" to "Strongly agree" are scale anchors)

Overall this export venture...

\section{A. Financial Export Performance}

FEP_1: has been very profitable

FEP_2: has generated a high sales volume

FEP_3: has achieved rapid growth

B. Strategic Export Performance

SEP_1: has improved our global competitiveness

SEP_2: has strengthened our strategic positioning

SEP_3: has significantly increased our global market share

C. Satisfaction with Export Performance

SEV_1: turned out to be very satisfactory

SEV_2: has been very successful

SEV_3: has fully met our expectations

Short-term Export Marketing Performance

(adapted from Lages and Lages 2004)

A. Satisfaction with Short-Term Performance Improvement

("Much less satisfied in 2003" to "Much more satisfied in 2003 than

2002" are scale anchors)

SSTPI_1: Export sales volume

SSTPI_2: Export profitability

SSTPI_3: Market share in the importing market

SSTPI_4: Overall export performance

B. Short-Term Export Intensity Improvement

("Large decrease from 2002 to 2003" and "Large increase from 2002 to

2003" are scale anchors)

STEII_1: Percentage of this export venture to total sales volume

STEII_2: Percentage of this export venture to total profitability

C. Expected Short-Term Performance Improvement

("Much less satisfied in 2003" to "Much more satisfied in 2003 than

2002" are scale anchors)

ESTPI_1: Export sales volume

ESTPI_2: Export profitability

ESTPI_3: Achievement of the objectives

ESTPI_4: Satisfaction 


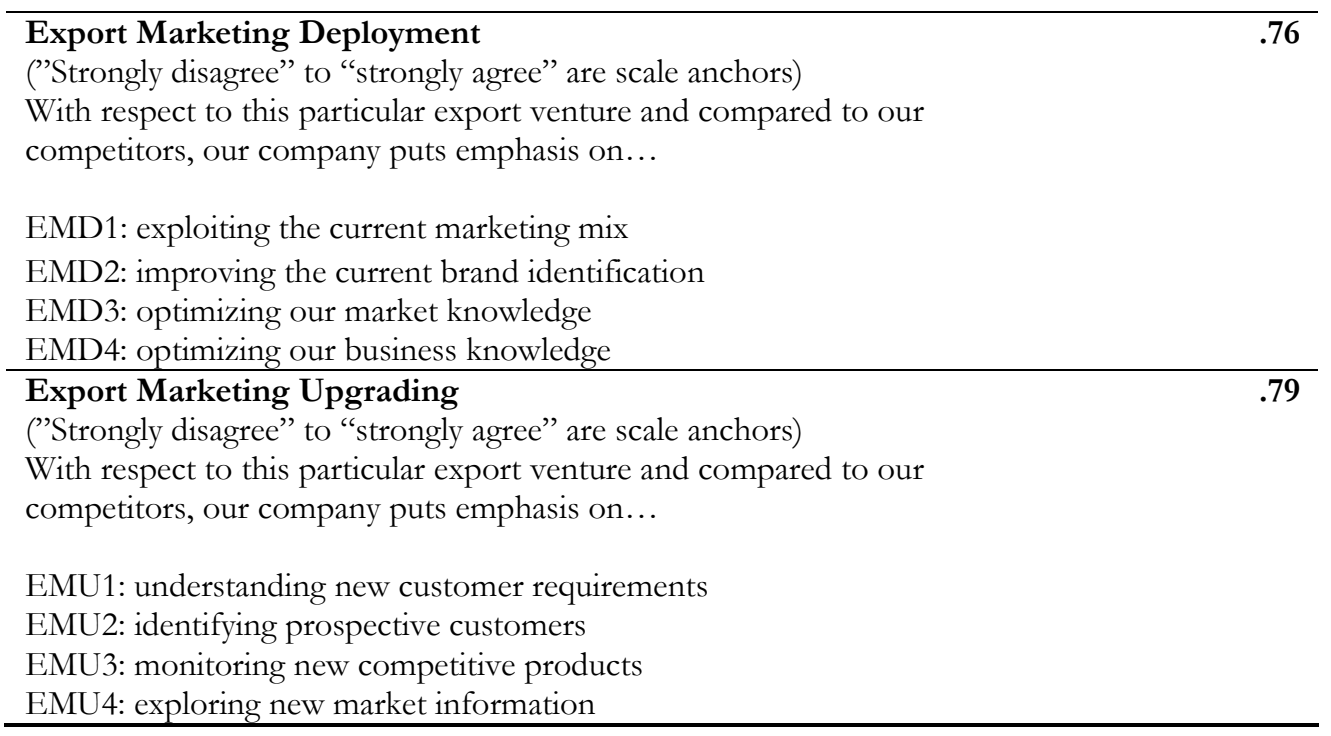

\section{Control Variables}

Construct and Measurement Items

Export Marketing Resources (adapted from Morgan et al. 2004)

("Much worse" and "Much better" compared with competitors are scale anchors)

\section{A. Experiential}

PR_1: your knowledge of the export venture

PR_2: your export experiences in this export venture

PR_3: your commitment to this export venture

PR_4: your past performance in this export venture

\section{B. Scale}

PR_5: your annual turnover in this export venture

PR_6: the number of employees mainly involved in this export venture

PR_7: the percentage of employees mainly involved in this venture

\section{Financial}

PR_8: the availability of financial resources to export activities

PR_9: the availability of financial resources to this export venture

D. Physical

PR_10: your company's use of modern technology and equipment in this export venture

PR_11: your company's preferential access to valuable sources of supply relevant for this export venture

PR_12: your production capacity for this export venture 
IT Infrastructure (adapted from Zhu et al. 2003)

("Strongly disagree" to "Strongly agree" compared with competitors are scale anchors)

IT1: we operate a system for electronic data interchange (EDI)

IT2: all employees have access to the Internet

IT3: we operate an intranet

IT4: we possess the required technical expertise for implementing online procurement

IT5: we possess the required technical expertise for implementing on-

line sales

IT6: we operate Internet-based electronic groupware tools

IT7/: we operate digital video-conferencing facilities

Competitive Intensity (adapted from Morgan et al. 2004)

("Strongly disagree" to "Strongly agree" compared with competitors are scale anchors)

CI1: competition is cut-throat

CI2: there are regular promotion wars

CI3: competitors can easily match each others' offers

CI4: price competition is a hallmark

CI5: competitive action/reaction is daily news 


\title{
Appendix C: Constructs, Measurement Items, and Reliabilities, Chapter 4
}

\author{
Construct and Measurement Items \\ Interactive Web Capabilities (adapted from Zhu and Kraemer 2002) \\ ("Strongly disagree" to "strongly agree" are scale anchors)

\section{Our capability of...} \\ IWC_1: allowing customers to configure product features on our Web \\ site so that products can be built-to-order on the basis of their \\ preferences \\ IWC_2: allowing users to register through our Web site to gain access to \\ personalized accounts or private messages \\ IWC_3: offering dynamic real-time product recommendations for our \\ customers on our Web site \\ IWC_4: enabling online visitors to customize the content viewed on our \\ Web site \\ IWC_5: offering real-time technical support through our Web site \\ IWC_6: allowing for Web-enabled procurement of raw material, supplies \\ and parts by our importing partners \\ IWC_7: using electronic data interchange (EDI) or the extranet for \\ supply chain management \\ IWC_8: offering an online community dedicated to suppliers \\ IWC_9: facilitating shipment and logistics management through our \\ Web site \\ IWC_10: facilitating inventory and information updates through our
}

Web site

Export Market Knowledge (adapted from Morgan et al. 2003)

("Much worse" to "much better" are scale anchors)

\section{Compared to your competitors...}

EMK_1: our customer knowledge in this export market is

EMK_2: our knowledge of competitors in this export market is

EMK_3: our knowledge of distributors in this export market is

EMK_4: our knowledge of business information in this export market is

Competitive Intensity (adapted from Morgan et al. 2004)

("Strongly disagree" to "strongly agree" are scale anchors)

In this export venture...

CI_1: competition is cut-throat

CI_2: there are regular promotion wars

CI_3: competitors can easily match each others' offers

CI_4: price competition is a hallmark

CI_5: competitive action/reaction is daily news 
International Business Experience (adapted from Cavusgil and Zou

1994)

("None" to "considerable" are scale anchors)

IBE_1: How strong is your firm's international business experience?

IBE_2: For how many years has your firm been involved in international business?

IBE_3: In how many foreign markets does your firm have regular operations?

IBE_4: What is the percentage of sales derived from foreign operations?

IBE_5: What is the percentage of profits derived from foreign operations?

Web Experience (adapted from Zhu et al. 2003)

n.a.

("Strongly disagree" to "strongly agree" are scale anchors for WE_2 -

WE_8)

\section{In our company...}

WE_1: for how many years does your company have a Web site?

WE_2: we operate a system for Electronic Data Interchange (EDI)

WE_3: all employees have access to the Internet

WE_4: we operate an intranet

WE_5: we possess the required technical expertise for implementing online procurement

WE_6: we possess the required technical expertise for implementing on-lir sales

WE_7: we operate internet-based electronic groupware tools

WE_8: we operate digital video-conferencing facilities 
Appendix D: Higher-Order Factors (Items) and Factor Loadings (Metric Invariance Model), Chapter 2

\begin{tabular}{|c|c|c|c|c|c|c|c|}
\hline \multicolumn{2}{|c|}{$\begin{array}{l}\text { Declarative } \\
\text { Knowledge }\end{array}$} & \multicolumn{2}{|c|}{$\begin{array}{l}\text { Experiential } \\
\text { Knowledge }\end{array}$} & \multicolumn{2}{|c|}{$\begin{array}{c}\text { Export Marketing } \\
\text { Capabilities }\end{array}$} & \multicolumn{2}{|c|}{ Export Marketing Strategy } \\
\hline Items & $\begin{array}{l}\text { Standardized } \\
\text { Loadings }\end{array}$ & Items & $\begin{array}{l}\text { Standardized } \\
\text { Loadings }\end{array}$ & $\begin{array}{l}\text { First-Order } \\
\text { Factors }\end{array}$ & $\begin{array}{l}\text { Standardized } \\
\text { Loadings }\end{array}$ & $\begin{array}{l}\text { First-Order } \\
\text { Factors }\end{array}$ & $\begin{array}{l}\text { Standardized } \\
\text { Loadings }\end{array}$ \\
\hline MK1 & $.80^{\mathrm{b}}$ & EK1 & $.77^{\mathrm{b}}$ & Informational & $.78^{\mathrm{b}}$ & Cost & $.69^{\mathrm{b}}$ \\
\hline MK2 & $.70(13.70)^{a}$ & EK2 & $.78(14.43)^{\mathrm{a}}$ & & & Leadership & \\
\hline \multirow[t]{4}{*}{ MK4 } & $.76(13.94)$ & EK3 & $.81(12.16)$ & Relationship & $.77(12.56)^{\mathrm{a}}$ & & \\
\hline & & & & Building & & $\begin{array}{l}\text { Market } \\
\text { Differentiation }\end{array}$ & $.69(9.16)^{a}$ \\
\hline & & & & Product & $.57(9.04)$ & & \\
\hline & & & & Development & & $\begin{array}{l}\text { Service } \\
\text { Differentiation }\end{array}$ & $.53(8.56)$ \\
\hline
\end{tabular}


Appendix D: Higher-Order Factor s (Items) and Factor Loadings (Metric Invariance Model), Chapter 2 (Continued)

\begin{tabular}{|c|c|c|c|c|c|}
\hline \multicolumn{2}{|c|}{ Web Capabilities } & \multicolumn{2}{|c|}{$\begin{array}{c}\text { Short-Term Export } \\
\text { Marketing Performance }\end{array}$} & \multicolumn{2}{|c|}{$\begin{array}{c}\text { Long-Term Export } \\
\text { Marketing Performance }\end{array}$} \\
\hline $\begin{array}{l}\text { First-Order } \\
\text { Factors }\end{array}$ & $\begin{array}{l}\text { Standardized } \\
\text { Loadings }\end{array}$ & $\begin{array}{l}\text { First-Order } \\
\text { Factors }\end{array}$ & $\begin{array}{l}\text { Standardized } \\
\text { Loadings }\end{array}$ & $\begin{array}{l}\text { First-Order } \\
\text { Factors }\end{array}$ & $\begin{array}{l}\text { Standardized } \\
\text { Loadings }\end{array}$ \\
\hline Information & $.50^{\mathrm{b}} .75(8.67)^{\mathrm{a}}$ & $\begin{array}{l}\text { Satisfaction with } \\
\text { short-term } \\
\text { performance }\end{array}$ & $.84^{\mathrm{b}}$ & $\begin{array}{l}\text { Financial export } \\
\text { performance }\end{array}$ & $.77 \mathrm{~b}$ \\
\hline Interaction & $.86(9.16)$ & improvement & $.86(14.21)^{\mathrm{a}}$ & $\begin{array}{l}\text { Strategic export } \\
\text { performance }\end{array}$ & $.74(13.75)^{a}$ \\
\hline $\begin{array}{l}\text { Supplier } \\
\text { Connection }\end{array}$ & $.83(7.97)$ & $\begin{array}{l}\text { Short-term } \\
\text { export } \\
\text { intensity } \\
\text { improvement }\end{array}$ & $.54(9.01)$ & $\begin{array}{l}\text { Satisfaction with } \\
\text { export venture }\end{array}$ & $.81(14.64)$ \\
\hline & & $\begin{array}{l}\text { Expected short- } \\
\text { term } \\
\text { performance } \\
\text { improvement }\end{array}$ & & & \\
\hline \multicolumn{6}{|c|}{$\begin{array}{l}\text { Goodness-of-Fit Statistics (Partial Measurement Invariance Model): Chi-Square }=537.21, \mathrm{df}=391, \mathrm{CFI}=.98, \\
\text { NNFI }=.97, \text { RMSEA }=.049 . \\
\text { a The t-values are in parentheses. } \\
\text { b Fixed parameter. }\end{array}$} \\
\hline
\end{tabular}




\section{Appendix E \\ Technical Appendix, Chapter 3}

We followed the approach of Lindell and Whitney (2001). First, we calculated the correlations among all variables. Second, we subtracted the lowest correlation $\left(r_{s}\right)$ across all possible pairs of variables from the total correlation between each pair. Equation 1 shows the calculation, where $r_{i j}$ specifies the partial correlation between variable $i$ and $j$, controlling for CMV $(M)$.

$$
r_{i j \cdot M}=\frac{r_{i j}-r_{s}}{1-r_{s}} .
$$

Equation 2 shows the computation for the accompanying t-statistic.

$$
t_{\alpha / 2, N-3}=\frac{r_{i j \cdot M}}{\sqrt{\left(1-r_{i j \cdot M}^{2}\right) /(N-3)}} .
$$

Next, we compared the correlation coefficients that are unadjusted for CMV $\left(r_{i j}\right)$ with the adjusted correlation coefficients $\left(r_{i j \cdot M}\right)$ to investigate if CMV effects our results. According to Lindell and Whitney (2001), a significant tstatistic (cf. significant unadjusted correlation coefficient) indicates that CMV does not bias the results.

The results indicate that after controlling for CMV, we still find significant results at the 0.05 level for almost all relationships. 
Table TA-3.1: Correlation matrix containing unadjusted zero-order correlations coefficients $\left(r_{i j}\right)$, adjusted zero-order correlations coefficients $\left(r_{i j \cdot C M V}\right)$, and $\mathrm{t}-$ statistics accompanying the adjusted zero-order correlations coefficients $\left(r_{i j \cdot C M V}\right)$. Notes: We use the abbreviations ST for short-term and LT for long-term export marketing performance.

\begin{tabular}{|c|c|c|c|c|c|c|}
\hline & $\begin{array}{c}\text { Web } \\
\text { Capabilities }\end{array}$ & $\begin{array}{c}\text { Interactive } \\
\text { Trait of } \\
\text { Web } \\
\text { Capabilities }\end{array}$ & $\begin{array}{c}\text { Export } \\
\text { Marketing } \\
\text { Deployment }\end{array}$ & $\begin{array}{c}\text { Export } \\
\text { Marketing } \\
\text { Upgrading }\end{array}$ & $\begin{array}{l}\text { ST Export } \\
\text { Marketing } \\
\text { Performance } \\
\text { (at } t)\end{array}$ & $\begin{array}{c}\text { LT Export } \\
\text { Marketing } \\
\text { Performance } \\
\text { (at } t+4)\end{array}$ \\
\hline $\begin{array}{l}\text { Web } \\
\text { Capabilities }\end{array}$ & 1.000 & & & & & \\
\hline $\begin{array}{l}\text { Interactive } \\
\text { Trait of } \\
\text { Web } \\
\text { Capabilities }\end{array}$ & $\begin{array}{c}.222 \\
.213 \\
(2.859)\end{array}$ & 1.000 & & & & \\
\hline $\begin{array}{l}\text { Export } \\
\text { Marketing } \\
\text { Deploy- } \\
\text { ment }\end{array}$ & $\begin{array}{c}.266 \\
.275 \\
(3.751)\end{array}$ & $\begin{array}{l}.060 \\
.049 \\
(.643)\end{array}$ & 1.000 & & & \\
\hline $\begin{array}{l}\text { Export } \\
\text { Marketing } \\
\text { Up- } \\
\text { grading }\end{array}$ & $\begin{array}{c}.228 \\
.219 \\
(2.944)\end{array}$ & $\begin{array}{l}.067 \\
.056 \\
(.736)\end{array}$ & $\begin{array}{c}.593 \\
.588 \\
(9.534)\end{array}$ & 1.000 & & \\
\hline $\begin{array}{l}\text { ST Export } \\
\text { Marketing } \\
\text { Perfor- } \\
\text { mance } \\
\text { (at } t \text { ) }\end{array}$ & $\begin{array}{c}.179 \\
.169 \\
(2.249)\end{array}$ & $\begin{array}{c}.012 \\
.000 \\
(.000)\end{array}$ & $\begin{array}{c}.253 \\
.244 \\
(3.300)\end{array}$ & $\begin{array}{c}.160 \\
.150 \\
(1.990)\end{array}$ & 1.000 & \\
\hline $\begin{array}{l}\text { LT Export } \\
\text { Marketing } \\
\text { Perfor- } \\
\text { mance } \\
(\text { at } t+4)\end{array}$ & $\begin{array}{l}-.026 \\
-.038 \\
(-.499)\end{array}$ & $\begin{array}{l}-.072 \\
-.085 \\
(1.119)\end{array}$ & $\begin{array}{c}.163 \\
.153 \\
(2.030)\end{array}$ & $\begin{array}{c}.227 \\
.218 \\
(2.930)\end{array}$ & $\begin{array}{l}.015 \\
.003 \\
(.039)\end{array}$ & 1.000 \\
\hline
\end{tabular}


Appendix F

Higher-Order Factors, Items of Lower-Order Factors, and Factor Loadings, Chapter 3

\begin{tabular}{|c|c|c|c|c|c|c|c|}
\hline \multicolumn{2}{|c|}{ Web Capabilities } & \multicolumn{2}{|c|}{$\begin{array}{l}\text { Export Marketing } \\
\text { Resources }\end{array}$} & \multicolumn{2}{|c|}{$\begin{array}{c}\text { Short-term Export } \\
\text { Marketing Performance ( } \text { (ear }_{t} \text { ) }\end{array}$} & \multicolumn{2}{|c|}{$\begin{array}{c}\text { Long-term Export } \\
\text { Marketing Performance }\left(\text { year }_{t+4}\right)\end{array}$} \\
\hline $\begin{array}{l}\text { First-Order } \\
\text { Factors }\end{array}$ & $\begin{array}{l}\text { Standard. } \\
\text { Loadings }\end{array}$ & $\begin{array}{l}\text { First-Order } \\
\text { Factors }\end{array}$ & $\begin{array}{l}\text { Standard. } \\
\text { Loadings }\end{array}$ & $\begin{array}{l}\text { First-Order } \\
\text { Factors }\end{array}$ & $\begin{array}{l}\text { Standard. } \\
\text { Loadings }\end{array}$ & $\begin{array}{l}\text { First-Order } \\
\text { Factors }\end{array}$ & $\begin{array}{l}\text { Standard. } \\
\text { Loadings }\end{array}$ \\
\hline Information & .67 & Experiential & .87 & $\begin{array}{l}\text { Satisfaction with } \\
\text { ST Improvement }\end{array}$ & .86 & $\begin{array}{l}\text { Financial Export } \\
\text { Performance }\end{array}$ & .98 \\
\hline Transaction & .86 & Scale & .86 & tensity & .78 & & 95 \\
\hline Interaction & .87 & Financial & .70 & Improvement & & Performance & \\
\hline $\begin{array}{l}\text { Supplier } \\
\text { Connection }\end{array}$ & .82 & Physical & .69 & $\begin{array}{l}\text { Expected ST } \\
\text { Performance } \\
\text { Improvement }\end{array}$ & .73 & $\begin{array}{l}\text { Satisfaction with } \\
\text { Export Performance }\end{array}$ & .97 \\
\hline
\end{tabular}

\begin{tabular}{llll}
\multicolumn{2}{c}{ Lower-Order Factors } & & \\
\hline \multicolumn{2}{c}{$\begin{array}{c}\text { Export Marketing } \\
\text { Deployment }\end{array}$} & \multicolumn{2}{c}{$\begin{array}{c}\text { Export Marketing } \\
\text { Upgrading }\end{array}$} \\
\hline Items & $\begin{array}{l}\text { Standard. } \\
\text { Loadings }\end{array}$ & Items & $\begin{array}{l}\text { Standard. } \\
\text { Loadings }\end{array}$ \\
& & & \\
EMD1 & .69 & EMU1 & .77 \\
EMD2 & .73 & EMU2 & .73 \\
EMD3 & .68 & EMU3 & $.55)$ \\
EMD4 & .68 & EMU4 & .73 \\
\hline
\end{tabular}



References 
$\underline{\mathbf{A}}$

Amit, Raphael and Paul J. H. Schoemaker (1993), "Strategic Assets and Organizational Rent," Strategic Management Journal, 14 (1), 33-46.

Albert, Terri C., Paulo B. Goes, and Alok Guptak (2004), "GIST: A Model for Design and Management of Content and Interactivity of Customer-Centric Websites," MIS Quarterly, 28 (2), 161-82.

Andersen, Poul Houman (2005), "Export Intermediation and the Internet: An Activity-Unbundling Approach," Management International Review, 22 (2), 147-64.

Anderson, James C. and David W. Gerbing (1988), "Structural Equation Modeling in Practice: A Review and Recommended Two-Step Approach," Psychological Bulletin, 103 (3), 411-23.

Arnott, David C. and Susan Bridgewater (2002), "Internet, Interaction and Implications for Marketing," Marketing Intelligence and Planning, 20 (2), 86 $-95$.

Avlonitis, George J. and Despinci A. Karayanni (2000), "The Impact of Internet Use on Business-to-Business Marketing: Examples from American and European Companies," Industrial Marketing Management, 29 (5), 441-59.

$\underline{\text { B }}$

Bagozzi, Richard P. (1994), "Structural Equation Models in Marketing Research: Basic Principles," in Bagozzi, R.P. (Eds), Principles of Marketing Research. Malden, MA: Blackwell.

Bagozzi, Richard P. and Todd F. Heatherton (1994), "A General Approach to Representing Multifaceted Personality Constructs: Application to SelfEsteem," Structural Equation Modeling, 1 (1), 35-67.

---- and Youjae Yi (1989), "On the Use of Structural Equation Models in Experimential Designs," Journal of Marketing Research, 26 (3), 271-84.

Baker, William E. and James M. Sinkula. (1999), "The Synergistic Effect of Market Orientation and Learning Orientation on Organizational Performance," Journal of the Academy of Marketing Science, 27 (4), 411-27.

Bandalos, Deborah L. (2002), "The Effects of Item Parceling on Goodness-of-Fit and Parameter Estimate Bias in Structural Equation Modeling," Structural Equation Modeling, 9 (1), 78-102.

Banker, Rajiv D., Indranil Bardhan, and Ozer Asdemir (2006), "Understanding the Impact of Collaboration Software on Product Design and Development," Information Systems Research, 17 (4), 352-73.

Barkema, Harry G., John H. J. Bell, and Johannes M. Pennings (1996), "Foreign Entry, Cultural Barriers, and Learning," Strategic Management Journal, 17 (2), 151-66.

Barkema, Harry G., Oded Shenkar, Freek Vermeulen, and John H. J. Bell (1997), "Working Abroad, Working with Others: How Firms Learn to Operate International Joint Ventures," Academy of Management Journal, 40 (2), 426 -42 . 
Barney, Jay B. (1991), "Firm Resources and Sustained Competitive Advantage," Journal of Management, 17 (1), 99-120.

Barney, Jay B. (1996), "The Resource-based Theory of the Firm," Organization Science, 7 (5), 469-69.

Barwise, Patrick and John U. Farley (2005), "The State of Interactive Marketing in Seven Countries: Interactive Marketing Comes of Age," Journal of Interactive Marketing, 19 (3), 67-80.

Bello, Daniel C. and David I. Gilliland (1997), "The Effect of Output Controls, Process Controls, and Flexibility on Export Channel Performance," Journal of Marketing, 61 (1), 22-38.

Benner, M. J. and Michael L. Tushman (2002), "Process Management and Technological Innovation: A Longitudinal Study of the Photography and Paint Industries," Administrative Science Quarterly, 47 (4), 676-706.

Bergh, Donald B (1998), "Product-Market Uncertainty, Portfolio Restructuring, and Performance: An Information-Processing and Resource-Based View," Journal of Management, 24 (2), 135-155.

Bernoff, Josh and Charlene Li (2008), "Harnessing the Power of the Oh-So-Social Web," MIT Sloan Management Review, 49 (3), 36-42.

Bhagat, Rabi S., Ben L. Kedia, and Paula D. Harveston (2002), "Cultural Variations in the Cross-Border Transfer of Organizational Knowledge: an Integrative Framework," Academy of Management Review, 27 (2), 204-19.

Bharadwaj, Anandhi S. (2000), "A Resource-Based Perspective on Information Technology Capability and Firm Performance: An Empirical Investigation," MIS Quarterly, 24 (1), 169.

Bhatt, Ganesh D. and Varun Grover (2005), "Types of Information Technology Capabilities and Their Role in Competitive Advantage: An Empirical Study," Journal of Management Information Systems, 22 (2), 253-77.

Biswas, Abhijt and Ram Krishnan (2002), "The Internet's Impact on Marketing: Introduction to the JBR Special Issue on "Marketing on the Web Behavioral, Strategy and Practices and Public Policies," Journal of Business Research, 57 (7), 681-84.

Black, Janice A. and Kimberly B. Boal (1994), "Strategic Resources: Traits, Configurations and Paths to Sustainable Competitive Advantages," Strategic Management Journal, 15 (Special Issue), 131-48.

Bollen, Kenneth A. and Richard Lennox (1991), "Conventional Wisdom on Measurement: A Structural Equation Perspective," Psychological Bulletin, 110 (2), 305-14.

Bonner, Joseph M. and Orville C. Walker Jr. (2004), "Selecting Influential Businessto -Business Customers in New Product Development: Relational Embeddedness and Knowledge Heterogeneity Considerations," Journal of Product Innovation Management, 21 (3), 155-69.

Bono, Joyce E. and Amy E. Colbert (2005), "Understanding Response to MultiSource Feedback: The Role of Core Self-Evaluations," Personnel Psychology, 58 (1), 171-203.

Brouthers, Keith D., Lance E. Brouthers, and Steve Werner 2008, "Resource-Based Advantages in an International Context," Journal of Management, 34 (2), 189 217. 
Brynjolfsson, Erik (1993), "The Productivity Paradox of Information Technology, Association for Computing Machinery," Communications of the ACM, 36 (12), 66-7.

Bughin, Jacques, Michael Chui, and Brad Johnson (2008), "The Next Step in Open Innovation," The McKinsey Quarterly, Issue 4, 1-8.

Bush, Victoria D., Gregory M. Rose, Faye Gilbert, and Thomas N. Ingram (2001), "Managing Culturally Diverse Buyer-Seller Relationships: The Role of Intercultural Disposition and Adaptive Selling in Developing Intercultural Communication Competence," Journal of the Academy of Marketing Science, 29 (4), 391-404.

\section{C}

Cadogan, John W., Adamantios Diamantopoulos, and Charles P. de Mortanges (1999), “A Measure of Export Market Orientation: Scale Development and Cross-Cultural Validation," Journal of International Business Studies, 30 (4), 689707.

Cadogan, John W., Adamantios Diamantopoulos, and Judy A. Siguaw (2002), "Export-Market Oriented Activities: Their Antecedents and Performance Consequences," Journal of International Business Studies, 33 (3), 615-626.

Calantone, Roger, Jeffrey B. Schmidt, and Michael X. Song (1996), "Controllable Factors of New Product Success: A Cross-National Comparison," Marketing Science, 15 (4), 341-58.

Carr, Nicolas (2003), "IT Doesn't Matter," Harvard Business Review, 81 (5), 41-49.

Cavusgil, S. Tamer and Shaoming Zou (1994), "Marketing Strategy-Performance Relationship: An Investigation of the Empirical Link in Export," Journal of Marketing, 58 (1), 1-21.

CBS (2004), "The Netherlands in Figures," CBS, retrieved March 20, 2007 from the World Wide Web: http://www.cbs.nl/.

---- (2005), “The Digital Economy 2005,” CBS, retrieved December 17, 2007 from the World Wide Web: http://www.cbs.nl/.

---- (2008), "Netherlands Europe's Third Exporting Country," CBS, retrieved July 4, 2008 from the World Wide Web: http://www.cbs.nl/.

Cepeda, Gabriel and Dusya Vera (2007), "Dynamic Capabilities and Operational Capabilities: A Knowledge Management Perspective," Journal of Business Research, 60 (5), 426-37.

Chatterjee, Debabroto, Rajdeep Grewal, and V. Sambamurthy (2002), "Shaping Up for E- Commerce: Institutional Enablers of the Organizational Assimilation of Web Technologies," MIS Quarterly, 26 (2), 65-89.

Cheung, Gordon W. and Roger B. Rensvold (1999), "Testing Factorial Invariance Across Groups: A Reconceptualization and Proposed New Method," Journal of Management, 25 (1), 1-27.

Chetty, Sylvie., Kent Eriksson, and Jessica Lindbergh (2006), "The Effect of Specificity of Experience on a Firm's Perceived Importance of Institutional Knowledge in an Ongoing Business," Journal of International Business Studies, 37 (5), 699-712.

Chin, Wynne W. (2001), PLS-Graph user's guide version 3.0. C.T. Bauer College of Business, University of Houston (Houston, TX). 
Chin, Wynne W., Barbara L. Marcolin, and Peter R. Newsted (2003), “A Partial Least Squares Latent Variable Modeling Approach for Measuring Interaction Effects: Results from a Monte Carlo Simulation Study and an ElectronicMail Motion/Adoption Study," Information Systems Research, 14 (2), 189-217.

Choudhury, Vivek and Elena Karahanna. (2008), "The Relative Advantage of Electronic Channels: A Multidimensional View," MIS Quarterly, 32 (1), 179-200.

Chui, Michael, Andy Miller, and Roger P. Roberts (2009), "Six Ways To Make Web 2.0 Work," The McKinsey Quarterly, 1-7.

Churchill, Gilbert A. Jr. (1979), "A Paradigm for Developing Better Measures of Marketing Constructs," Journal of Marketing Research, 16 (1), 64-73.

Cockburn, Iain M. and John C. Henderson (1998), "Absorptive Capacity, CoAuthoring Behavior, and the Organization of Research in Drug Discovery," Journal of Industrial Economics, 46 (2), 157-83.

Cohen, Michael D. and Paul Bacdayan (1994), "Organizational Routines are Stored as Procedural Memory: Evidence from a Laboratory Study," Organization Science, 5 (4), 554-68.

Cooke, Mike and Nick Buckley (2008), "Web 2.0, Social Networks and the Future of Market Research," International Journal of Market Research, 50 (2), 267-292.

Cohen, Jacob, Patricia Cohen, Stephen G. West, Leona S. Aiken (2003), Applied Multiple Regression/Correlation Analysis for the Behavioral Sciences. Mahwah, NJ: Erlbaum.

Cohen, Wesley M. and Daniel A. Levinthal (1990), "Absorptive Capacity: A New Perspective on Learning and Innovation," Administrative Science Quarterly, 35 (1), 128- 52.

Curran, Patrick J., Stephen G. West, and John F. Finch (1996), "The Robustness of Test Statistics to Nonnormality and Specification Error in Confirmatory Factor Analysis," Psychological Methods, 1 (1), 16-29.

$\underline{\text { D }}$

Daft, Richard L. and Robert H. Lengel (1986), "Organizational Information Requirements, Media Richness and Structural Design," Management Science, 32 (5), 554-71.

Day, George S. (1994), “The Capabilities of Market-Driven Organizations," Journal of Marketing, 58 (4), 37-52.

DeCarlo, Lawrence T. (1997), "On the Meaning and Use of Kurtosis," Psychological Methods, 2 (3), 292-307.

De Luca, Luigi M. and Kwaku Atuahene-Gima (2007), "Market Knowledge Dimensions and Cross-Functional Collaboration: Examining the Different Routes to Product Innovation Performance. Journal of Marketing, 71 (1), 95-112.

Dess, Gregory G., and Richard B. Robinson Jr. (1984), "Measuring Organizational Performance in the Absence of Objective Measures: The Case of the Privately-Held Firm and Conglomerate Business Unit," Strategic Management Journal, 5 (3), 265-73. 
Deutskens, Elisabeth C., Ko de Ruyter, Martin G. M. Wetzels, and Paul Oosterveld (2004), "Response Rate and Response Quality of Internet-Based Surveys: An Experimental Study," Marketing Letters, 15 (1), 21-36.

Devaraj, Sarv and Rajiv Kohli (2003), "Performance Impacts of Information Technology: Is Actual Usage the Missing Link?," Management Science, 49 (3), 273-89.

Diamantopoulos, Adamantios and Nikolaos Kakkos (2007), "Managerial Assessments of Export Performance: Conceptual Framework and Empirical Illustration," Journal of International Marketing, 15 (3), 1-31.

Dierickx, Ingemar and Karel Cool (1989), "Asset Stock Accumulation and the Sustainability of Competitive Advantage: Reply," Management Science, 35(12), 1514-14.

Dou, Wenyu, Ulrik O. Nielsen, and Chee M. Tan (2002), "Using Corporate Websites for Export Marketing," Journal of Advertising Research, 42 (5), 10515.

Dyer, Jeffrey H. and Habir Singh (1998), "The Relational View: Cooperative Strategy and Sources of Interorganizational Competitive Advantage," Academy of Management Review, 23 (4), 660-79.

\section{$\underline{\mathbf{E}}$}

Economist (2007), "Country Briefings Netherlands: Economic Structure," The Economist, retrieved April 16, 2009 from the World Wide Web: http://www.economist.com/

Edmondson, Amy C., Ann B. Winslow, Richard M. J. Bohmer, and G. P. Pisano (2003), "Learning How and Learning What: Effects of Tacit and Codified Knowledge on Performance Improvement Following Technology Adoption," Decision Sciences, 34 (2), 197.

Eisenhardt, Kathleen M. and Jeffrey A. Martin (2000), "Dynamic Capabilities: What are they?," Strategic Management Journal, 21 (10-11), 1105-21.

Eid, Riyad, Ibrahim Elbeltagi, and Mohamed Zairi (2006), "Making Business-toBusiness International Internet Marketing Effective: A Study of Critical Factors Using a Case-Study Approach," Journal of International Marketing, 14 (4), 87-109.

Elk, van J. W., M.H.H. Van Lin, Rob C. Augusteijn, Koen de Pater, Johan de Vries, Paul Westhead, Mike Wright, Deniz Ucbarasan (2005), "Entrepreneurship in the Netherlands; SMEs and International Co-operation, Ministry of Economic Affairs, retrieved April 14, 2009 from the World Wide Web: http://www.ondernemerschap.nl/

Eriksson, Kent and Sylvie Chetty (2003), "The Effect of Experience and Absorptive Capacity on Foreign Market Knowledge," International Business Review, 12 (6), 673-695.

Eriksson, Kent, Jan Johanson, Anders Majkgård, and D. Deo Sharma (1997), "Experiential Knowledge and Cost in the Internationalization Process," Journal of International Business Studies, 28 (2), 337-60.

Eurostat (2006), "Internet Usage in the EU 25," Eurostat, retrieved June 3, 2007 from the World Wide Web: http://ec.europa.eu/eurostat/ 
Eurostat (2007), "EU Engineering Competitive Update June 2007", Eurostat, retrieved July 16, 2008 from the World Wide Web: http://ec.europa.eu/eurostat/.

$\underline{\mathbf{F}}$

Fisher, Julie, Annemieke Craig, and John Bentley (2007), "Moving From a Web Presence to E-Commerce: The Importance of a Business - Web Strategy for Small-Business Owners," Electronic Markets, 17 (4), 253-62.

Froehle, Craig M. (2006), 'Service Personnel, Technology, and Their Interaction in Influencing Customer Satisfaction,” Decision Sciences, 37 (1), 5-38.

\section{$\underline{\mathbf{G}}$}

Ghose, Sanjoy and Wenyu Dou (1998), "Interactive Functions and Their Impacts on the Appeal of Internet Presence Sites," Journal of Advertising Research, 38 (2), 29-43.

Grant, Robert M. (1991), “The Resource-Based Theory of Competitive Advantage: Implications for Strategy Formulation," California Management Review, 33 (3), 114-35.

---- (1996), "Toward a Knowledge-Based Theory of the Firm," Strategic Management Journal, 17 (Special Issue), 109-22.

Grant, Robert M., Azar P. Jammine, and Howard Thomas (1988), "Diversity, Diversification, and Profitability Among British Manufacturing Companies, 1972-84," Academy of Management Journal, 31 (4), 771-801.

Greenspan, Robyn (2002), "EU B2B Expected to Explode," The ClickZ Network, retrieved November 19, 2006 from the World Wide Web: http://www.clickz.com/stats/.

Gregory, Gary, Munib Karavdic, and Shaoming Zou (2007), "The Effects of ECommerce Drivers on Export Marketing Strategy," Journal of International Marketing, 15 (2), 30-57.

Grewal, Raijdeep, and Rebecca J. Slotegraaf (2007), "Embeddedness of Organizational Capabilities," Decision Sciences, 38 (3), 451-488.

Grewal, Raijdeep, and Patriya Tansuhaj (2001), "Building Organizational Capabilities for Managing Economic Crisis: The Role of Market Orientation and Strategic Flexibility," Journal of Marketing, 65 (2), 67-80.

Griffith, David A., Matthew B. Myers. and Michael G. Harvey (2006), "An Investigation of National Culture's Influence on Relationship and Knowledge Resources in Interorganizational Relationships between Japan and the United States," Journal of International Marketing, 14 (3), 1-32.

Gulati, Ranjay (1999), "Network Location and Learning: The Influence of Network Resources and Firm Capabilities on Alliance Formation," Strategic Management Journal, 20 (5), 397-420.

Gulati, Ranjay and Habir Singh (1998), "The Architecture of Cooperation: Managing Coordination Costs and Appropriation Concerns in Strategic Alliances," Administrative Science Quarterly, 43 (4), 781-814. 
Gupta, Alok., Bo-chiuan Su and Zhiping Walter (2004), “An Empirical Study of Consumer Switching from Traditional to Electronic Channels: A Purchase-Decision Process Perspective," International Journal of Electronic Commerce, 8 (3), 131-61.

\section{$\underline{H}$}

Hamill, Jim (1997), “The Internet and International Marketing," International Marketing Review, 14 (4/5), 300.

Haeubl, Gerald and Valerie Trifts (2000), "Consumer Decision Making in Online Shopping Environments: The Effects of Interactive Decision Aids," Marketing Science, 19 (1), 4.

Hardy, Cynthia, Nelson Phillips and Thomas B. Lawrence (2003), "Resources, Knowledge and Influence: The Organizational Effects of Interorganizational Collaboration," Journal of Management Studies, 40 (2), $321-47$.

Heimeriks, Koen H. and Geert Duysters (2007), "Alliance Capability as a Mediator between Experience and Alliance Performance: An Empirical Investigation into the Alliance Capability Development Process," Journal of Management Studies, 44 (1), 25-49.

Helfat, Constance E. and Margaret A. Peteraf (2003), "The Dynamic Resource Based View: Capability Lifecycles," Strategic Management Journal, 24: 997-1010.

Henderson, John C. and N. Venkatraman (1999), "Strategic Alignment: Leveraging Information Technology For Transforming Organizations," IBM Systems Journal, 38 (2/3), 472-85.

Hoffman, Donna L (2008), “The Evolution of Customer Experience: 10 Trends You Can't Afford to Miss, MSI Conference on Leveraging Online Media and Online Marketing, February 6-8, 2008, Palm Springs, CA.

Hofstede, Geert (1983), "National Cultures in Four Dimensions: A Research-Based Theory of Cultural Differences Among Nations," International Studies of Management and Organization, 18 (1-2), 46-74.

Holzwarth, Martin, Chris Janiszewski and Marcus M. Neumann (2006), "The Influence of Avatars on Online Consumer Shopping Behavior," Journal of Marketing, 70 (4), 19-36.

Howell, Roy (1987), "Covariance Structure Modeling and Measurement Issues: A Note on Interrelations Among a Channel Entity's Power Sources and Consequences," Journal of Marketing Research, 24 (1), 119-26.

$\mathrm{Hu}$, Li-tze and Peter M. Bentler (1998), "Fit Indices in Covariance Structure Modeling: Sensitivity to Underparameterized Model Misspecification," Psychological Methods, 3 (4), 424-53.

Huber, George P. (1991), "Organizational learning: The Contributing Processes and the Literatures," Organization Science, 2 (1), 88-115.

Hulland, John (1999), "Use of Partial-Least-Squares (PLS) in Strategic Management Research: A Review of Four Recent Studies. Strategic Management Journal, 20 (2), 195-204.

Hult, G. Tomas M., David J. Ketchen Jr., David A. Griffith, Brian R. Chabowski, Mary K. Hamman, Bernadine J. Dykes, Wesley A. Pollittee, and S. Tamer 
Cavusgil (2008), "An Assessment of the Measurement of Performance in International Business Research," Journal of International Business Studies, 39 (6), 1064-1080.

Hunt, Shelby D. and Robert M. Morgan (1996), “The Resource-Advantage Theory of Competition: Dynamics, Path Dependencies, and Evolutionary Dimensions," Journal of Marketing, 60 (4), 107-14.

$\underline{I}$

Instituto Nacional de Estastística (2008), "Statistical Yearbook of Portugal," INE, retrieved June 9, 2008 from the World Wide Web: http://www.ine.pt/.

$\mathrm{J}$

Jap, Sandy D. (2007), "The impact of Online Reverse Auction Design on BuyerSupplier Relationships," Journal of Marketing, 71 (1), 146-59.

Javalgi, Rajshekhar and Rosemary Ramsey (2001), "Strategic Issues of E-Commerce as an Alternative Global Distribution System," International Marketing Review, 18 (4), 376-91.

Jaworski, Bernard J. and Ajay K. Kohli (1993), "Market Orientation: Antecedents and Consequences," Journal of Marketing, 57 (3), 53.

Jean, Ruey-Jer "Bryan" (2007), "The Ambiguous Relationship of ICT and Organizational Performance: A Literature Review," Critical Perspectives on International Business, 3 (4), 306-21.

Johanson, Jan and Jan-Erik Vahlne (1977), "The Internationalization Process of the Firm: A Model of Knowledge Development And Increasing Market Commitments," Journal of International Business Studies, 8 (1), 23-32.

Johnsen, Rohna E. and David Ford (2006), "Interaction Capability Development of Smaller Suppliers in Relationships with Larger Customers," Industrial Marketing Management, 35 (8), 1002-15.

Johnson, Bradford C., James M., Manyika, and Lareina A. Yee (2005), “The Next Revolution in Interactions," The McKinsey Quarterly, 20-33.

\section{$\underline{\mathbf{K}}$}

Kogut, Bruce and Udo Zander (1992), "Knowledge of the Firm, Combinative Capabilities, and the Replication of Technology," Organization Science, 3 (3), 383-97.

Kogut, Bruce and Udo Zander (1996), "What Firms Do? Coordination, Identity, and Learning," Organization Science, 7 (5), 502-18.

Kogut, Bruce and Harry Singh (1988), "The Effect of National Culture on the Choice of Entry Mode," Journal of International Business Studies, 19 (3), 41132.

Komiak, Sherry and Izak Benbasat (2006), "The Effects of Personalization and Familiarity on Trust and Adoption of Recommendation Agents," MIS Quarterly, 30 (4), 941-60. 
Kumar, Ajith and William R. Dillon (1987), "Some Further Remarks on Measurement- Structure Interaction and the Unidimensionality of Constructs," Journal of Marketing Research, 24 (4), 438-44.

Kumar, V. and J. Andrew Petersen (2005), "Using a Customer-Level Marketing Strategy to Enhance Firm Performance: A Review of Theoretical and Empirical Evidence," Journal of the Academy of Marketing Science, 33 (4), 50419.

$\underline{\mathbf{L}}$

Lages, Luis F., Sandy D. Jap, and David A. Griffith (2008), "The Role of Past Performance in Export Ventures: A Short-Term Reactive Approach," Journal of International Business Studies, 39 (2), 304-325.

Lages, Luis F. and Cristiana R. Lages (2004), "The STEP Scale: A Measure of Short-Term Export Performance Improvement," Journal of International Marketing, 12 (1), 36-56.

Lages, Luis F., Lages, Carmen Lages, and Cristiana R. Lages (2005), "Bringing Export Performance Metrics into Annual Reports: The APEV Scale and the PERFEX Scorecard, Journal of International Marketing, 13 (3), 79-104.

Lam, Alice (2000), "Tacit Knowledge, Organizational Learning and Societal Institutions: An Integrated Framework," Organization Studies 21 (3), 487.

Leidner, Dorothy E. and Tymothy Kayworth (2006), "Review: A Review of Culture in Information Systems Research. Toward a Theory of Information Technology Culture Conflict," MIS Quarterly, 30 (2), 357-99.

Leonard-Barton, Dorothy (1992), "Core Capabilities and Core Rigidities: A Paradox in Managing New Product Development," Strategic Management Journal, 13 (5), 111-25.

Li, Dahui, Glenn J. Browne, and James C. Wetherbe (2006), "Why do Internet Users Stick with a Specific Web Site? A Relationship Perspective," International Journal of Electronic Commerce, 10 (4), 105-41.

Lieberman, Marvin B. and Cynthia A. Montgomery (1998), "First-Mover (Dis)Advantages: Retrospective and Link with the Resource-Based View," Strategic Management Journal, 19 (12), 1111-25.

Lieberman, Marvin B. and Cynthia A. Montgomery (1988), "First Mover Advantages," Strategic Management Journal, 9 (Special Issue Summer), 41-58.

Liesch, Peter W. and Gary A. Knight (1999), "Information Internalization and Hurdle Rates in Small and Medium Enterprise Internationalization," Journal of International Business Studies, 30 (1), 383-94.

Lindell, Michael K. and David J. Whitney (2001), "Accounting for Common Method Variance in Cross-Sectional Research Designs," Journal of Applied Psychology, 86 (1), 114-121.

Liu, Yuping and L.J. Shrum (2002), "What is Interactivity and is it Always Such a Good Thing? Implications of Definition, Person, and Situation for the Influence of Interactivity on Advertising Effectiveness," Journal of Advertising, 31 (4), 53-64.

Lohrke, Franz T., Geralyne McClure Franklin and Cynthia Frownfelter-Lohrke (2006), "The Internet as an Information Conduit," International Small Business Journal, 24 (2), 159-78. 
Looney, Stephen W. (1995), "How to Use Tests for Univariate Normality to Assess Multivariate Normality," The American Statistician, 49 (1), 64-70.

Lu, Jane W. and Paul W. Beamish (2001), "The Internationalization and Performance of SMEs," Strategic Management Journal, 22 (6-7), 565-86.

Lu, Jane W. and Ma Xufei (2008), "The Contingent Value of Local Partners' Business Group Affiliations," Academy of Management Journal, 51 (2), 295314.

Luk, Sheriff T.K., Wesley P.S. Chan, and Esther L.Y. Li (2002), “The Content of Internet Advertisements and Its Impact on Awareness and Selling Performance," Journal of Marketing Management, 18 (7/8), 693.719.

Luo, Yadong (2000), "Dynamic Capabilities in International Expansion," Journal of World Business, 35 (4), 355-378.

Luo, Yadong (2002), "Capability Exploitation and Building in a Foreign Market: Implications for Multinational Enterprises," Organization Science, 13 (1), 4863.

Luo, Yadong and Mike W. Peng (1999), "Learning to Compete in a Transition Economy: Experience, Evironment and Performance," Journal of International Business Studies, 30 (2), 269-95.

Lyles, Marjorie A. and Jane E. Salk (1996), "Knowledge Acquisition from Foreign Parents in International Joint Ventures: An Empirical Examination in the Hungarian Context," Journal of International Business Studies, 27 (5), 877-903.

\section{M}

Manyika, James M., Roger P. Roberts, and Kara L. Sprague (2008), "Eight Business Technology Trends to Watch," The McKinsey Quarterly, Issue 1, 60-71.

March, James G. (1991), "Exploration and Exploitation in Organizational Learning," Organization Science, 2 (1), 71.

Mardia, Kanti. V. (1970), "Measures of Multivariate Skewness and Kurtosis with Applications," Biometrika, 57 (3), 519-530.

Mardia, Kanti V. (1985), "Mardia's Test of Multinormality," in Encyclopedia of Statistical Science, New York: Wiley, 217-221.

Marsh, Herbert W., Kit-Tai Hau, and Zhonglin Wen (2004), "In Search of Golden Rules: Comment on Hypothesis-Testing Approaches to Setting Cutoff Values for Fit Indexes and Dangers in Overgeneralizing $\mathrm{Hu}$ and Bentler's (1999) Findings," Structural Equation Modeling, 11 (3), 320-41.

McEvily, Bill and Alfred Markus (2005), "Embedded Ties and the Acquisition of Competitive Capabilities," Strategic Management Journal, 26 (11), 1033-55.

McKinsey (2007a), "How Companies are Marketing Online: A McKinsey Global Survey," The McKinsey Quarterly, July 2007 McKinsey Quarterly survey of business executives: 1-8.

McKinsey (2007b), "How Businesses are Using Web 2.0: A McKinsey Global Survey," The McKinsey Quarterly, 2007 McKinsey Quarterly survey on Internet technologies: 1-16.

McKinsey (2009), "How Companies make good decisions: McKinsey Global Survey Results," The McKinsey Quarterly, 2009 McKinsey Quarterly survey on strategic decision-making: 1-7. 
McMillan, Sally J. and Jang-Sun Hwang (2002), "Measures of Perceived Interactivity: An Exploration of the Role of Direction of Communication, User Control, and Time in Shaping Perceptions of Interactivity," Journal of Advertising 31 (3), 29-41.

Metz, Michael (2008), "Marketing 2.0 Accelerating Customer Engagement," MSI Conference on Leveraging Online Media and Online Marketing, February 6-8, 2008, Palm Springs, CA.

Michailova, Snejina and Kate Hutchings (2006), "National Cultural Influences on Knowledge Sharing," Journal of Management Studies, 43 (3), 383-405.

Miller, Stewart R. and Lorraine Eden (2006), "Local Density and Foreign Subsidiary Performance," Academy of Management Journal, 49 (2), 341-55.

Mitra, Debanjan and Peter N. Golder (2002), "Whose Culture Matters? NearMarket Knowledge and its Impact on Foreign Market Entry Timing," Journal of Marketing Research, 39 (3), 350-65.

Moen, Øystein, Iver Endresen, and Morten Gavlen (2003), "Executive Insights: Use of the Internet in International Marketing: A Case Study of Small Computer Software Firms," Journal of International Marketing, 11 (4), 129-49.

Moon, Youngme (2000), "Intimate Exchanges: Using Computers to Elicit SelfDisclosure from Consumers," Journal of Consumer Research, 26 (4), 323-39.

Moorman, Christine Anne S. Miner (1997), "The Impact of Organizational Memory on New Product Performance and Creativity," Journal of Marketing Research, 34 (1), 91-106.

Moorman, Christine and Rebecca J. Slotegraaf (1999), "The Contingency Value of Complementary Capabilities in Product Development," Journal of Marketing Research, 36 (2), 239-57.

Morgan-Thomas, Anna and Susan Bridgewater (2004), "Internet and Exporting: Determinants of Success in Virtual Export Channels," International Marketing Review, 21 (4-5), 393-408.

Morgan, Neil A., Anna Kaleka, and Constantine S. Katsikeas (2004), “Antecedents of Export Venture Performance: A Theoretical Model and Empirical Assessment," Journal of Marketing, 68 (1), 90-108.

----, Neil A., Douglas W. Vorhies, and Bodo B. Schlegelmilch (2006), "Resource Performance Relationships in Industrial Export Ventures: The Role of Resource Inimitability and Substitutability," Industrial Marketing Management, 35 (5), 621-633.

----, Shaoming Zou, Douglas W. Vorhies, and Constantine S. Katsikeas (2003), "Experiential and Informational Knowledge, Architectural Marketing Capabilities, and the Adaptive Performance of Export Ventures: A CrossNational Study," Decision Sciences, 34 (2), 287-321.

Morosini, Piero., Scott Shane, and Harbir Singh (1998), "National Culture Distance and Cross-Border Acquisition Performance'. Journal of International Business Studies, 29 (1), 137-58.

Murray, Janet Y., Gerald Y. Gao, Masaaki Kotabe, and Nan Zhou (2007), "Assessing Measurement Invariance of Export Market Orientation: A study of Chinese and Non-Chinese Firms in China," Journal of International Marketing, 15 (4), 41-62. 
Nambisan, Satish and Robert A. Baron (2007), "Interactions in Virtual Customer Environments: Implications for Product Support and Customer Relationship Management," Journal of Interactive Marketing, 21 (2), 42-62.

Netemeyer, Richard G., Thomas Brashear-Alejandro, and James S. Boles (2004), "A Cross -National Model of Job-Related Outcomes of Work Role and Family Role Variables: A Retail Sales Context," Journal of the Academy of Marketing Science, 32 (1), 49-60.

Neter, John, William Wasserman, and Michael Kutner (1985), Applied linear statistical model (2nd ed.). Homewood, IL: Irwin.

Nguyen, Tho D. and Nigel J. Barrett (2006), "The Knowledge-Creating Role of the Internet in International Business: Evidence from Vietnam," Journal of International Marketing, 14 (2), 116-47.

Nicovich, Stef and Bettina T. Cornwell (1998), "An Internet Culture?: Implications for Marketing. Journal of Interactive Marketing, 12 (4), 22-33.

Nonaka, Ikujiro (1994), "A Dynamic Theory of Organizational Knowledge Creation,"Organization Science, 5 (1), 14-37.

Nonaka, Ikujiro and Hirotaka Takeuchi (1995), The knowledge-creating company: how Japanese companies create the dynamic of innovation. New York: Oxford University Press.

Novak, Thomas P., Donna L. Hoffman, and Yung Yiu-Fai (2000). "Measuring the Customer Experience in Online Environments: A Structural Modeling Approach," Marketing Science, 19 (1), 22.

$\underline{\mathbf{O}}$

O'Grady, Shawna and Henry W. Lane (1996), "The Psychic Distance Paradox," Journal of International Business Studies, 27 (2), 309-33.

OECD (2005a), "Information and Communication Technology, Broadband Statistics, June 2005," OECD, retrieved March 18, 2007 from the World Wide Web: http://www.oecd.org/.

OECD (2005b), “OECD (2005), National Accounts of OECD countries," OECD, retrieved January 13, 2007 from the World Wide Web: http://stats.oecd.org/.

OECD (2006), "Governments Should Do More to Help SMEs Expand Abroad," OECD, retrieved August 29, 2008 from the World Wide Web: http://stats.oecd.org/.

Ojala, Arto and Pasi Tyrväinen (2007), "Market Entry and Priority of Small and Medium -Sized Enterprises in the Software Industry: An Empirical Analysis of Cultural Distance, Geographic Distance, and Market Size," Journal of International Marketing, 15 (3), 123-49.

$\mathbf{P}$

Paik, Yongsun (1993), “The Impact of Strategic Flexibility on Business Performance in the International Business Environment," Journal of International Business Studies, 23 (3), 591-592. 
Palmatier, Robert W. (2008), "Interfirm Relational Drivers of Customer Value," Journal of Marketing, 72 (4), 76-89.

Palmatier, Robert W., Rajiv P. Dant, and Dhruv Grewal (2007), “A Comparative Longitundal Analysis of Theoretical Perspective of Interorganizational Relationship Performance," Journal of Marketing, 71 (4), 172-94.

Parasuraman, A. and George M. Zinkhan (2002), "Marketing to and Serving Customers through the Internet: An Overview and Research Agenda," Journal of the Academy of Marketing Science, 30 (4), 286-95.

Park, Seung H. and Michael V. Russo (1996), "When Competition Eclipses Cooperation: an Event History Analysis of Joint Venture Failure," Management Science, 42 (6), 875-90.

Parkhe, Arvind (1993), "Partner Nationality and the Structure-Performance Relationships in Strategic Alliances," Organization Science, 36 (4), 301-14.

Pelham, Alfred M. and David T. Wilson (1996), "A Longitudinal Study of the Impact of Market Structure, Firm Structure, Strategy, and Market Orientation Culture on Dimensions of Small-Firm Performance," Journal of the Academy of Marketing Science, 24 (1), 27-43.

Peteraf, Margaret A. (1993), "The Cornerstones of Competitive Advantage: A Resource-Based View," Strategic Management Journal, 14 (3), 179-91.

Podsakoff, Philipp M., Scott B. MacKenzie, Jeong-Yeon Lee, and Nathan P. Podsakoff (2003), "Common Method Biases in Behavioral Research: A Critical Review of the Literature and Recommended Remedies," Journal of Applied Psychology, 88 (5), 879-904.

Powell, Walter W., Kenneth W. Koput, and Laurel Smith-Doerr (1996), "Interorganizational Collaboration and the Locus of Innovation: Networks of Learning in Biotechnology," Administrative Science Quarterly, 41 (1), 116-46.

Prasad, V. Kanti, K. Ramamurthy, and G. M. Naidu (2001), "The Influence of Internet-Marketing Integration on Marketing Competencies and Export Performance," Journal of International Marketing, 9 (4), 82-110.

$\underline{\mathbf{Q}}$

Quelch, John A. and Lisa R. Klein. 1996, "The Internet and International Marketing," Sloan Management Review, 3, 60-75.

$\underline{\mathbf{R}}$

Ramani, Girish and V. Kumar (2008), "Interaction Orientation and Firm Performance," Journal of Marketing, 72 (1), 27-45.

Ravinchandran, T. and Chalermsak Lertwongsatien (2005), "Effect of Information System Resources and Capabilities on Firm Performance: A Resource-Based Perspective," Journal of Management Information Systems, 21 (4), 237-67.

Ray, Gautam, Jay B. Barney, and Waleed A. Muhanna (2004), "Capabilities, Business Processes, and Competitive Advantage: Choosing the Dependent Variable in Empirical Tests of the Resource-Based View," Strategic Management Journal, 25 (1), 23-37. 
Rindfleisch, Aric and Christine Moorman (2001), "The Acquisition and Utilization of Information in New Product Alliances: A Strength-of-Ties Perspective," Journal of Marketing, 65 (2), 1-18.

Rindskopf, David and Tedd Rose (1988), "Some Theory and Applications of Confirmatory Second-Order Factor Analysis," Multivariate Behavioral Research, 23 (1), 51-67.

Romano, Nicholas C. Jr. (2003), "Customer Relationship Management for the Web-Access Challenged: Inaccessability of Fortune 250 Business Web Sites," International Journal of Electronic Commerce, 7 (2), 81-117.

$\underline{\mathrm{S}}$

Saeed, Khawaja A., Whang Yujong, and Varun Grover (2002), "Investigating the Impact of Web site Value and Advertising on Firm Performance in Electronic Commerce," International Journal of Electronic Commerce, 7 (2), 119-41.

Samiee, Saeed (1998), "The Internet and International Marketing: Is there a Fit?," Journal of Interactive Marketing, 12 (4), 5-21.

Satorra, Albert and Peter M. Bentler (2001), "A Scaled Difference Chi-Square Test Statistic For Moment Structure Analysis," Psychometrika, 66 (4), 507-14.

Sawhney, Mohanbir, Verone Gianmario, and Emanuela Prandelli (2005), "Collaborating to Create: The Internet as a Platform for Customer Engagement in Product Innovation," Journal of Interactive Marketing, 19 (4), 4-17.

Schillewaert, Niels and Pascale Meulemeester (2005), "Comparing Response Distributions of Offline and Online Data Collection Methods," International Journal of Market Research, 47 (2), 163-78.

Schreyögg, Georg and Martina Kliesch-Eberl (2007), "How Dynamic Can Organizational Capabilities Be? Towards A Dual-Process Model of Capability Dynamization," Strategic Management Journal, 28 (9), 913-33.

Seilheimer, Steven D. (2004), "Productive Development of World Wide Web Sites Intended for International Use," Journal of Information Management, 24 (5), 363-73.

Sethi, Rajesh and Zafar Iqbal (2008), "Stage-Gate Controls, Learning Failure, and Adverse Effect on Novel New Products. Journal of Marketing, 72 (1), 118-134.

Sharp, Duane E. (1998), "Extranets: Borderless Internet/Intranet Networking," Information Systems Management, 15 (3), 31-36.

Shenkar, Oded (2001), "Cultural Distance Revisited: Towards a more Rigorous Conceptualization and Measurement of Cultural Differences," Journal of International Business Studies, 32 (3), 519-35.

Shenkar, Oded, Luo, Yadong and Orly Yeheskel (2008), "From "Distance" to "Friction": Substitution Metaphors and Redirecting Intercultural Research," Academy of Management Review, 33 (4), 905-23.

Sicilia, Maria, Salvador Ruiz, and Jose L. Munuera (2005), "Effects of Interactivity in a Web Site," Journal of Advertising, 34 (3), 31-45.

Sidhu, Jatinder, Harry R. Commandeur, and Henk W. Volberda (2007), "The Multifaceted Nature of Exploration and Exploitation: Value of Supply, 
Demand, and Spatial Search for Innovation," Organization Science, 18 (1), 20-38.

Simonin, Bernard L. (1999), “Transfer of Marketing Know-How in International Strategic Alliances: An Empirical Investigation of the Role and Antecedents of Knowledge Ambiguity," Journal of International Business Studies, 30 (3), 463-90.

Simonson, Itamar (2005), “Determinants of Customers' Responses to Customized Offers: Conceptual Framework and Research Propositions," Journal of Marketing, 69 (1), 32-45.

Slaughter, Sandra A., Linda Levine, Balasubramanian Ramesh, Jan Pries-Heje, and Richard Baskerville (2007), "Aligning Software Processes with Strategy," MIS Quarterly, 30 (4), 891-918.

Smith, Ken G., Collins, Christopher J., and Kevin D. Clark (2005), "Existing Knowledge, Knowledge Creation Capability, and the Rate of New Product-Introduction in High-Technology Firms," Academy of Management Journal, 48 (2), 346-57.

Song, Ji H. and George M. Zinkhan (2008), "Determinants of Perceived Web Site Interactivity," Journal of Marketing, 72 (2), 99-113.

Souchon, Anne and Adamantios Diamantopoulos (1996), "A Conceptual Framework of Export Marketing Information Use: Key Issues and Research Propositions," Journal of International Marketing, 4 (3), 49-71.

Souchon, Anne, Adamantios Diamantopoulos, Hartmut H. Holzmüller, Catherine N. Axinn., James M. Sinkula, Heike Simmet, and Geoffrey R. Durden (2003), "Export Information Use: A Five-Country Investigation of Key Determinants," Journal of International Marketing, 11 (3), 106-27.

Spithoven, Antoon H. G. M. (2003), "The Productivity Paradox and the Business Cycle," International Journal of Social Economics, 30 (6), 679-99.

Srinivasan, Raji and Christine Moorman (2005), "Strategic Firm Commitments and Rewards for Customer Relationship Management in Online Retailing," Journal of Marketing, 69 (4), 193-200.

Steenkamp, Jan-Benedict E. M. and Hans Baumgartner (1998), "Assessing Measurement Invariance in Cross-National Consumer Research," Journal of Consumer Research, 25 (1), 78-90.

Steenkamp, Jan-Benedict E. M. and Hans C. M. van Trijp (1991), "The Use of Lisrel in Validating Marketing Constructs, " International Journal of Research in Marketing, 8 (4), 283-299.

Styles, Chris, Patterson, Paul G., and Ahmed Farid (2008), "A Relational Model of Export Performance," Journal of International Business Studies, 39 (5), 880-900.

Sun, Baohong (2006), "Technology Innovation and Implications for Customer Relationship Management," Marketing Science, 26 (6), 594-97.

Sussman, Stephanie W. and Wendy S. Siegal (2003), "Informational Influence in Organizations: An Integrated Approach to Knowledge Adoption," Information Systems Research, 14 (1), 47-65.

Swink, Morgan, Narasimham, Ram, \& Kim, Soo Wook (2005), "Manufacturing Practices and Strategy Integration: Effects on Cost Efficiency, Flexibility, and Market-Based Performance. Decision Sciences, 36 (3), 427-457. 
Szulanski, Gabriel (1996), "Exploring Internal Stickiness: Impediments to the Transfer of Best Practice within the Firm," Strategic Management Journal, 17 (Special Issue), 27-43.

$\underline{\mathbf{T}}$

Tam, Kar Yan and Shuk Ying Ho (2006), "Understanding the Impact of Web Personalization on User Information Processing and Decision Outcomes," MIS Quarterly, 30(4), 865-90.

Tanriverdi, Hüseyin (2005), "Information Technology Relatedness Knowledge Management Capability, and Performance of Multibusiness Firms," MIS Quarterly, 29 (2), 311-34.

Teece, David J., Gary Pisano, and Amy Shuen (1997), "Dynamic Capabilities and Strategic Management," Strategic Management Journal, 18 (7), 509-33.

Tenenhaus, Michel, Vincenzo E. Vinzi, Yves-Marie Chatelin, and Carlo Lauro (2005), "PLS Path Modeling," Computational Statistics \& Data Analysis, 48 (1), 159205.

The Economist (2006), "Truth in Advertising: "Click Fraud" Causes a Threat to the Boom in Internet Advertising," The Economist, retrieved January 13, 2007 from the World Wide Web: http://www.economist.com/research/.

The Observatory of European SMEs (2002), "SMEs in Focus: Main Results from the 2002 Observatory of European SMEs," European Commission, retrieved November 8, 2007 from the World Wide Web: http://ec.europa.eu/.

Tiessen, James H., Richard W. Wright, and Ian Turner (2001), "A Model of ECommerce Use by Internationalizing SMEs," Journal of International Management, 7 (3), 211-233.

Trevor, Charlie O. and Anthony J. Nyberg (2008), "Keeping Your Headcount when all about You are Losing Theirs: Downsizing, Voluntary Turnover Rates, and the Moderating Role of HR Practices," Academy of Management Journal, 51 (2), 259-76.

Tse, David K., Kam-hon Lee, Ilan Vartinsky, and Donald A. Wehrung (1988), "Does Culture Matter? A Cross-Cultural Study of Executive Choice, Decisiveness, and Risk Adjustment in International Marketing," Journal of Marketing, 52 (4), 81-95.

Tucker, Ledyard R. and Charles Lewis (1973), "A Reliability Coefficient for Maximum Likelihood Factor Analysis,” Psychometrika, 38 (1), 1-10.

$\underline{\mathbf{U}}$

Urban, Glen L. and John R. Hauser (2004), "Listening in" to Find and Explore New Combinations of Customer Needs," Journal of Marketing, 68 (2), 72-87.

Uzzi, Brian (1997), "Social Structure and Competition in Interfirm Networks: The Paradox of Embeddedness," Administrative Science Quarterly, 42 (1), 35-67.

Uzzi, Brian and Ryon Lancaster (2003), "Relational Embeddedness and Learning: The Case of Bank Loan Managers and Their Clients," Management Science, 49 (4), 383-99. 
$\underline{\mathbf{V}}$

Vandenberg, Robert J. (2002), "Toward a Further Understanding of and Improvement in Measurement Invariance Methods and Procedures," Organizational Research Methods, 5 (2), 139-58.

--- and Charles E. Lance (2000), “A Review and Synthesis of the Measurement Invariance Literature: Suggestions, Practices, and Recommendations for Organizational Research," Organizational Research Methods, 3 (1), 4-70.

Van den Bosch, Frans A. J., Henk W. Volberda and Michiel De Boer (1999), "Coevolution of Firm Absorptive Capacity and Knowledge Environment: Organizational Forms and Combinative Capabilities," Organization Science, 10 (5), 551-68.

van Oudenhoven, Jan P. and Karen I. van der Zee (2002), "Successful International Cooperation: The Influence of Cultural Similarity, Strategic Differences, and International Experience," Applied Psychology, 51 (4), 633-53.

Varadarajan, P. Rajan and Manjit S. Yadav (2002), "Marketing Strategy and the Internet: An Organizing Framework," Journal of the Academy of Marketing Science, 30 (4), 296-312.

Venkatraman, N. and John E. Prescott. 1990, "Environment-Strategy Coalignment: An Empirical Test of Its Performance Implications," Strategic Management Journal, 11(1), 1-25.

von Hippel, Eric and Georg von Krogh (2003), "Open Source Software and the 'Private -Collective' Innovation Model: Issues for Organization Science," Organization Science, 14 (2), 209-23.

$\underline{\mathbf{W}}$

Wade, Michael and John Hulland (2004), "Review: The Resource -Based View and Information Systems Research: Review, Extension, and Suggestions for Future Research," MIS Quarterly, 28 (1), 107-42.

Wadhwa, Anu and Suresh Kotha (2006), "Knowledge Creation Through External Venturing: Evidence From the Telecommunications Equipment Manufacturing Industry," Academy of Management Journal, 49 (4), 819-35.

Wang, Liz C., Julie Baker, Judy A. Wagner, and Kirk Wakefield (2007), "Can a Retail Web Site Be Social?," Journal of Marketing, 71 (3), 143-57.

Wetzels, Martin G. M, Gaby Odekerken-Schröder, and Claudia Van Oppen (2008), "Using PLS Path Modeling for Assessing Hierarchical Construct Models: Guidelines and Empirical Illustration," MIS Quarterly, forthcoming.

Weinberger, David (2002). Small pieces loosely joined: a unified theory of the Web. New York: Perseus Books.

Wiertz, Caroline and Ko de Ruyter (2007), "Beyond the Call of Duty: Why Customers Participate in Firm-Hosted Online Communities," Organization Studies, 28 (3), 349-78.

Winter, Sidney G. (2003), "Understanding Dynamic Capabilities," Strategic Management Journal, 24 (10), 991-995. 
Wu, Fang, Vijay Mahajan, and Sridhar Balasubramanian (2003), "An Analysis of EBusiness Adoption and its Impact on Business Performance," Journal of the Academy of Marketing Science, 31 (4), 425-47.

$\underline{\mathbf{Y}}$

Yamin, M. and R. R. Sinkovics (2006), "Online Internationalisation, Psychic Distance Reduction and the Virtuality Trap," International Business Review, 15, 339-60.

$\underline{Z}$

Zaheer, Akbar and Geoffrey G. Bell (2005), "Benefiting from Network Position: Firm Capabilities, Structural Holes, and Performance," Strategic Management Journal, 26 (9), 809-25.

Zahra, Shaker A. and Gerard George (2002), "Absorptive Capacity: A Review, Reconceptualization, and Extension," Academy of Management Review, 27 (2), 185-203.

Zander, Udo and Bruce Kogut (1995), "Knowledge and the Speed of the Transfer and Imitation of Organizational Capabilities: An Empirical Test," Organization Science, 6 (1), 76-92.

Zhan, Wu and Yadong Luo (2008), "Performance Implications of Capability Exploitation and Upgrading in International Joint Ventures," Management International Review, 48 (2), 227-253.

Zhou, Lianxi, Weiping Wu and Xueming Luo (2007), "Internationalization and the Performance of Born-Global SMEs: The Mediating Role of Social Networks," Journal of International Business Studies, 38 (4), 673-690.

Zhu, Kevin (2004), "The Complementarity of Information Technology Infrastructure and E-Commerce Capability: A Resource-Based Assessment of Their Business Value," Journal of Management Information Systems, 21 (1), 167-202.

Zhu, Kevin and Kenneth L. Kraemer (2002), "E-Commerce Metrics for NetEnhanced Organizations: Assessing the Value of e-Commerce to Firm Performance in the Manufacturing Sector," Information Systems Research, 13 (3), 275-95.

Zollo, Maurizio and Sidney G. Winter (2002), "Deliberate Learning and the Evolution of Dynamic Capabilities," Organization Science, 13 (3), 339-51.

Zou, Shaoming, Eric Fang, and Shuming Zhao (2003), "The Effect of Export Marketing Capabilities on Export Performance: An Investigation of Chinese Exporters," Journal of International Marketing, 11 (4), 32-55.

---, Charles R. Taylor, and Gregory E. Osland (1998), "The EXPERF Scale: A Cross-National Generalized Export Performance Measure," Journal of International Marketing, 6 (3), 37-58.

---, Stan, Simona (1998). "The Determinants of Export Performance: A Review of the Empirical Literature between 1987 and 1997," International Marketing Review, 15 (5), 333-356. 



\section{Curriculum Vitae}

Ingrid Beckers was born on February 10, 1981 in Eschweiler, Germany. After completing secondary school at Gymnasium Haus Overbach, Barmen, Germany (1991-2000), she studied at the Faculty of Economics and Business Administration of Maastricht University, the Netherlands (2000-2004), where she obtained a Master's Degree in International Business.

In September 2004, she started her $\mathrm{PhD}$ at the marketing department of Maastricht University. Until April 2009 she worked on her dissertation entitled $\boldsymbol{W} \boldsymbol{W} \boldsymbol{W}$ and its $\boldsymbol{E}$ nduring $\boldsymbol{E} f$ fects on $\boldsymbol{E x p o r t}$ Marketing: Do Web Capabilities Matter?. Her main research interests include international and strategic marketing.

As of November 2008 she is working as a Business Intelligence Manager at DMV-Fonterra Excipients in Goch, Germany. 